STATE OF ILLINOIS

DEPARTMENT OF REGISTRATION AND EDUCATION

DIVISION OF THE

NATURAL HISTORY SURVEY

THEODORE :H. FRISON, Chief

\title{
Initial Studies of American Elm Diseases in Illinois
}

\author{
HUBERT A. HARRIS
}

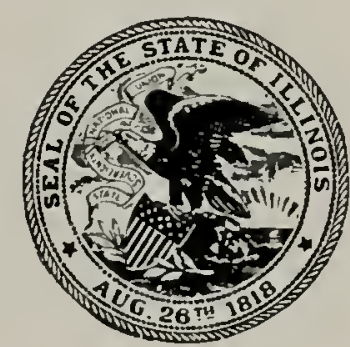

PRINTED BY AUTHORITY OF THE STATE OF ILLINOIS 


\section{STATE OF ILLINOIS \\ DEPARTMENT OF REGISTRATION AND EDUCATION \\ M. F. Walsh, Director}

\section{BOARD OF NATURAL RESOURCES AND CONSERVATION}

M. F. Walsh, Chairman

William Trelease, Biology

Hexry C. Cowles, Forestry

EDson S. Bastin, Geology

William A. Noyes, Chemistry
JoHn W. Alvord, Engineering

Charles M. Thompsos, Representing the President of the University of Illinois

\section{STATE NATURAL HISTORY SURVEY DIVISION}

Theodore H. Frison, Chief

Carroli Chouinard, Elitor

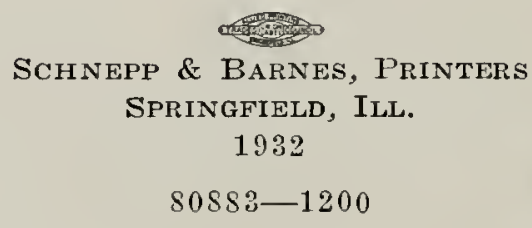




\section{CONTENTS}

PAGE

INTRODUCTION $\ldots \ldots \ldots \ldots \ldots \ldots \ldots \ldots \ldots \ldots \ldots \ldots \ldots \ldots \ldots \ldots \ldots \ldots$

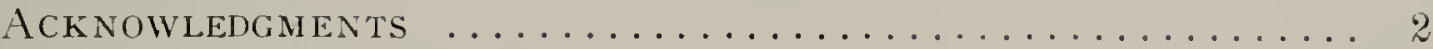

Scope of Present Report....................... 3

Previous Outbreaks of Elm Disease in Illinois............ 3

Character of the Present Elm Malady............... 6

Importance in Nurseries...................... 9

Importance in Cities......................

Methods . . . . . . . . . . .

Isolation of Fungi from Diseased Wood.............. 12

Culturing Fungi from Spores................. 1\%

Histological Technique ................... 1:3

Recording Data ....................... 14

General Results of Cultural Tests............... 1.j

Specific Diseases . . . . . . . . . . . . . . . . . 20

Tracheomycosis Associated with Coniothyrium spp........20

Vermicularia Disease ....................... 38

Phoma Cankers ..........................41

Sphaeropsis Dieback and Canker................ 4.

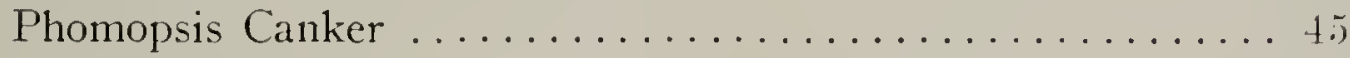

Verticillium Wilt ......................

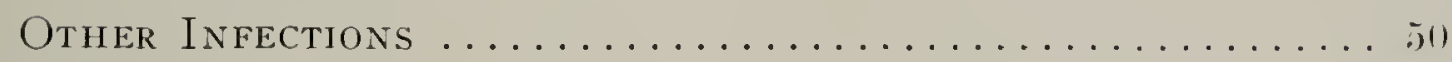

Fusaria .......................

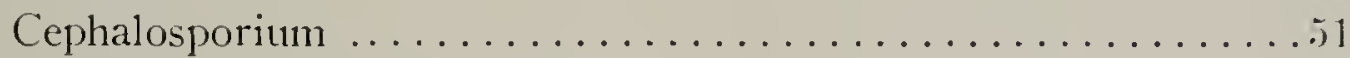

Alternaria and Stemphylium................ 1

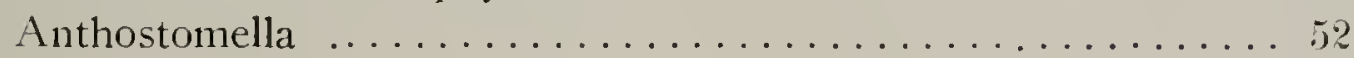

Cytospora Canker . .................... 52

Diplodia Canker ..........................

Nigrospora ........................... 5

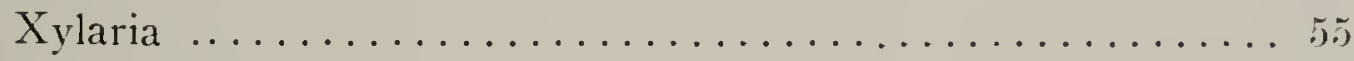

Other Fungi ........................

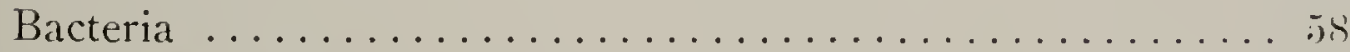

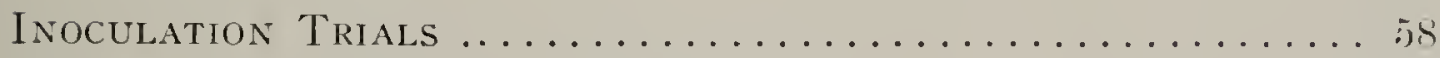

Preliminary Control Experiments................ 59

Experiment No. $1 \ldots \ldots \ldots \ldots \ldots \ldots \ldots \ldots \ldots \ldots \ldots \ldots \ldots \ldots$

Experiment No. 2........................6. 63

Relation to the Problem of Control................ 6.5

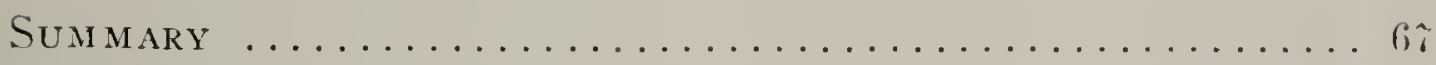

Literature Cited ..................... 



\section{Initial Studies of American Elm Diseases in Illinois}

\section{HUBERT A. HARRIS}

\section{INTRODUCTION}

TuE diseases of the American elm (Ulmus ancricana L.), like those of most trees grown for ornament and shade, have not been extensively investigated in America. Two diseases of minor importance in most years, the leaf spot caused by Gnomonia umca (Sacc.) Thuem. and the anthracnose caused by Mycosphacrella Ulmi Kleb., have attracted attention, as have also some wood rots. The list of fungi thus far recorded upon the American elm in this country includes, according to Seymour (192!) $)^{1}$, 112 species, but the majority of then are of only scientific interest.

When the dying of elms began recently to attract attention in Illinois, it was suspecterl by some that the cause of their dying might be the Dutch elm disease. The investigations of Westerdijk and Buisman in Holland were published in 1929, and subsequently wicle publicity was given to the destructive character of the Dutch elm disease. To anyone not acquainted with the technical aspects of tree pathology and not practiced in the diagnosis of tree diseases, both external and internal manifestations of the prevalent Anerican elm malady would be very difficult to distinguish from the reported symptoms of the Dutch elm disease, as may be understood from the fact that the American malady is often called "elm wilt." That May (1930) found the Dutch elm disease in Ohio during the summer of 1930 served, of course, to add emphasis to the possibility that elms in Illinois were affected by it.

However, even before an investigation was undertaken, it was indicated that diseased elnus in llinois were not suffering from the Dutch elm disease. In the summer of 1930 Dr. Buisman, who was then making a tour of the United States to sturly elm diseases, eximinerl a number of diseased elms in Illinois. After having seen typical material in nurseries, in eity parkways and in private plantings, she was of the

${ }^{1}$ References in this work made by athor and year, p. 67, Literature citerl. 
opinion that though the malady was unknown to her it certainly was not the Dutch elm disease.

It has therefore remained for us to confirm Dr. Buisman's opinion, by both microscopical and cultural laboratory procedure, and to establish the real nature of the malady. From none of the many diseased elm trees examined by us have we secured Graphinm Ulmi Schwarz or its ascigerous stage, Ceratostomella Ulmi Buisman (1930), the fungus which causes the Dutch elm disease.

\section{ACKNOWLEDGEMENTS}

DURING the course of the work herein reported, the writer has had the cordial and helpful assistance of several persons, to all of whom he wishes to extend his thanks and appreciation. P. A. Glenn, Chief Plant Inspector for the State of Illinois, has given his personal help in advocating the prosecution of these studies and in furnishing diseased material personally and through several of his assistants. He has also made available his intinate knowledge of nursery conditions in connection with the prevalence of disease and in selection of the plantations used in our preliminary control studies. Mrs. Thelma Alexander of the Ohio Agricultural Experiment Station rendered excellent assistance, in the early stages of the investigation, in the preparation of wood sections for microscopical examination, as attested by the photomicrograph, figure 11, page 24 . Leo Campbell, formerly of the botany department of the University of Illinois, assisted in the culturing of fungi during the summer of 1931 . Dr. C. D. Sherbakoff has examined and identified for us specimens of Fusarium. Ray R. Hamm deserves special thanks for his willing coöperation in producing the fine photographic illustrations. The Illinois State Nurserymen's Association and its secretary, Miles W. Bryant, have rendered many services, notable among which is the establishment for us of a one-quarter acre experimental elm nursery. The Swain-Nelson and Freeman nurseries have coöperated splendidly in the preliminary control experiments by allowing the use of special elm blocks and by contributing labor and equipment. Thanks are due Dr. John T. Buchholz of the Department of Botany, University of Illinois, for suggestions in the making and staining of microscopic wood sections and for the use of micro-projection apparatus. The investigation has been conducted under the supervision of $L$. R. Tehon, Botanist of the Natural History Surver. The writer owes him much for the invaluable suggestions and criticism offered, and the constant personal interest manifested throughout the work. 


\section{SCOPE OF PRESENT REPORT}

A PLANT disease epidenic is difficult enough to combat when the cause of the disease is known. but when it is mnknown, as in the case of this elm malady, the problem is even more serions. As the prevalence of this elm malady in Illinois was steadily increasing year after year, it became obvious that immediate steps were required to prevent an epidemic which might prove very destructive to the clms of the state. In the latter part of September 1930. the Illinois State Natural HisTORY SURVEY molertook an investigation of the elm malady. This was done at the request of the state's Chief Plant Inspector, whose desire in this regard was endorsed by the Illinois State Nurserymen's Association.

This paper is a report of the first results of the investigation. It includes an account of previous work on Illinois elm discases, the importance of the present malady in nurseries and cities, the general symptoms manifested by diseased clms in Illinois. a detailed consideration of symptoms, effects, and probable pathogens for several important and minor diseases and of fungi obtained infrequently, as well as an account of two prelininary experiments relating to the control of "elm wilt" in nurseries.

It is realized that much more experinentation is necessary to complete our knowledge of the elm malady and especially to develop control measures more adequate than those reported herein. It is not, therefore, intended that the facts given here shall be taken as complete and absolute, but instead that they are the best statements regarding the Illinois "elm wilt" that can be made at this time.

\section{PREVIOUS OUTBREAKS OF ELM DISEASE IN ILLINOIS}

DYisg of elnus is not a new occurrence in Illinois. Elm diseases have attained considerable importance and have received recognition at various times during the past fifty years. The first investigator to direct his attention to the problem was Dr. S. A. Forbes (1885) who, as State Entomologist, observed a dying of elms for sereral years prior to 1883 . When, in that year a general destruction of elms occurred throughout central Illinois, an investigation to determine its cause was begun. The trouble was at that time thought to be entomological in nature, and Forbes, in his report, attributed it to injury inflicted by the elm borer (Saperda tridenta Olivier). Twenty-seven years later Forbes (1912) directed attention to a similar elm malady which had centered this time chiefly in the southern and western parts of the state. While the ultimate death of the elms was occasioned by elm borers, they apparently attacked trees only after a weakened condition had resulted from improper care, from a lack of sufficient moisture supply, or from improper fertilization. 


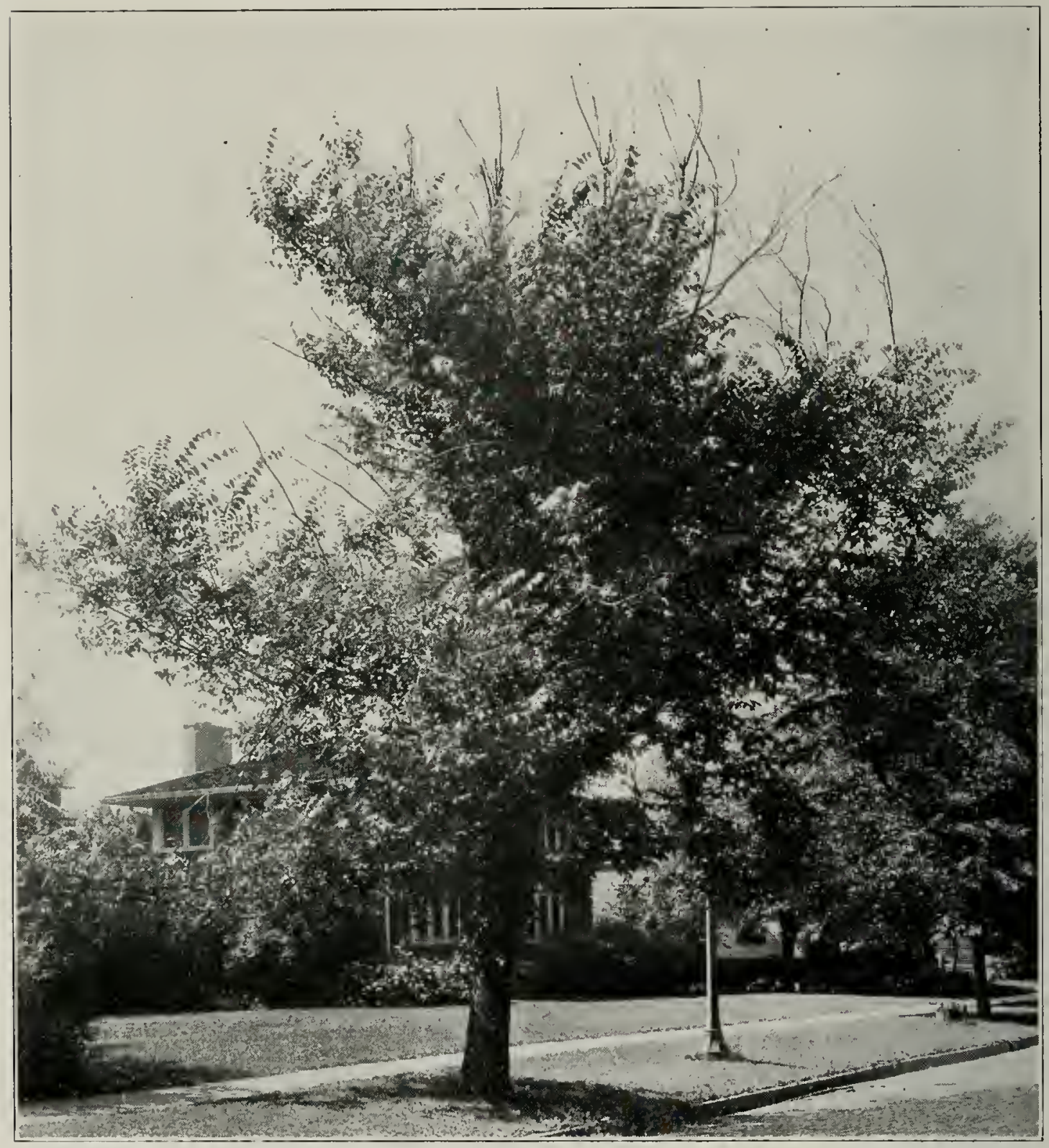

Fig. 1.-A diseased American elm. This shade tree is very severely infected, as is evident from the great number of dead twigs and branches. Photographed July \&, 1931.

Outbreaks quite similar to those described by Forbes were reported by Garman (1899) to have occurred in Massachusetts in 1848 and in Kentucky in 1892 .

In 1913 Humphrey noticed an unthrifty and apparently diseased condition of elms at Rockford, Illinois. In several trees the tops were dead, and limbs were frequently seen which had died back for distances of 10 to 15 feet from the tip. A sloughing off of the bark which occurred in some cases was limited to small areas at the base of the trunk. The cambium beneath these areas was still alive except in a very limited area. Humphrey concluded that the trouble was due to severe winter injury, since no signs of parasitic fungi were visible and only a very few elm borers were present. 


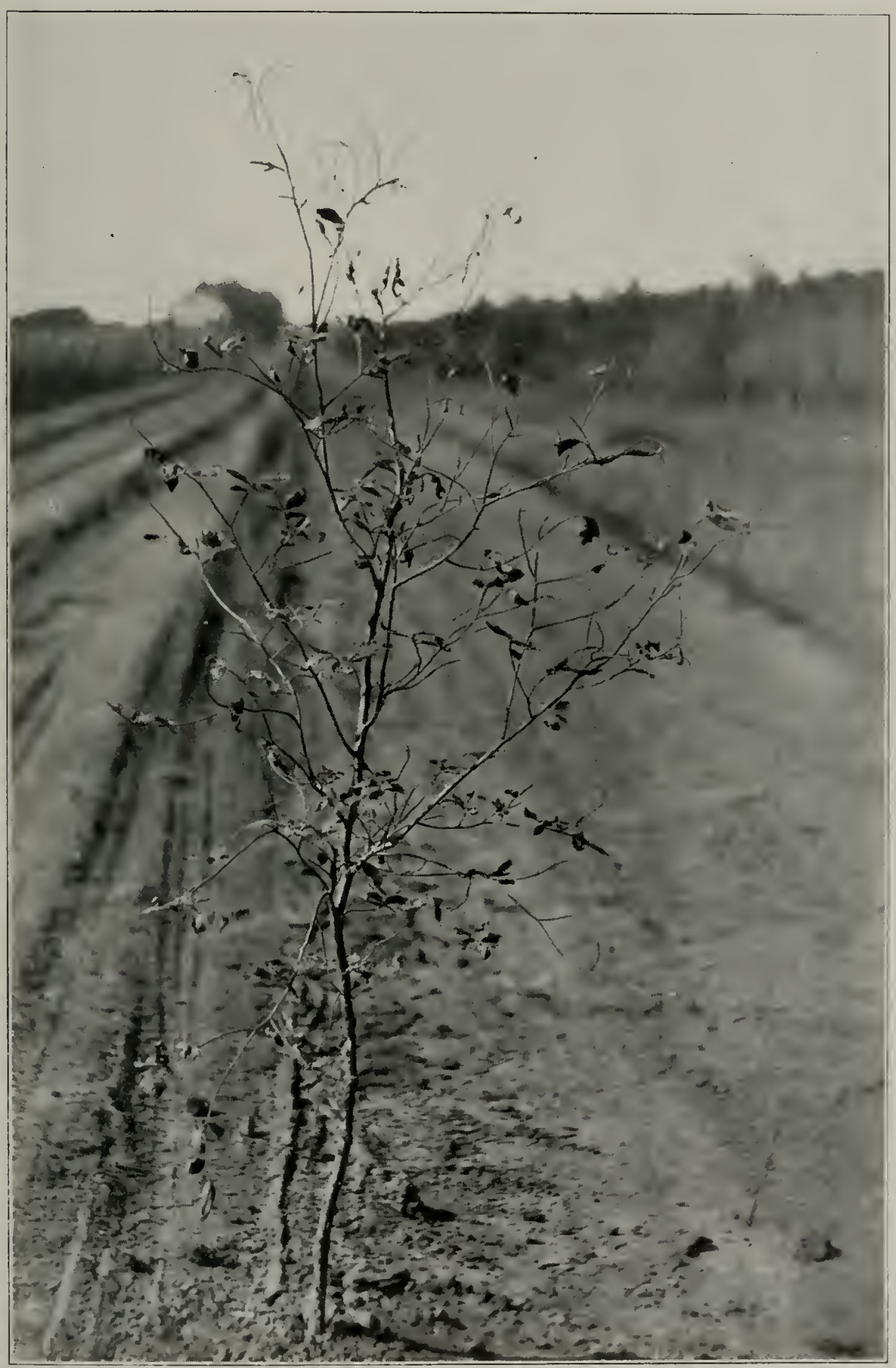

Fig. 2.--A diseased American elm, showing the appearance of "elm wilt" in nursery stock. The disease has caused a general blighting of small twigs and branches throughout the tree. Photographed October 17, 1931. 
The view that all past elm troubles have been due entirely to insects or environmental injury cannot be entertained now. Fungous organisms capable of attacking elms and cansing their death undoubtedly existed then, as they do now. In fact, these early investigators cited examples of trees which, although entirely dead showed not the slightest trace of insect attack or injury. These trees did, however, have their inner bark discolored though intact, and the discoloration as these workers described it is now accepted, on the basis of a much fuller knowledge of tree pathology, as a very common and characteristic symptom of fungous parasitization of woody plant tissue.

\section{CHARACTER OF THE PRESENT ELM MALADY}

CERTAin general symptoms are exhibited by diseased elms, by means of which the fact that they are diseased can very readily be ascertained. Most obvious is the presence of dead limbs, branches or twigs. These may occur in any part of the tree, but usually they stand out prominently in the top or toward the ends of large branches. There may, however, be only a general blighting or dying of twigs on one or more branches; or the indication of disease may be found in the tendency of the leaves on one or more branches to wilt.

An advanced stage of disease is exhibited by the elm shown in figure 1. Limned against the sky, the dead, leafless twigs and branches show abundantly throughout the top of the tree, and a large open space in the left side of the tree shows where disease has killed a large branch. The immediate result, as the picture shows, is to ruin the beauty of the tree. Its value, and the value of the property on which it stands, are both decreased. In three or, at most, four years, the tree will die.

In nursery stock the general symptoms of disease are very similar to those shown by older trees. Young twigs die and the leaves fall from them. Usually this occurs first toward the ends of lateral branches, less frequently at the end of leaders, but in severe cases, or in trees infected for one or more seasons, it may take place throughout the tree. Such a case is shown in figure 2, and the result of continued progress of the disease is illustrated by the nursery tree shown in figure 10 .

One outstanding characteristic of the so-called "elm wilt," as it appears in nursery trees, is shown in figure 3 . Though the manner in which infection gains entrance to the tree is not known, the disease apparently begins in the young growth of the current year. New twigs die from the tip backward, and there is much similarity in their dying to the progress of a true wilt. The progress and nature of the disease may, perhaps, best be illustrated by reproducing here notes made June 25,1931 , on the tree from which the diseased twig shown in figure 3 


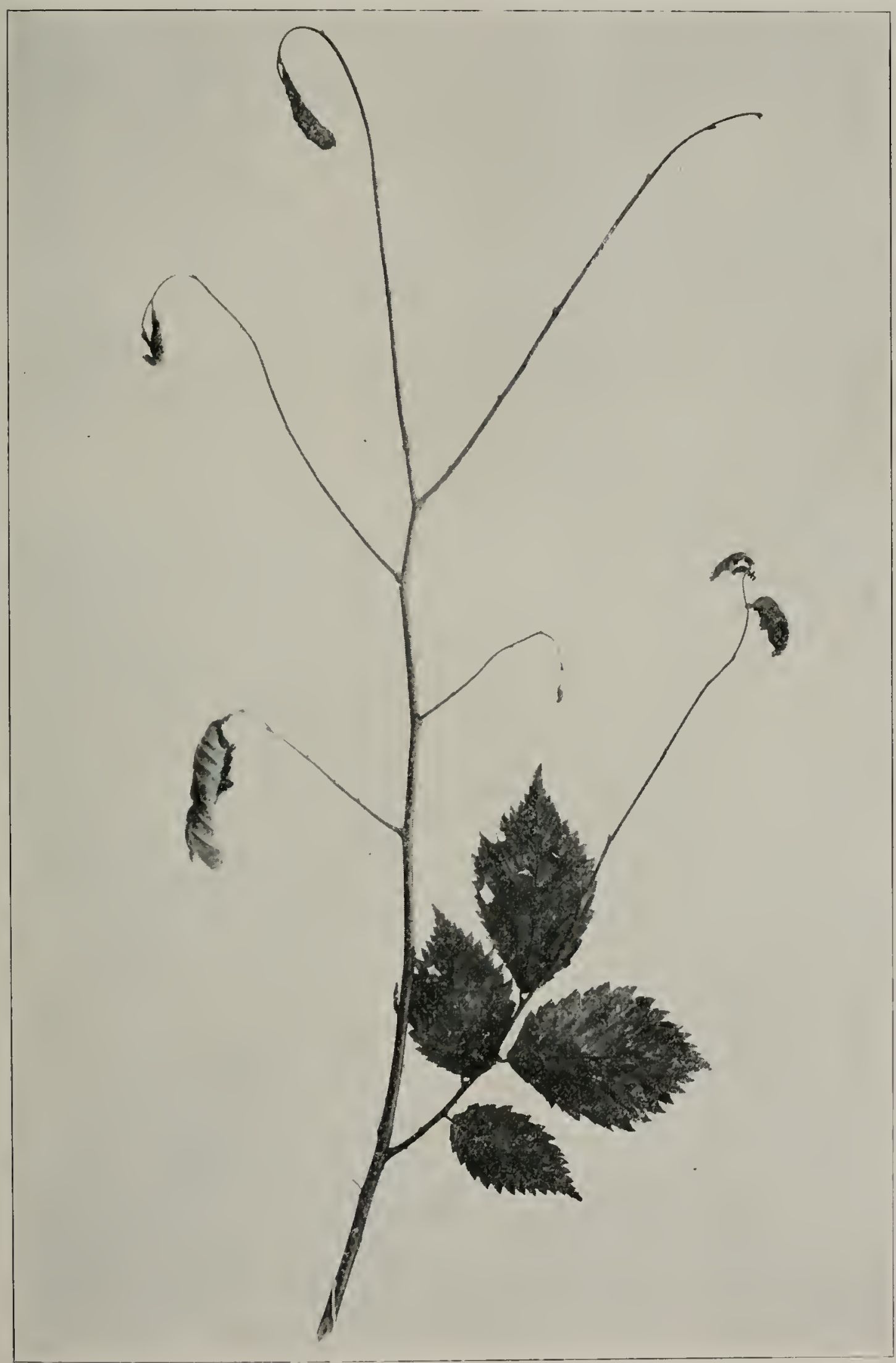

Fig. 3.-Tip of a lateral branch, showing the manner in which the presence of disease is first manifested. Crooking of the twig tips and retention of the end leaves are typical early symptoms. Only the terminal part of the lowest twig has become infected, as is indicated by the presence of healthy leaves toward its base. Photographed June 27, 1931. $\times 1 / 2$. 
was taken for photographing.

"The type of malady shown this summer is striking in that twigs and branchlets arising from the laterals and trunk in all parts of the tree die back from the tips. The terminal growth is killed, and frequently the end leaf clings to the twig, though the other leaves soon fall off. The season's growth soon becomes dead and dry and is typically curved backward so as to resemble a shepherd's crook. It is not apparent where the infection took place, but the indications are that the buds from which the new twigs sprang served as an infection court or that the infection might have gained entrance by way of the axils of the new leaves.

"These newly diseased twigs show internal evidence of infection only toward their tips and, when cut off at the laterals from which they spring, show no indication of diseased wood (at this date) at the point of severance.

"Leaves of these blighted spurs at first turn yellow at the tip, then wilt, and eventually become withered, brown and brittle. They cling for a while to their twigs but eventually all but the end leaf fall."

In addition to the general symptoms just described, other signs of disease may be found by examining the trees closely. One of these is the presence of cankers on limbs and twigs. These cankers may vary widely in their external appearance. They may be smooth and raised, like the one shown in figure $4 \mathrm{~A}$, or they may be sunken and rough as in figure $\% \mathrm{~A}$. Often they extend lengthwise along one side of the stem, but often, also, they encircle and girdle the stem. Whether they extend over a considerable area or are limited to a small portion of the stem is of importance in distinguishing specific diseases. This is also true of the color which the various kinds of cankers exhibit. Another feature of these cankers, and one which indicates with certainty that the elm branch is attacked by a fungus, is the presence of small, pimple-like eruptions, such as those shown in figure $t \mathrm{~B}$. A number of fungi that cause disease in the elm produce their spores in fructifications of this kind. Sometimes these pustules are so small that they may be entirely overlooked unless a magnifying glass is used.

The most definite and characteristic sympton shown by an elm parasitized by a fungus is discoloration of the wood (see figures $5, \%$, 9, 21 and $2 \%$ ). The character and appearance of this discoloration varies, as do the cankers, with the particular kind of fungus causing the disease. After the bark is removed from an affected stem, especially from the cankered side if a canker is present, a brownish discoloration of the wood may be seen. This discoloration may not extend deeply into the wood, and is then most readily seen if only the bark. is removed. But it may extend deep into the wood and then it can be seen very easily by cutting the stem transversely or longitudinally, as shown in 
figure 5, whereupon the dark, discolored wood will contrast sharply with the white, healthy wood. The brown discoloration produced by a fungus should not be confused, however, with the general browning which occurs in the sapwood of a healthy elm soon after the bark has been removed and the wood has been exposed to the air.

The tendency of dead leaves to persist upon an elm in the fall for some time after normal leaf abscission has taken place is a late season symptom characteristic of diseased elms. These leaves may cling to the affected tree through most of the winter. Also, yellowing and shedding of leaves in the early and middle parts of the growing season indicates that a tree may be diseased. Such a condition need not, however, always be attributed to fungi, for it may be the result also of a lack of water or of an unbalanced nutritional condition of the soil.

Importance in nurseries.-Because of the general rrevalence of the elm malady in Illinois nurseries, large losses have been incurred by nurserymen, especially in the northern part of the state. Since the "elm wilt" was first observed in one of the northern nurseries in 1925 it has spread widely, and during the past seven years thousands of young elms have been lost either because of the complete destruction of trees by disease or as a result of injury sufficient to render them commercially unsalable. Not only has there been direct economic loss; there has also been an indirect loss of time and money expended in planting and caring for trees which were killed by the disease after several seasons of care.

The elm malady is of state-wide distribution, and is most prevalent in the north. It is, however; more abundant in some nurseries than in others, and in a given nursery one block of elm stock may suffer to a greater extent than others. Since this investigation was begun many nurseries have been visited, and as yet no nursery has been encountered in which the elms are entirely free of disease.

It has been impossible to recommend to nurserymen or tree owners any dependable means for controlling or treating the elm malady. Not only was its cause unknown; it was even uncertain whether one disease or several existed. The general practice of nurseries in Illinois of following the instructions of the state's nursery inspector to cut out completely diseased trees which are obviously injured beyond saving and to prune out affected limbs when only slight disease is manifest has, however, resulted in a distinct protection to the purchaser of nursery elm stock.

Importance in cities.-Interest in this investigation has naturally centered upon the disease in nurseries, but it has not been entirely so restricted. Upon request, many elms grown for lawn or parkway 


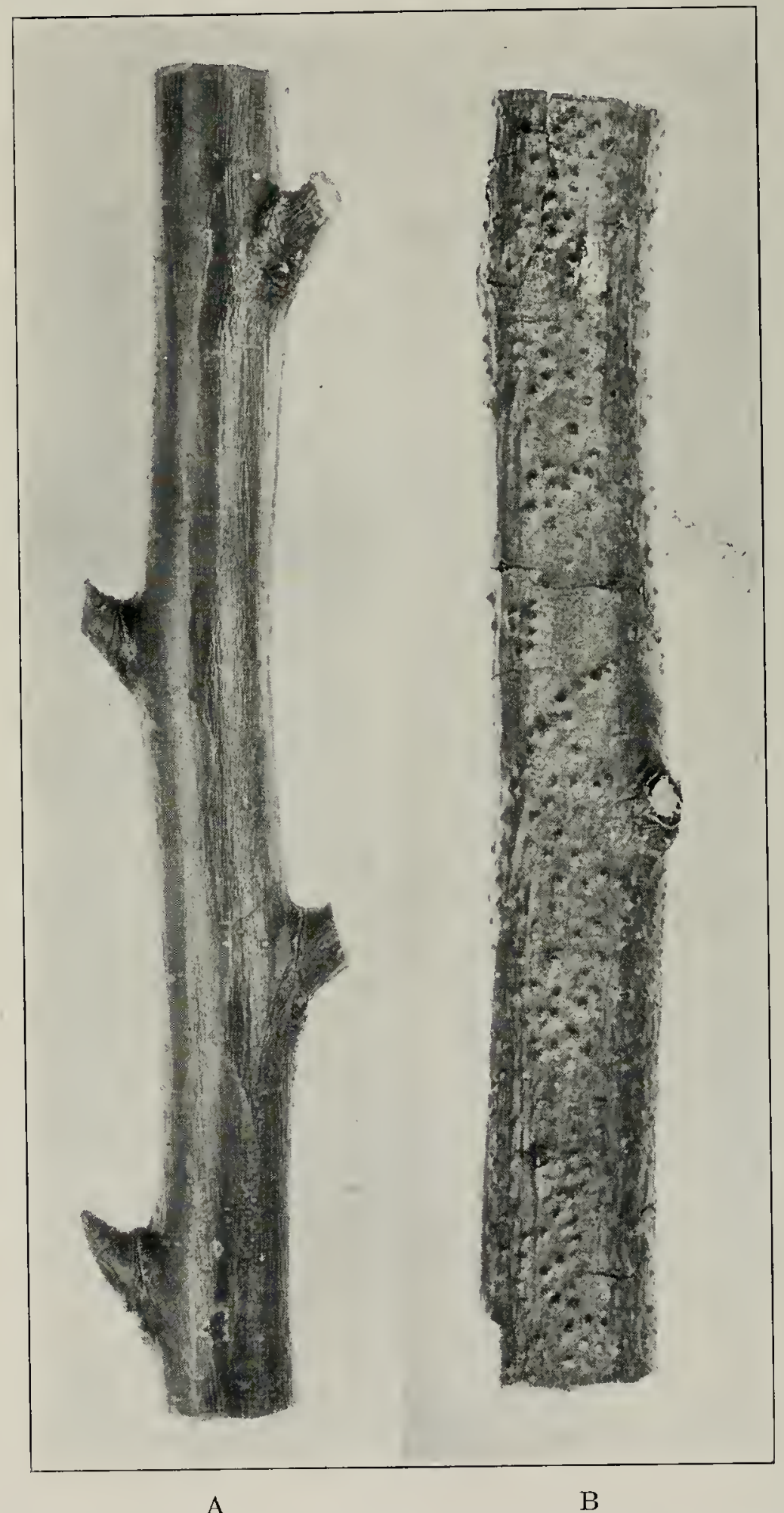

A

Fig. 4.-Cankers on elm branches. A.-The young canker, which extends along the upper side of the branch, is raised, thickened, and smoother than the healthy bark. B.-An old canker, through the dead bark of which an abundance of pycnidial pustules protrude. $\times 2$.

shading have been examined also, and the results of these examinations are included in this study.

In general, elms in parkways and lawns are not nearly so subject to disease as those in nurseries. This is probably due in part to the 


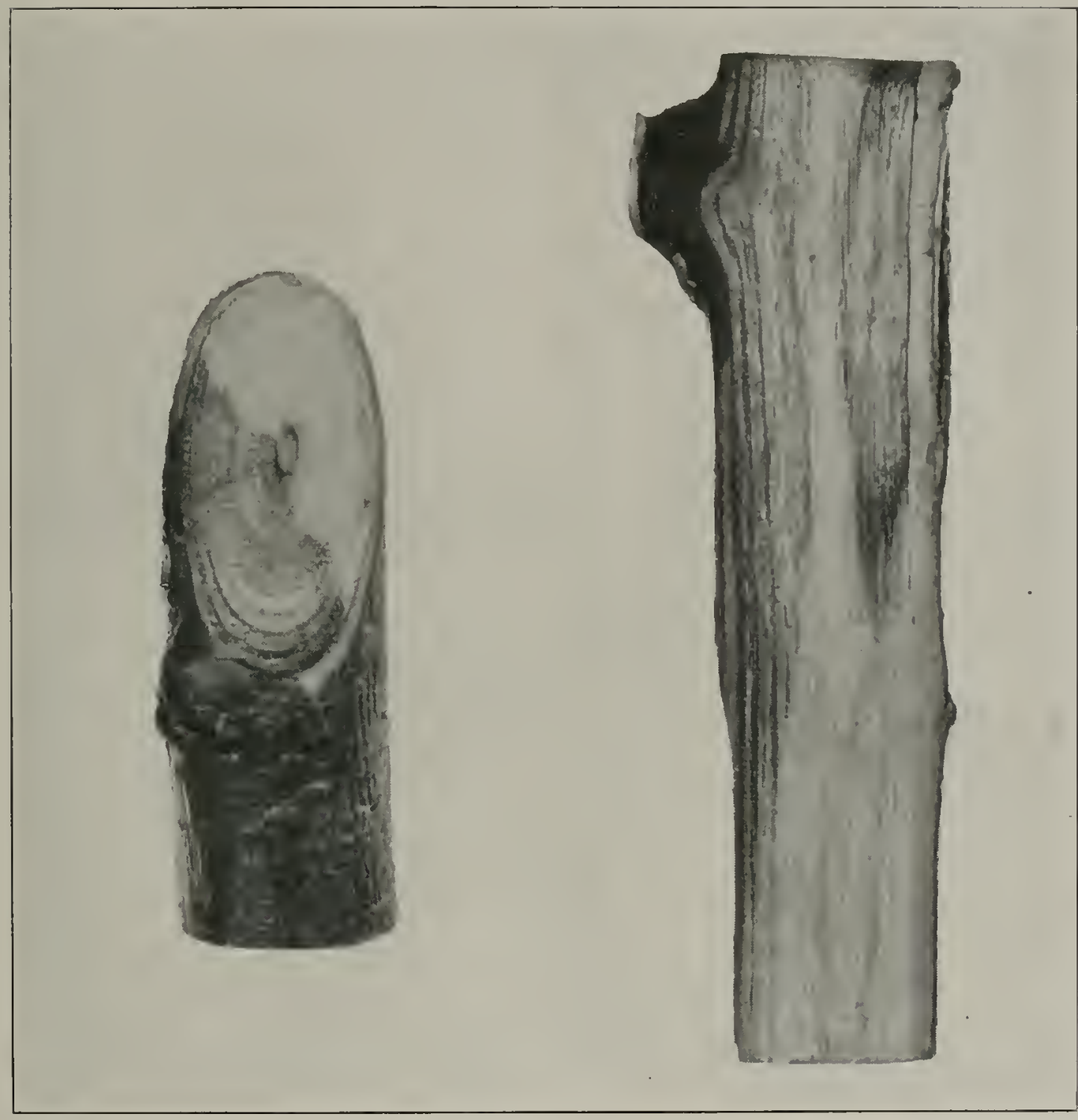

A

$\mathrm{B}$

Fig. 5.- Wood discoloration typical of the presence of disease. A.An oblique cut showing that the discoloration lies beneath the canker and may extend to the heartwood. B.-A piece of branch split lengthwise shows the discoloration, above, in contrast with healthy wood, at the bottom. $\times 2$.

fact that these trees stand at some distance from each other, for infection apparently does not spread among them as readily as it does among crowded nursery trees. It has also been found that the fungi isolated from diseased trees in cities and towns are often quite different from those that attack trees in nurseries. This, however, is more fully explained in the subsequent discussion.

Some examinations have been made also of wild elms. These seem freer from clisease than trees in city lawns and parkways. Usually they are in surroundings to which they are best adapted and scem, consequently, to be able to maintain a vigorous, healthy growth. 


\section{METHODS}

THE initial objective of the investigation was to obtain as extensive an isolation of fungi associated with diseased elms as possible. This was a prerequisite for subsequent progress, because it is by studying the various organisms associated with a group of diseases that those actually causing disease are eventually selected.

Isolation of fungi from diseased wood.-In obtaining isolations of fungi from diseased trees several methods have been used. The usual procedure was to flame the outside of the twig after dipping it two or three times in 95 per cent alcohol. Next, thin slices were cut from the diseased portion of the stem with a sterile scalpel, and these, as soon as cut, were transferred with sterilized forceps to a dish of sterile water and rinsed thoroughly, usually in three changes of water. Then the wood slices were placed upon agar in Petri dishes, five or more to the plate as indicated in figure 6 , and maintained at $23-26^{\circ} \mathrm{C}$. As a rule fungi grew from the slices of wood into the agar after one to three days, but much longer periods were sometimes required, especially when high temperatures prevailed in the summer.

Another method used in some cases was to soak the slices of diseased wood in a 0.1 per cent solution of mercuric chloride immediately after they were cut. This treatment was found, however, to prevent or retard emergence of fungi from the wood, owing probably to the fact that elm being ring-porous the disinfectant penetrated too deeply into the large vessels to be rinsed out. This practice was finally discontinued, for sterilization of the surface or bark of twigs from diseased trees can be effected without the use of this disinfectant if care is used in flaming the outside surface of the stem. Rinsing the wood slices in sterile water may be omitted, also, since slices of dry wood will soon imbibe enough water from the agar to initiate growth of the fungus.

Culturing fungi from spores.-During the examination of specimens, particularly those bearing cankers, spore-producing fructifications of various fungi were often found. These were usually pycnidial structures, from which cultures were obtained either from single spores or by the spore dilution method.

In making spore dilutions, a single pycnidium was removed from a canker and placed in a drop of sterile water on a sterilized microscopical slide. Usually a cirrus of spores would exude from the ostiole of the pycnidium, though in some cases the pycnidium had to be crushed in order to release the spores. Then by means of a sterilized bacteriological loop, a loopful of the spore suspension was placed on an agar plate. Later, when growth had taken place, a transfer was made of a portion of the resultant growth. 
The method used in making single-spore isolations has been outlined recently by Davis $(1930)$, who states that it is sinilar to the method used by Rosenbaum (191\%) for culturing Thiclaria and by Anderson (1913) for culturing Endothia. It is essentially as follow's.

A dilution of the spore sample is prepared in sterile distilled water so that when a loop ful is removed it contains five to 20 spores. Several loopfuls of suspension are added to and mixed thoroughly in a tube of agar maintained slightly above the congealing point. Then the tube is emptied into a Petri dish and allowed to solidify. The spores, if large enough, can be located with the low power objective of a microscope and circled by a ring of India ink. After it is ascertained by careful focusing that no other spores are present in the ringed area at varions depths of the agar, the encircled spore together with the surrounding agar is transferred to a separate agar plate for germination and development. In case the spores are hyaline and too small to be readily located. they may be allowed to attain an early stage of growth before being removed to separate plates.

The majority of our isolations of elm-inhabiting fungi were made upon "Difco" corn meal agar, though in some cases "Difco" potato dextrose agar was used. Most fungi produced their fructilications in greater abundance on the latter medium. Acidified agar was also used at times to inhibit the growth of bacterial colonies which. especially in the stmmer, developed in the plates. Acidification was accomplished by adding five drops of a 10 per cent solution of either acetic or lactic acid to a tube of agar. Stock cultures of all isolations have been mantained upon corn meal agar slants lept in a refrigerator at about $1: 2^{\circ} \mathrm{C}$.

Histological technique.-Some histological studies have been made in order to secure an explanation of certain phenomena issociated with the elm malady but this phase of the investigation has been restricted intentionally as relatively mimportant at the present time. It will be necessary to determine more fully which fungi are parasitic and which saprophytic before an extensive histological study will be justified.

In order to section diseased branches, they were cut into pieces : to 3 inches long and softened by being liept in lacto-phenol ? I to ts hours. They were then washed in water and transferred to a solution made up of 1 part of glycerine, 2 parts of 9.5 per cent alcohol and :3 parts of water, and kept in it for several weeks prior to sectioning. This treatment so softened the wood that satisfactory sections $i-10 \mu$ thick could be obtained from stems $1 \mathrm{~cm}$. in diancter. Very satisfactory differentiation between the fungus and the host tissue wats secured with the Pianeze III-b stain described by Vaughan (1914). 
Recording data.-For convenience and uniformity it has been found desirable to follow a definite plan in recording the data and notes pertaining to each specimen. An example of the method followed is reproduced in figure 6.

Specimen No. 9 .

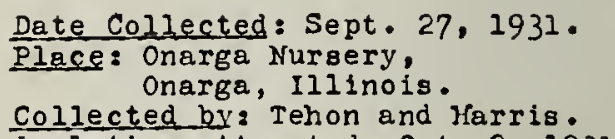
Isolation attemeted: Oct. 2, 1931.

Description: Specimen taken from tree No. 18 of Row No. 17. Tree $4 \frac{1}{2} \mathrm{ft}$. high and with canker on one side of main terminal or leader. Specimen cut off $1 \mathrm{ft}$. below outside canker. Brown wood discoloration beneath canker and also the bark below canker.

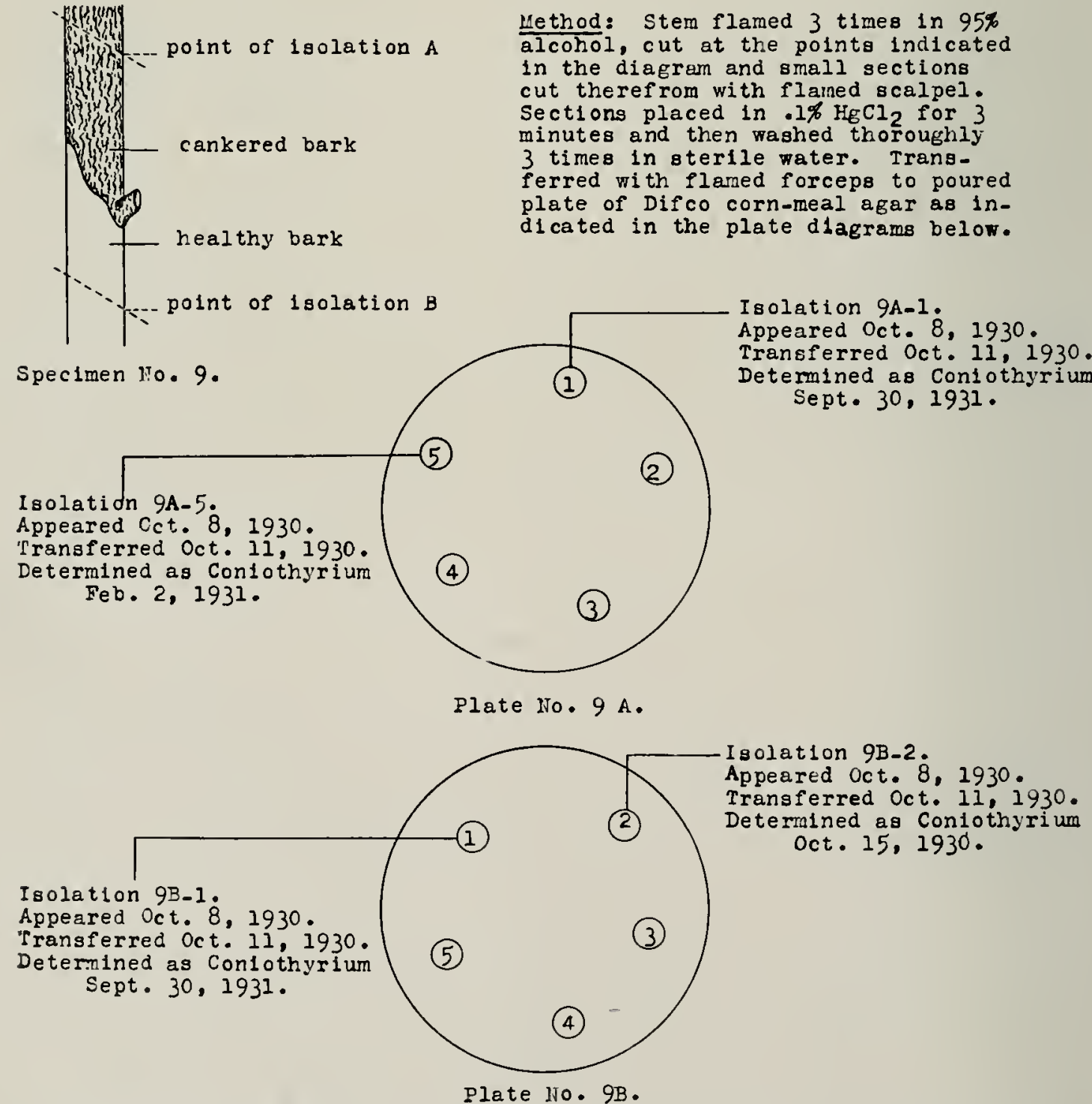

Fig. 6.-Form used in recording data concerning isolation tests of material from diseased elms.

The specimens are numbered consecutively in the order of their collection, and the number of each placed in the upper left corner of the 
sheet. In the upper right corner the date, place, collector and the date an attempt was made to isolate a parasite are recorded. Next follow's a brief description of the symptoms manifested by the diseased tree and also by the particular specimen taken from the tree. The diagram at the left shows the piece of diseased stem from which isolation trials were made, and the points from which slices were taken for plating are marked.

Description of the method used in making isolations from the stem stands at the right of the diagram of the stem, while the lower half of the page contains diagrams of the plates and of the wood slices planted on them. Each plate is numbered to correspond to the specimen from which it was made, various plantings of the same material being designated as A, B, C, etc., and the wood slices in each plate are numbered consecutively. Each fungus isolated receives its number from the plate and the wood slice from which it grew. Thus, an isolation from plate $9 \mathrm{~A}$ and wood slice 5 is designated $9 \mathrm{~A}-5$. The rlate on which the fungus first appeared, the date of its transfer to stock culture and its determination are also recorded on this sheet, as well as the final disposition of the plate.

When a fungus grew from a wood slice a transfer from it was made to a stock slant of corn meal agar. Subcultures on plates were made subsequently from the stock for further study of the fungus. especially if fructifications were not formed by the original isolation. Data pertaining to the later development of each isolation were recorded on separate sheets, one for each isolation, and additional sheets were inserted when necessary.

\section{GENERAL RESULTS OF CULTURAL TESTS}

As previously stated, the preliminary work in this investigation has been concerned chiefly with determining what fungi are associated with the elm malady. In order to accomplish this, specimens from diseased elnus have been collected from as many parts of the state as possible, and numerous specimens have been received from nurseries, nursery inspectors and laymen. This has greatly increased the extent to which the diseases prevalent in different localities could be determined.

Shortly after the isolation of fungi from diseased material was begun, it became quite evident that the elm malady in Illinois was not a single disease caused by one organism but was, rather, a number of diseases caused in all probability by an equal number of different organisms. At this writing. approximately 200 specimens have been examined or cultured and from them 512 isolations of fungi have been made. Among these isolations 20 genera of fungi are now recognized and there are, besides, 101 isolations, or about 20 per cent, which have as 


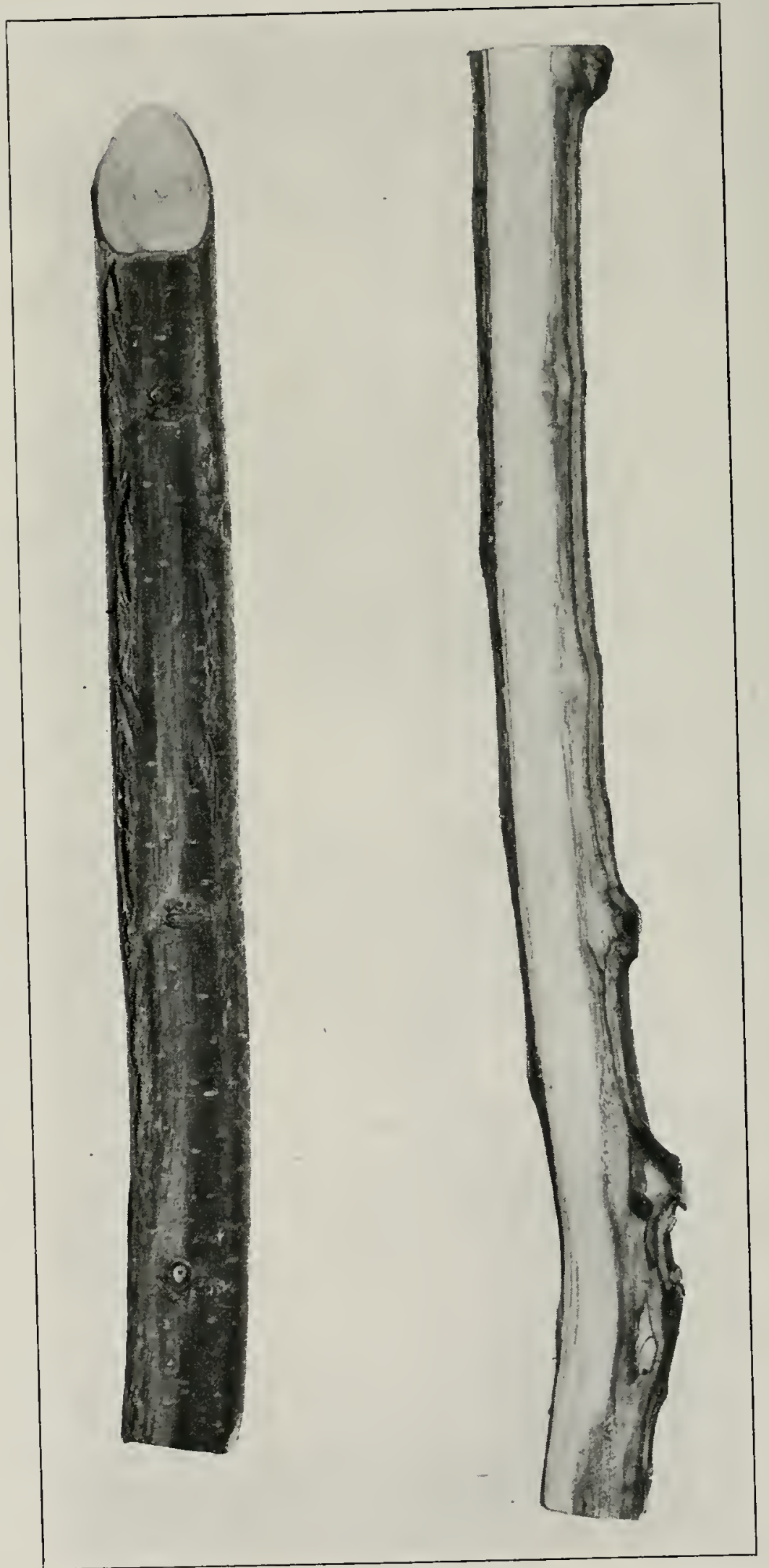

A

B

Fig. 7.-Canker characteristic of the Coniothyrium disease. A.-Outwardly, the cankered side of the branch is flattened and the bark has cracked wumerous pycnidia of the fungus are present in the along its margin. Numerous pycnidia of the readily overlooked. B.cankered area but are so small as to be quins a very definite, continuous, diffused discoloration along the cankered side. $\times 1$. 
yet not been induced to fruit in onr cultures. Consernently, the number of genera and species of fungi nltimately to be represented in this collection will undoubtedly be increased consiclerably. In several instances different species of fungi belonging to the same genus have been isolated. so that nearly 30 distinct species are now recognized.

The results of the isolations of fungi from diseased elms have been compiled in table I to show the number of tines each organism has been isolated and also its per cent of occurrence anong the total number of isolations.

In addition to the fungi listed in table I three genera, Cytospora, ${ }^{2}$ Diplodia and Phomopsis, have been derived from diseased elms by

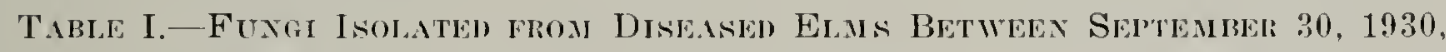
Axn Decenber 31, 1931, Arraxgen ix Them Crifr of Frequexcy.

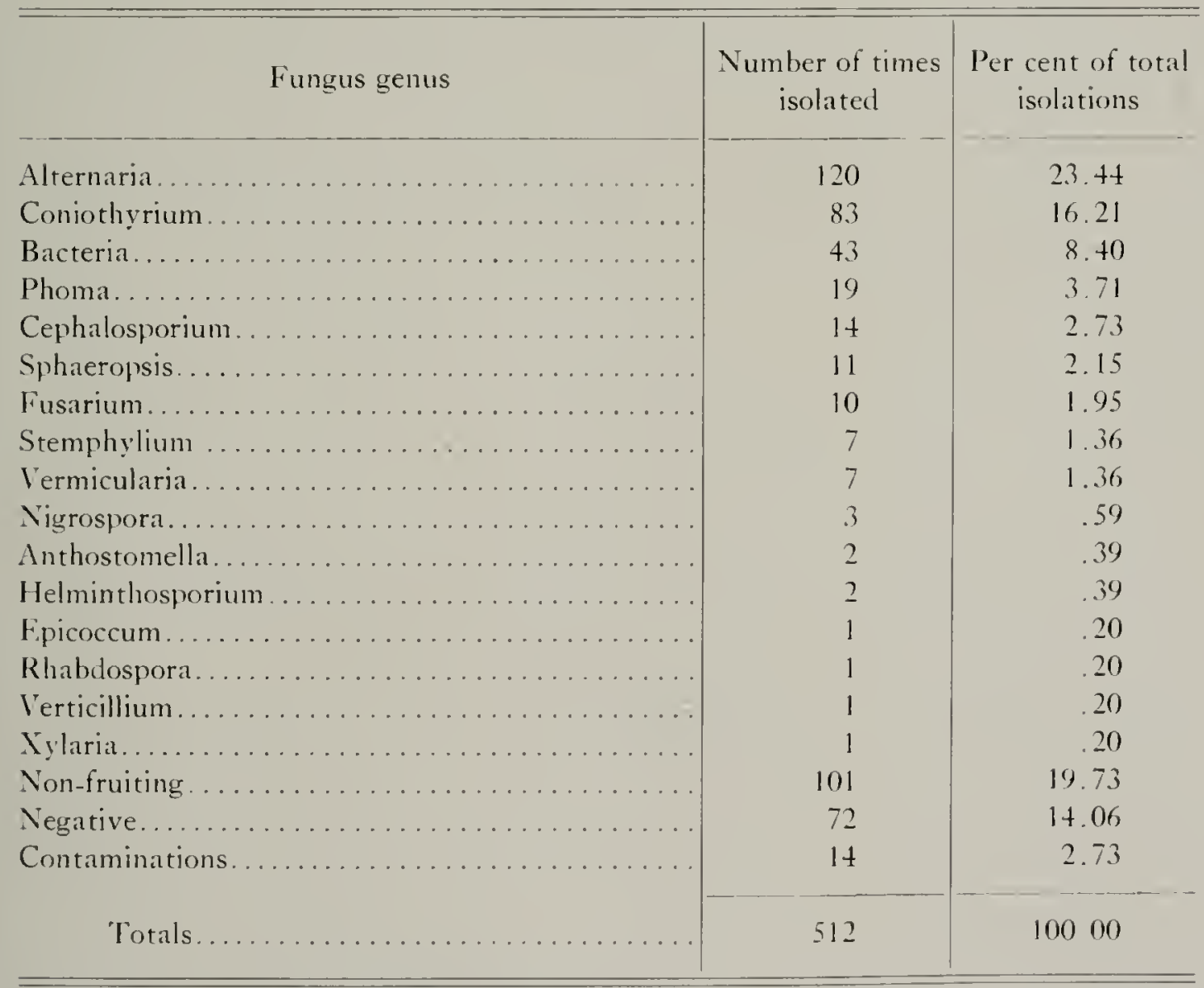

single-spore isolations, the pycnidia and spores laving been encombered during microscopical examination of diseased specinens.

From the data given in table $I$ it is rearlily seen that almost one fourth of the cultural isolations are Alternarias. Jowever, this fungus

2 Since completion of this report, Cllospora has been obtained also by rirect culture from diseased wood. 


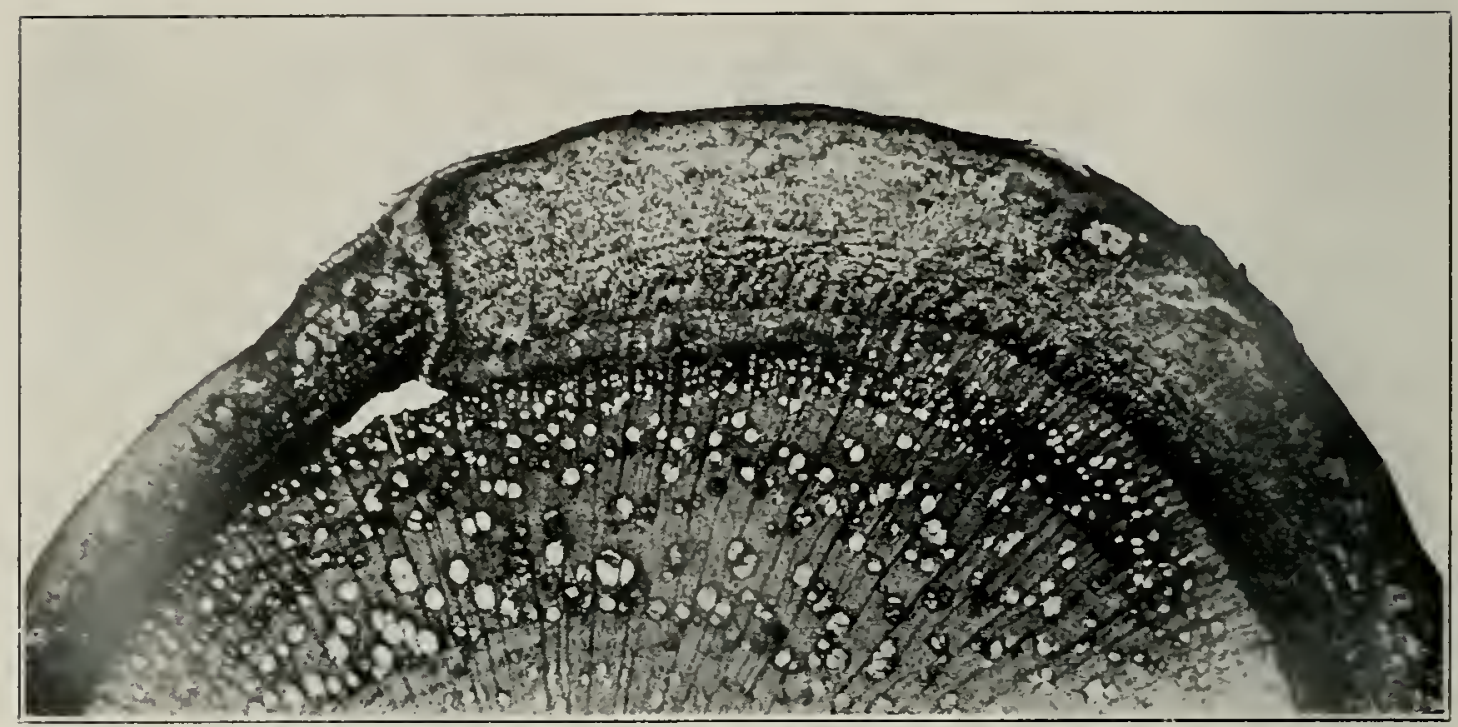

Fig. 8.-Effect of the Coniothyrium disease upon growth, as shown by a microscopic cross section, $X 25$. To the left is the canker, separated by a callus tissue from the healthy part. The tissues in the cankered region are dead, but the liealthy side of the stem has continued to form new wood and cortex. Notice how the tissues have been torn apart where the diseased and healthy regions join.

and Stcmphlinum, so far as the investigation reveals, are chance inhabitants of the bark and do not produce any serious or destructive clisease. Coniothyrium, which constitutes 16 per cent of the isolations, is the one outstanding fungus responsible for serious disease. Bacteria, which as a group occur to the extent of 8 per cent and rank next highest, are of doubtful importance. In some instances they may have been obtained in culture because of incomplete surface sterilization of the sections. Many times, too, they failed to grow from one or more of the rood slices in a given plate.

Of the remaining fungi, those which appear to be more or less important as causes of disease are Phoma, Sphacropsis, Vcrmicularia. and Verticillimm. The pathogenicity of Sphaeropsis (Hubert, 1931, and Hubert and Humphrey, 1920) and Verticillium (Meer, 1926) has already been demonstrated by previous investigators; but since they have occurred in our cultures much less frequently than Coniothyrium. they must be considered less important in Illinois than they are thought to be elsewhere, though their attack upon a single elm is, it is true, very serious. The other fungi listed in the table have been obtained but very few times in our isolations and must therefore be considered of minor importance, even though their rôle as parasites may be established later. Nearly 14 per cent of the attempted isolations remained sterile and only a very small number, less than 3 per cent, became contaminated to the extent that growths emanating from wood slices could not be used reliably. 
In platings such as we have made, it frequently happens that the same original material, when tested, yields several different fungi. To date, 32 culture plates have yielded more than one fungus, and 13 different combinations of twos or threes have occurred. These combinations and the number of times each has occurred are shown in table II.

Table II.-Combixatusis of Fungi Obtanen in Agar Plate Isolations from DINEANEU Elas.

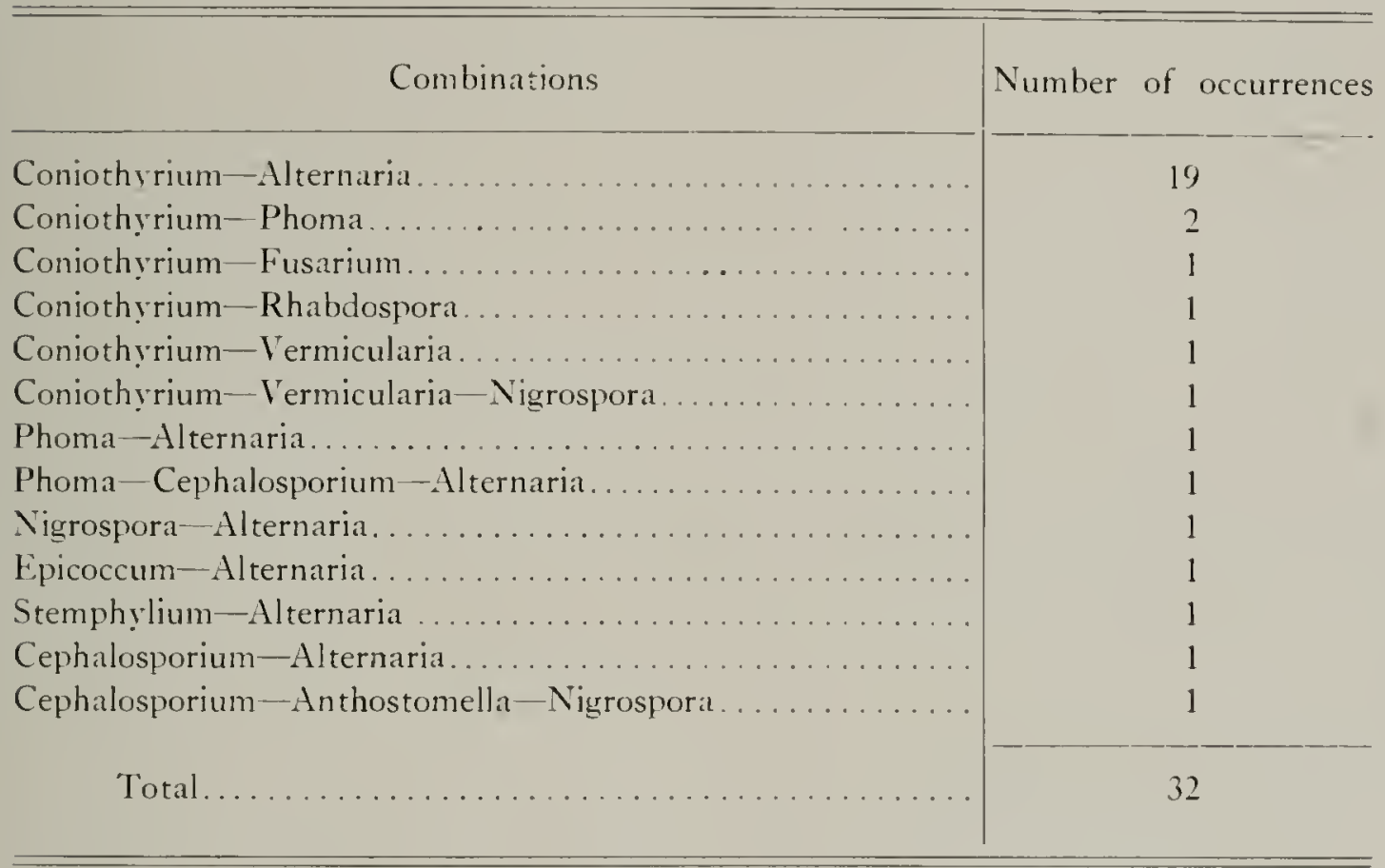

Some of the fungi in these combinations are uncloubtedly saprophytic and grow from the plated wood slices at the same time as the parasitic fungi, but until inoculation tests have definitely determined which are pathogenic a fully satisfactory explanation of all these combinations cannot be made. However, from the study that has been made of some of the fungi the relationship existing in at least some of these combinations appears fairly certain. In the Coniothyrum-Alternaria and Phoma-Altcrnaria combinations. Altcrnaria seems to be a seconclary invader with only a saprophytic role. It probalbly has the same relation in other combinations. It is conceivable that an elm may become infected by more than one parasitic fungus at points not greatly remote from each other. Later these fungi may so spread within the tree as to penetrate the same tissue and when platings are made they are, of course, secured in culture. In the Coniothyrium-Phoma and Coniothyrium-I crmicularia combinations, both fungi in each of the combinations were apparently parasitizing the same tree. Also, after 
a tree or branch has been killed by a parasitic fungus almost any numler of secondary saprophytes may invade the affected parts. As the parasite penctrates further into the living parts of the tree. the dead limbs are left to the saprophytes. This seems to have occurred in specimens from which only the Epicoccum-Altcrnaria and StemphylumAlternaria combinations were derived. The other combinations are of doubtful siguificance and must remain so until results from inoculation tests are completed.

\section{SPECIFIC DISEASES}

Tine malady now attacking elms in Illinois has been quite generally and popularly termed "elm wilt," especially by nurserymen, though it certainly is not a true wilt according to the pathological definition of the term. In popular usage the term probably refers to any condition in which wilhering and dying of foliage on the affected parts is conspicuous. In order to eliminate any possible misunderstanding as to the nature of elnu cliseases in Illinois, the term "wilt" should be restricted in application and in reference to those, diseases which are true wilts in accordance with the technical interpretation.

The various elm diseases in Illinois manifest themselves, as has been stated, in a number of ways, chief of which are the production of cankers, twig blights. diebacks and true wilts. Examples of fungi causing cankers are Coniothyrium. Phoma, Sphacropsis and Phomopsis. Pustules containing the pycnidia and spores of Diplodia and Cytospora have also been found to occur in cankers. In addition two fungi, Coniothyrium and Sphacropsis, also produce a blighting of the young twigs, and the latter is credited with causing a dieback. Verticillinm and Fusarium, which cause true wilt diseases in many kinds of plants. have also been obtained from diseased elms. This investigation has been chiefly concerned with the fungi attacking the stems and branches of elms, though it has also been observed that leaf spots due to Glcosporium and Gnomonia are of common occurrence on elms in the nurseries, just as they are on trees in cities. These leaf spots, which have already been investigated by Miles (1921). are unimportant except in unusual seasons, when they cause severe defoliation. Their economic importance lies in the fact that. in severe cases, they may weaken the tree.

TRACHEOMYCOSIS ASSOCIATED WITH CONIOTHYRIUM SPP.

As indicated in table I, the fungus thus far classified as Coniothy'rimm is the most important fungus involved in the elm malady. Other

: The tracheomycosis of elms most commonly found in nursery trees yields a fungus for which we are provisionally using the generic name Coniothyrim. The histologic aspects nt the disease are, however, so unusual for Coniothyrim. and certain points of morphology in the fungus ale so puzzling, that further study of the fungus is desirable befrire more definite identification is made. 
fungi may be equally as severe in their attack upon indiviclual elms, hut the fact that they are of less frequent occurrence and not nearly so widely distributed necessitates ranking them as less important than Coniothyrim. From the material thus far examined it is quite apparent that the Coniothyrim disease is widely distributed throughoun Illinois. It has been collected at Mounds (ity in the extreme sonthern portion of the state, and as far north as Libertyrille, in Lake connty. In western Illinois it has been found at El Dara, and in the eastern part at Danville. It is apparently most prevalent, however. in the cast-central and northeastern parts of the state.

The Coniothyrium clisease causes the death of an elm by sprearling: through the tree year after year. It has, however, been observed in some cases to produce only a twig blight involving either only a few or a considerable number of twigs. An elm very severely infected and damaged by the Coniothlrimm clisease is shown in figure 2. Blighting of small twigs is apparent in all parts of the tree but it is most evident and most abundant in the top. This blighting of small twigs by Coniothyrimu further substantiates the conclusion, previously set forth (p. 6). that the disease gains entrance into the tree through the young and actively growing shoots at the tips of branches. From observations made of the twig blight stage of Coniothyrimm infection, its apparent effect is not that of killing the tree at once but that of producing a general unthrifty condition. In arldition to the characteristically rearl and blighted twigs, infected trees produce not only fewer leaves than do normal trees but leaves which are both smaller and so widely scattered that they never form a very thick foliage. In the case of young seedling trees it has been noticed that

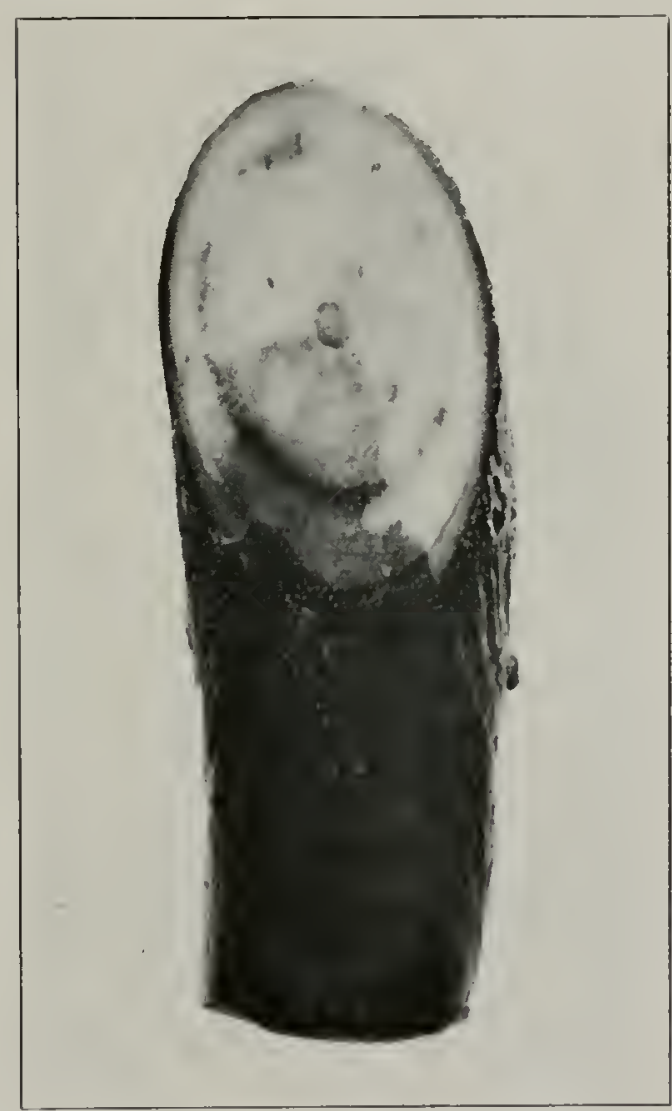

Fig. 9.-Elm stem cut obliquely to show the woor discoloration typical of the Coniothmilum disease. The discoloration occur's chiefly beneath the canker but is diffised deeply in the stem. In the current season's wood, however, it has formed a distinct though discontinuous rircle. $\times 2 \%$. although the terminal shoot becomes infected and blighted at the tip, for some reason the disease is sometimes incapahle of making further prog- 


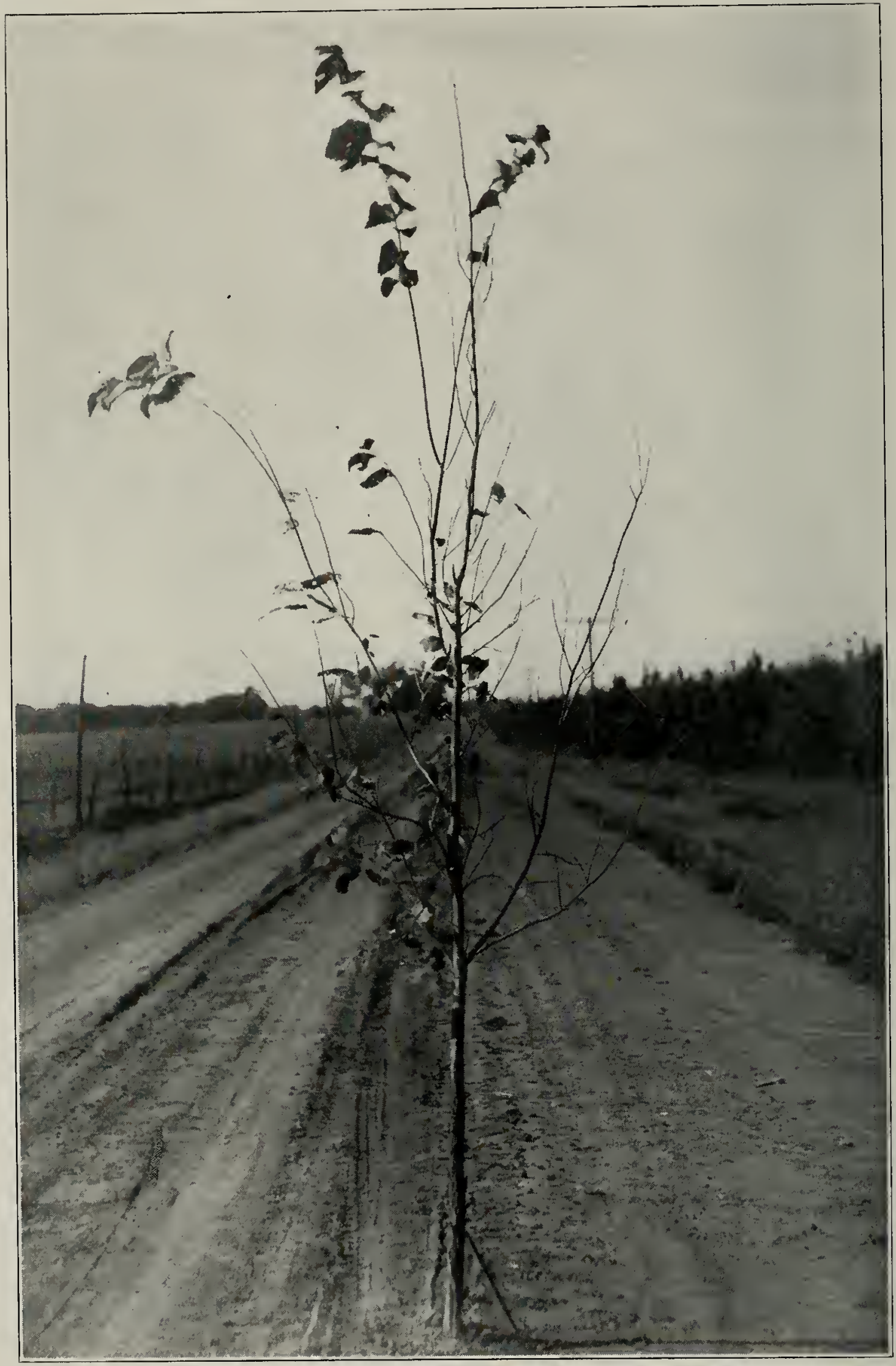

Fig. 10.-A young nursery elm dying from Coniothyrium infection. This tree shows the ultimate effect of the disease. The entire right half is dead and a severe blighting of twigs has taken place in the left side. The infection, which evidently first entered through the old leader, finally reached the base of the tree. Photographed October 17, 1931. 
ress. Save for these dead tips. such trees make a healthy growth, since the disease has not extended downward from the dead tip into the tree. It is more conmon, however, for Coniothyrimm wltinately to bring about death of the infected tree within two or three years.

The injury which may be done to a nursery tree by continued extension of the Coniothyrium riscase is very well shown in figure 10. The leader, or main shoot, of the tree shown in the picture had been pruned off the previous year in order to prevent, if possible, the downward progress of the disease. This treatment was ineffective, however, since the internal infection had already progressed some distance beyond the point of pruning. Conseguently the infection continued to grow through the tissues of the tree and infected the new leader and several of the lateral branches. The result has been destruction, practically, of the tree. Infection has progressed beyond any hope of stopping it, as discoloration of the wood was found to extend to the base of the tree.

The first manifestation of the disease, as it has been observed most often in the nursery, is dying of the tips of young shoots or small twigs. This usually occurs toward the top of the tree, but twigs and shoots arising from the lower laterals and the trunk may also be involved.

It has been impossible as yet to determine either the exact means by which the fungus gains entrance or the point at which infection starts. Careful examination of many examples indicates, however, that infection occurs early in the growing season, probably just as or slortly after the tree begins to leaf out, and that the fungus gains entrance either through the growing shoots or the unfolding terminal or axillary buds. After infection has taken place those leaves nearest the point of infection turn yellow and then gradually become light brown. Finally, when the tissue is dead, the leaf becomes dark brown, dry and brittle. This yellowing and browning does not necessarily occur at once over the entire leaf. A portion of the leaf nlay still be green while other parts are becoming yellow or brown, and all intermediate stages of dying tissue may be found simultaneously. The disease, however, is not in the leaf, but in the twig. and the dying of the leaves, which apparently is due to the water supply being cut off, is merely a symptom of the presence of infection in the twigs.

As the disease progresses downward through the shoot, additional leaves are killed and the diseased shoot curls at the tip in the nanner illustrated in figure 3 . Nost of the foliage falls, though terminal leaves persist for a long time. If infection takes place later in the year, the dead leaves usually do not fall very readily but have a tendency to persist and may remain attached to affecter trees for a considerable period 


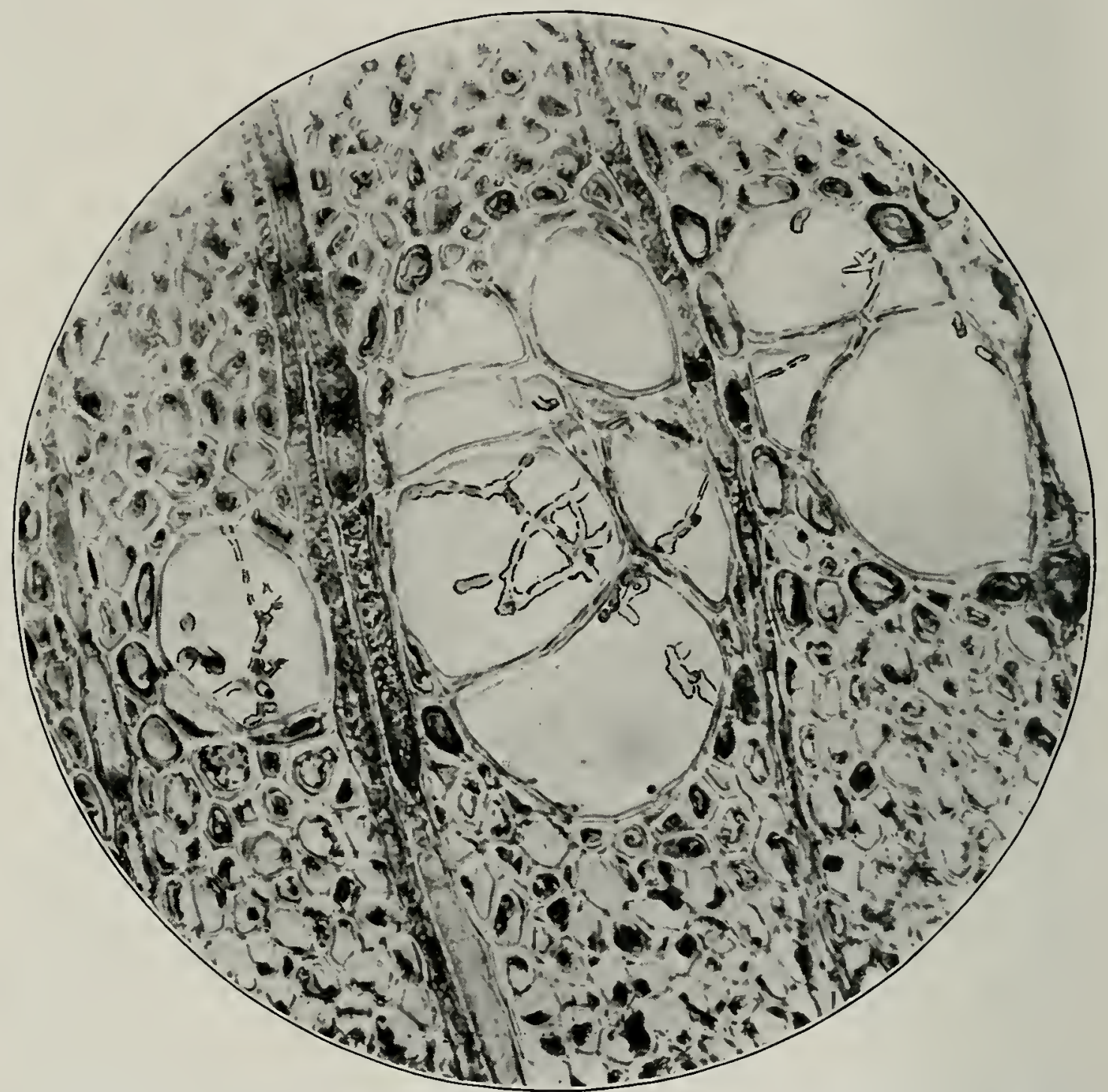

Fig. 11.-Photomicrographic cross section, $\times 450$, of diseased elm wood, showing the Coniothyrium fungus in the water ducts and in the surrounding wood fiber cells.

after normal leaf fall, due to the fact that a normal abscission layer was not formed. The characteristic shepherd's-crook curling of the tips of the shoots and the persistent dead leaves furnish a ready and certain means of locating diseased trees in nursery rows. These are not distinctive characteristics, however, which will adequately differentiate the Coniothyrimm disease from other diseases, since there are other elm diseases for which the persistency of dead leaves and crooking of diseased branches at the tip has been described.

As already stated, the Coniothyrium disease appears to begin in the top shoots of the tree. From these it progresses downward into the lateral branches or twigs. When the original infection seems to have occurred elsewhere than through the terminal shoots the disease may extend both up and down the branch from the infected twig. Small cankerous areas appear on the outside of infected branches. These 
are sunken, water soaked, and vary in color from reddish to greyish brown. They may extend entirely around young shoots and twigs, but on larger and older branches they show on only one side, as in figure $\mathrm{A}$. Large lesions are usually dark purple and are more or less water soaked. The branch is decidedly flattened on the cankered side, and the onter bark often splits or cracks at the edge of the lesion.

Flattening of the branch at the cankers results from the fungus killing the cambium on the diseased sicle, after which growth ceases there. The cambinm in the healthy portion of the stem continues, however, to form new wood. Lateral branchlets and twigs arising from the flattened, cankered side of a branch are almost invariably dead, while those arising along the healthy side continue to live until the fungus lills the entire branch.

The internal changes which occur when a stem is invaded by Coniothyrimm are shown in figure 8 , somewhat to the left of the center of the section. In the tissues peripheral to the xylem a radial callus has been formed between the cankered, diseased portion of the sten and the healthy part, the purpose of which is evidently to prevent spread of the fungus laterally. In the left third of the picture the cambium has been invaded and killed by the fungus, and :10 development has occurred. At the right, however, the cambium, protected by the callus between it and the dead portion, has continued to live and to produce a thick cortex. The increase of cortical tissue in the healthy region contrasts decidedly with the lack of development in the diseased part. A further difference between the diseased and healthy sides of the stem shown in figure $S$ is that a considerable amount of xylem or woody tissue has been produced on the healthy side since the occurrence of infection, while none has been formed in the cankered area. Where the cambium was not killed by the fungus it formed additional new layers of both xylem and phloem, resulting in an increase in stem diameter on that side, but where it was killed no new xylem or phloem could be formed and the canker remained flat and apparently smiken.

As a result of growth in the healthy regions the outer tissues were torn loose from the wood where the canker and healthy part joined, leaving an irregular cavity in the canker adjacent to the callus tissue. Sulbsequent growth brings about the cracking of the outer bark illustrated in figure $i \mathrm{~A}$.

In addition to the outward symptoms exhibited by the Coniothyrimm disease, a very marked discoloration of the wood of the stem occurs. It varies from light to dark brown, according to the stage of development of the disease. A transverse cut of an infected branch, such as that shown in figure 9, shows the discoloration to be more or 


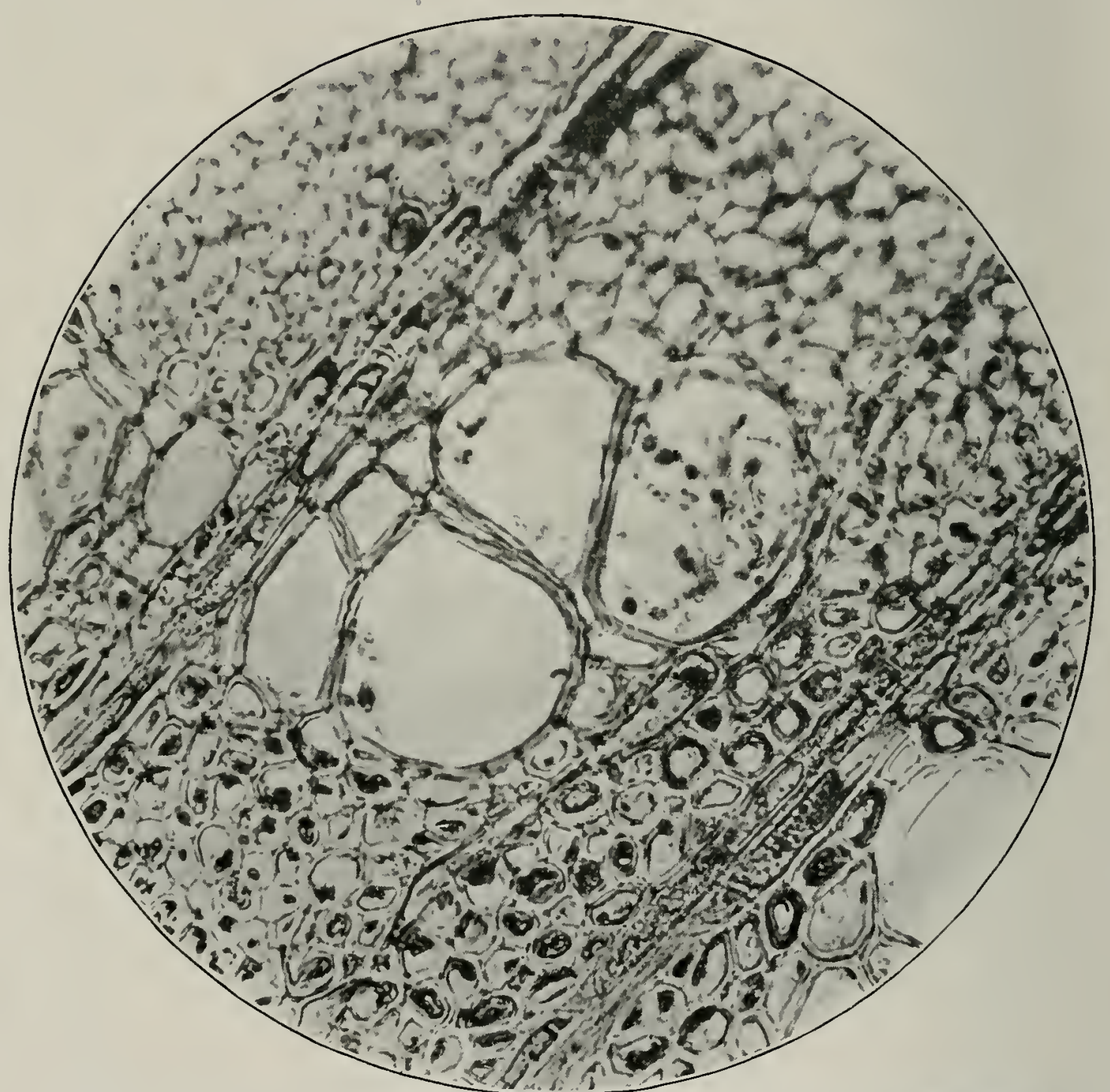

Fig. 12.-Photomicrographic cross section, $\times 450$, of Coniothyrium-infected elm wood, in which a large water duct is nearly plugged by the massed hyphae of the fungus.

less diffused and to be present chiefly in the cankered side of the stem. In the wood last formed the discoloration is darker and heavier. Very often the discoloration in the sapwood may form an almost continuous circle in the stem, but just as often the discoloration may appear in small scattered areas. The smaller discolored areas are not, however, sharply outlined in the stem but merge gradually into healthy wood.

If a branch be cut lengthwise, as shown in figure $8 \mathrm{~B}$, the wood discoloration will be found to extend mainly along one side of the stem, directly beneath the sunken and flattened canker. The discoloration is so evenly diffused that it forms a continuous brown stripe. In relatively new infections the discoloration may be light, but in older and more severe infections it is dark brown.

The minute, black pycnidial fructifications of the fungus are produced only after the diseased parts die. They have been found near the 
tips of small dead twigs and in cankered areas on larger stems. In the latter case the bark becomes shrunken and loose, and tends to split and peel from the cankers in thin layers or strips. Often the pyenicha, though not visible externally, can be found when the loose lark is removed. Abundant pycnidial formation has also been found to occur upon wood surfaces left exposed as a result of pruning. This, of course. happens only when an infection is not removed completely and cliseased wood has been left below the pruning point. The small stub left as a result of the pruning dies, and pycnidia develop on the exposed end of it.

A histological study of a diseased stem shows that the fungus first invades the cortex and the phloen and brings about a great disjunction and disorganization of the cells composing those tissues. Frequently the phloem is so severely attacked that it is almost completely destroyed. In both cortex and phloem the mycelium is both intercellular and intracellular. The cambium is killed next, and after that the fungus advances into the adjacent xylem, or sapwood, though apparently with more difficulty. In the early stages of its progress it is largely confined to the medullary rays, but from these it eventually extends into the xylem cells. In going from the meduliary rays into the xylar elements and from one xylar cell to another the fungous hyphae are capable of direct penetration of the walls, though they frequently accomplish the penetration of a new cell by means of the pits in the walls of tracheae and other cells. The fungus extends quite generally throughout the xylem in all directions, but, as shown in figure 11 , it is most easily seen in the large water conducting cells and produces there a typical tracheomycosis. It is, however, also abundant in the other xylar cells. In many cases the hyphae are so abundant in the tracheae and xylar elements that they almost fill the cells, as can be seen in one of the large tracheal vessels in figure 12 . The only apparent limitation of the mycelium suggested in figures 11 and 12 to a few isolated or scattered tracheae indicates that the tracheae are utilized as an important avenue of progress in the extension of infection up and down the stem.

The extent to which the mycelium of Coniothyrium is distributed in cliseased wood is illustrated better in longitudinal than in cross sections. Figure 13 shows a thin longitudinal section of diseased wood magnified 100 diameters. The clear spaces running horizontally through the picture are water ducts, and the fine bearllike strands in them are threads of the Coniothyrium fungus. At some points the water ducts are almost plugged by dense aggregations of such threads. A more detailed view of the fungus in the water ducts is shown at a magnification of 450 diameters in figure 14 , and there it can be seen how the fungous threads pass from one duct to another and even into 


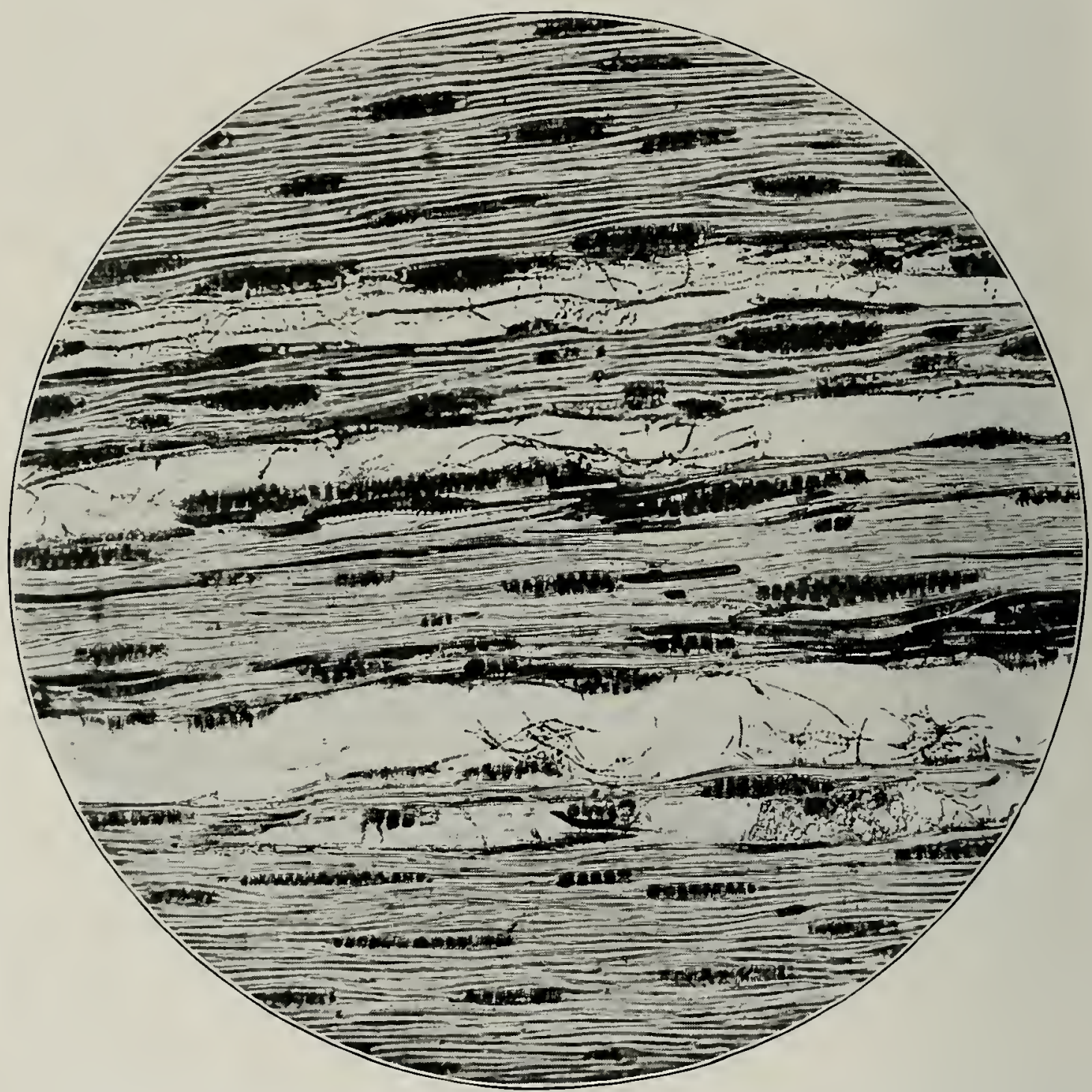

Fig. 13.-Longitudinal tangential section of diseased elm wood, $X 100$ showing the mycelial threads of Coniothyirum in the water ducts. The fungus evidently uses these mobstructed ducts as channels through which to proceed from the point of infection to other parts of the tree.

the dense, woody structure of the branch.

The fungous threads which traverse the water ducts are generally of large diameter, possessed of thick walls, and filled with densely granular protoplasm. From these ducts fine branches penetrate, by way of pits in the ressel walls and by dissolved passageways, into the wood fiber cells; and in the cavities of these cells the threads are smaller in diameter. A single thread, with its multitude of branches, can be traced for long distances through the wood. The manner in which the mycelium penetrates throughout the wood fibers is shown in figure 15, which shows a portion of a longitudinal section at a magnification of 300 diameters.

The pathological condition known as gummosis, which is often an accompanying microscopical sympton of fungous infection of living 


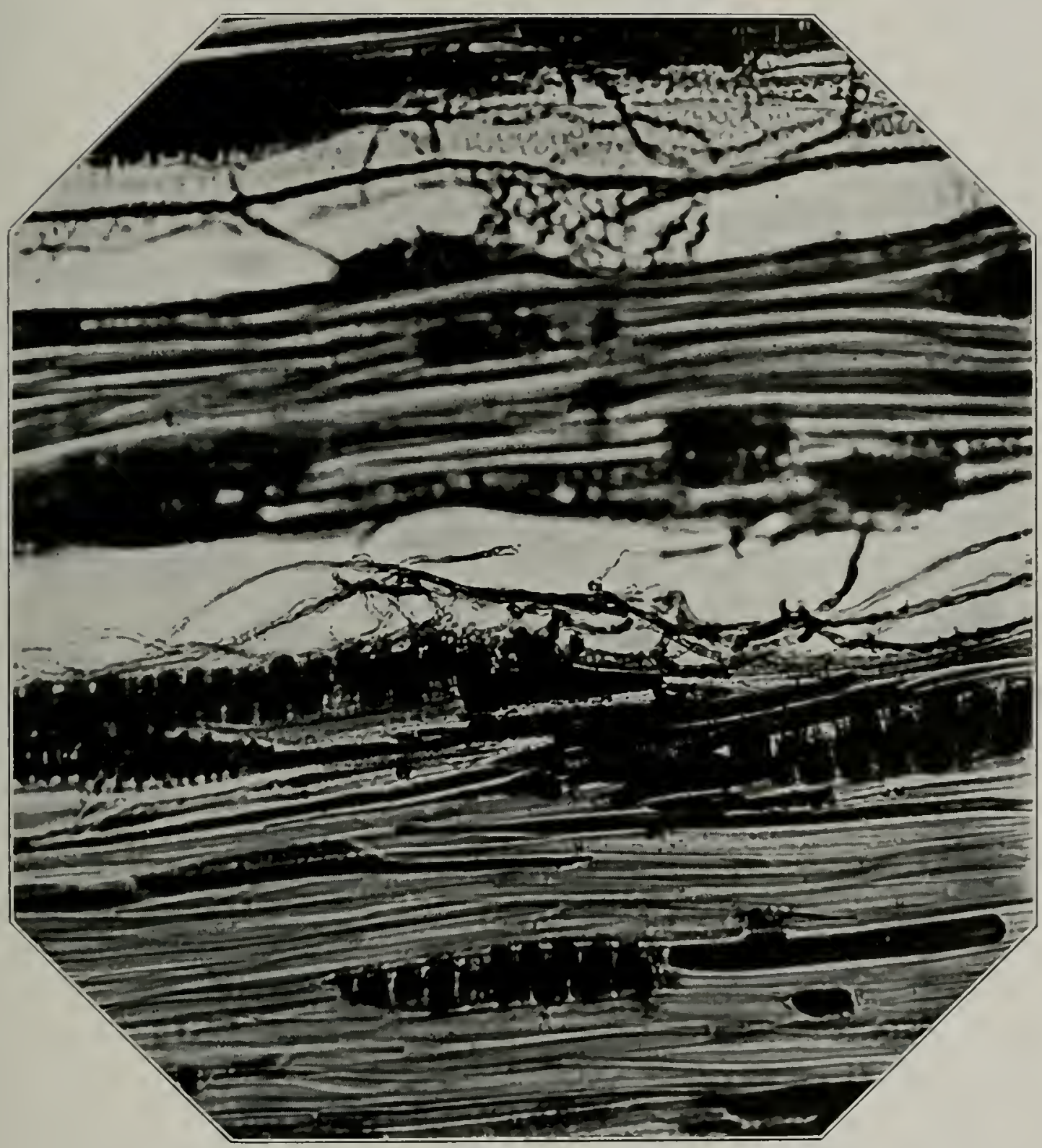

Fig. 14.-Longitudinal tangential section of diseased elm wood, $\times 450$, showing appearance of the mycelial threads of Coniothyrium in the large water ducts. Presence of the fungus stops the transportation of water, and those parts of the tree above the infection die from lack of water.

woody tissue, occurs conmonly in connection with the Coniothyrimm disease, as is shown in figure 16. The lumen of many of the xylar elements, especially the large tracheae, becomes completely filled with brownish granular gum. Walls of the cells that are filled with these deposits are usually much enlarged and swollen and appear to be undergoing dissolution. That these gummy deposits in the xylem are not normal resinous deposits such as occur in the nonfunctional heartwood of trees is eviclent from the fact that they are present even in the sapwood of very young stems. Examination of sections from a healthy elm twig has shown, too, that this gummosis cloes not exist in healthy xylem, though, as stated before, is of very common occur- 


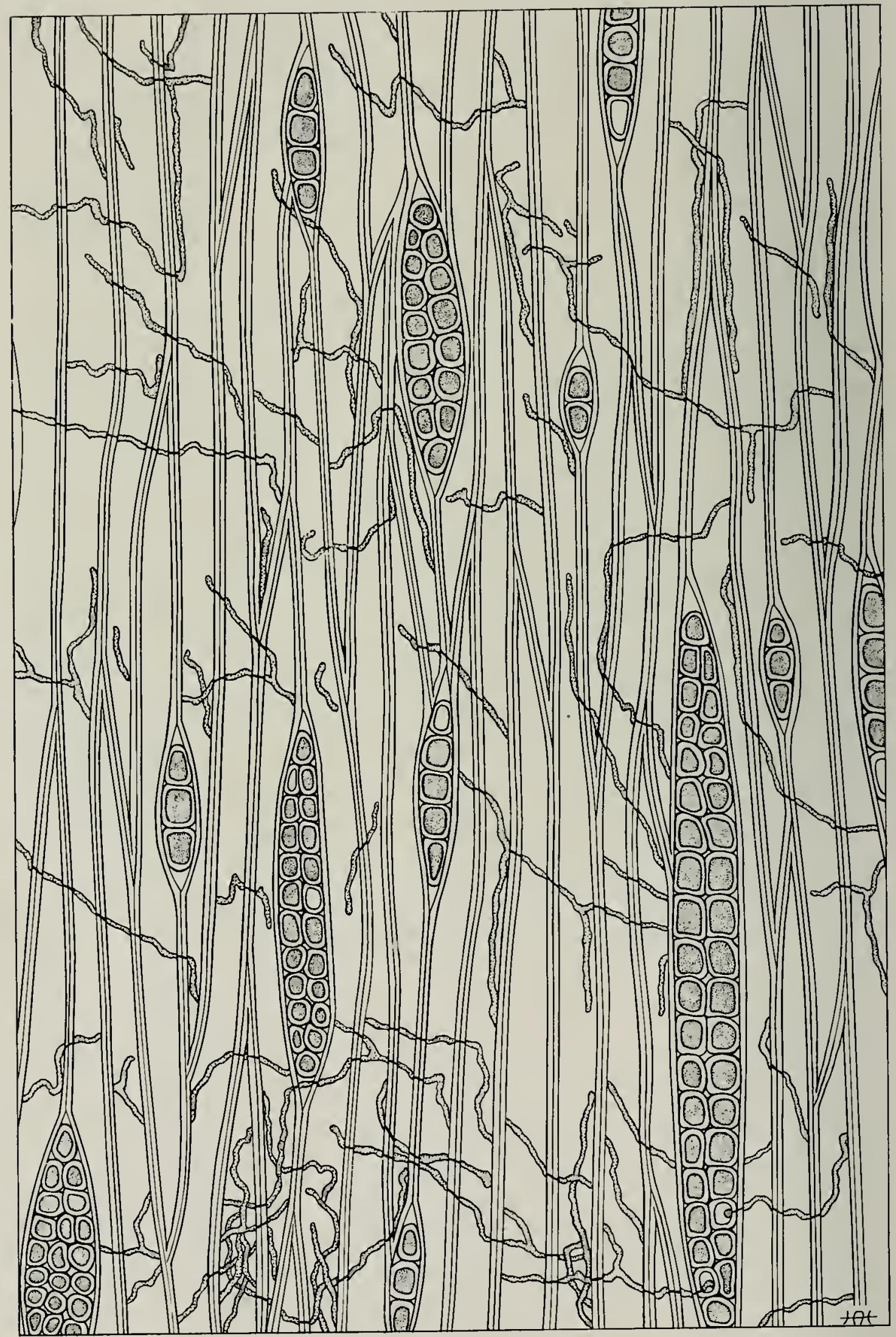

Fig. 15.-Direct reproduction at 300 diameters of a longitudinal section of diseased elm wood, showing how the Coniothyrium mycelium ramifies and penetrates throughout the woody structure. 


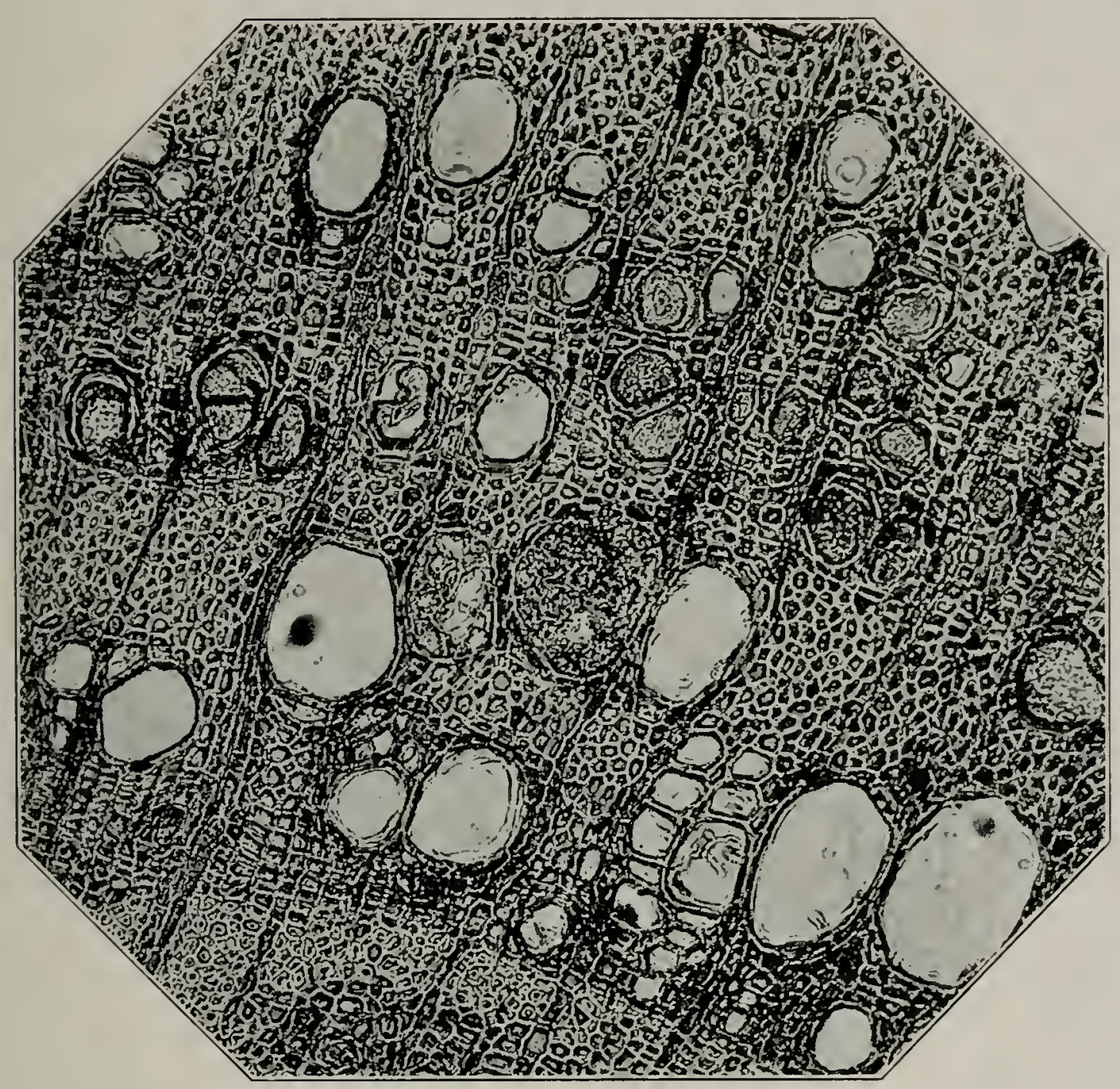

Fig. 16.-Cross section of diseased elm wood, $\times 450$, showing the effect of Coniothyrium infection upon the wood tissues. The mycelium of the fungus appears in some of the large water ducts, but other cells of the same kind are filled with dense deposits of gum. The walls of the gumfilled cells are indistinct and evidently partly disintegrated. (See text, p. 28$)$.

rence in the wood of cliseased stems.

In isolations made from material of the Coniothyrium disease two kinds of Coniothyrimm have been obtained. Neither of these Coniothyria have as yet been definitely identified. They are, however, quite readily distinguishable from each other, both in morphology and in cultural characteristics. For convenience of treatment here they will be referred to as Coniothyrimn $A$ and Coniothyrimm $b$.

The kind designated as Coniothyimm $A$ is of more common occurrence and has much larger spores than the other. Its pycnidia, which range from 95 to $350 \mu$ when formed on elm stems, are membranous, spherical to subglobose, and appear black and opaque until the spores are released, when they become light or dark translucent brown. A light colored stroma often surrounds the walls of pycnidia 


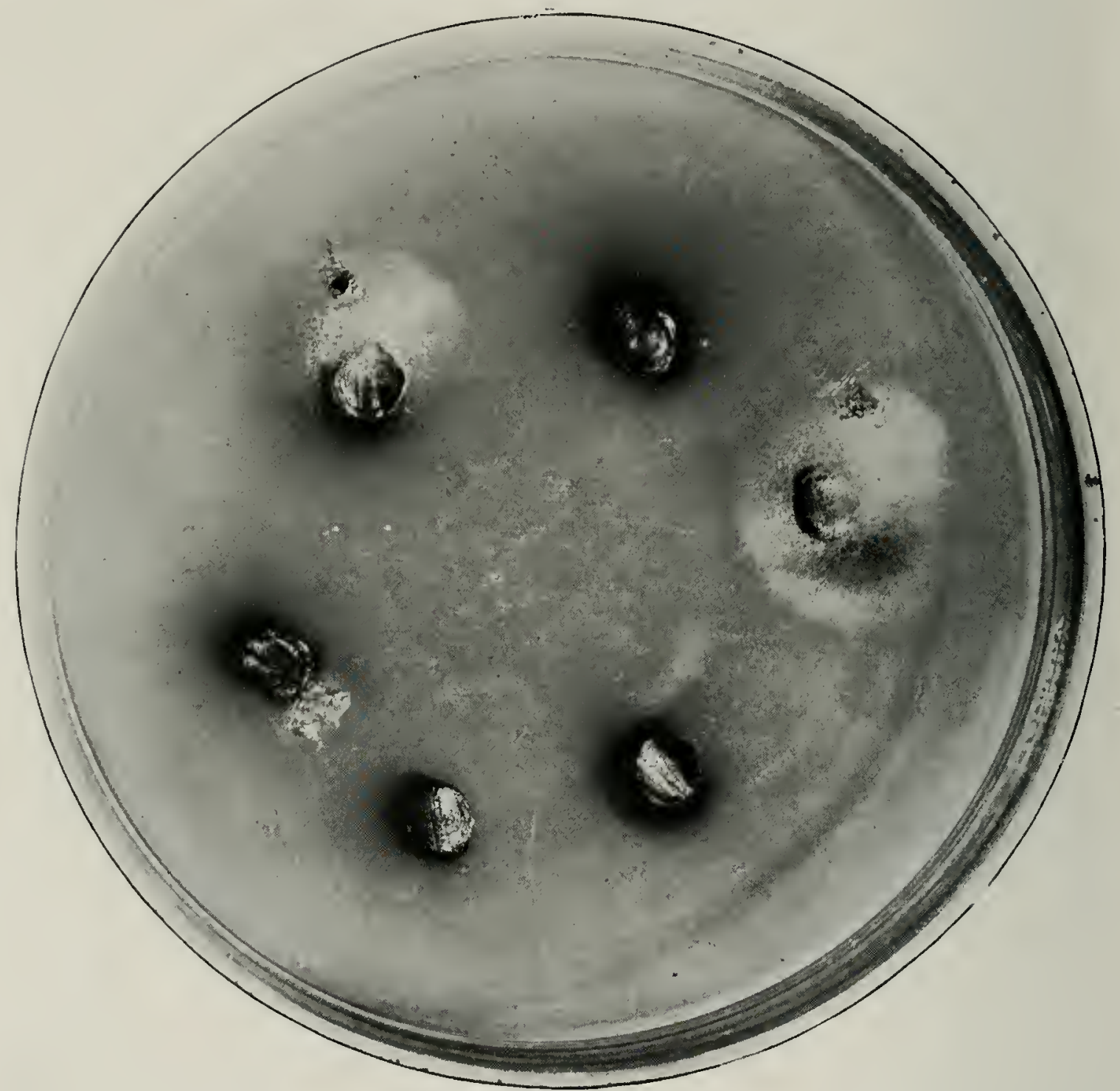

Fig. 17.-Cultural isolation of Coniothyrium. From three of the six slices of diseased wood Coniothyrium is growing, the other three remaining sterile. The discoloration in the agar around the wood slices is due to an outward diffusion of tannins and other substances from the wood.

formed in culture, but it is by no means always present. When mature the pycnidia have definite, centrally placed, regularly rounded ostioles which may or may not be raised. In agar cultures, pycnidia as large as $476 \mu$ in diameter have been observed. The spores are one-celled, olivaceous, spherical to oblong but chiefly oval. Their range in size is $3.6-7.3 \times 2.9-5.8 \mu$, but they are chiefly $5.1-5.8 \times 3.6-5.1 \mu$.

When isolated from wood slices upon corn meal agar Coniothyrium $A$ first grows out of the diseased pieces of wood as a short tuft of fine, whitish aerial mycelium. Within a day or two this aerial growth spreads to the agar, or additional hyphae may grow out from the wood, and a fine, whitish, regular mycelial growth is produced. Figure 17 shows a plating of wood slices from a diseased elm upon corn meal agar from which three growths of Coniothyrimm $A$ were secured. They 


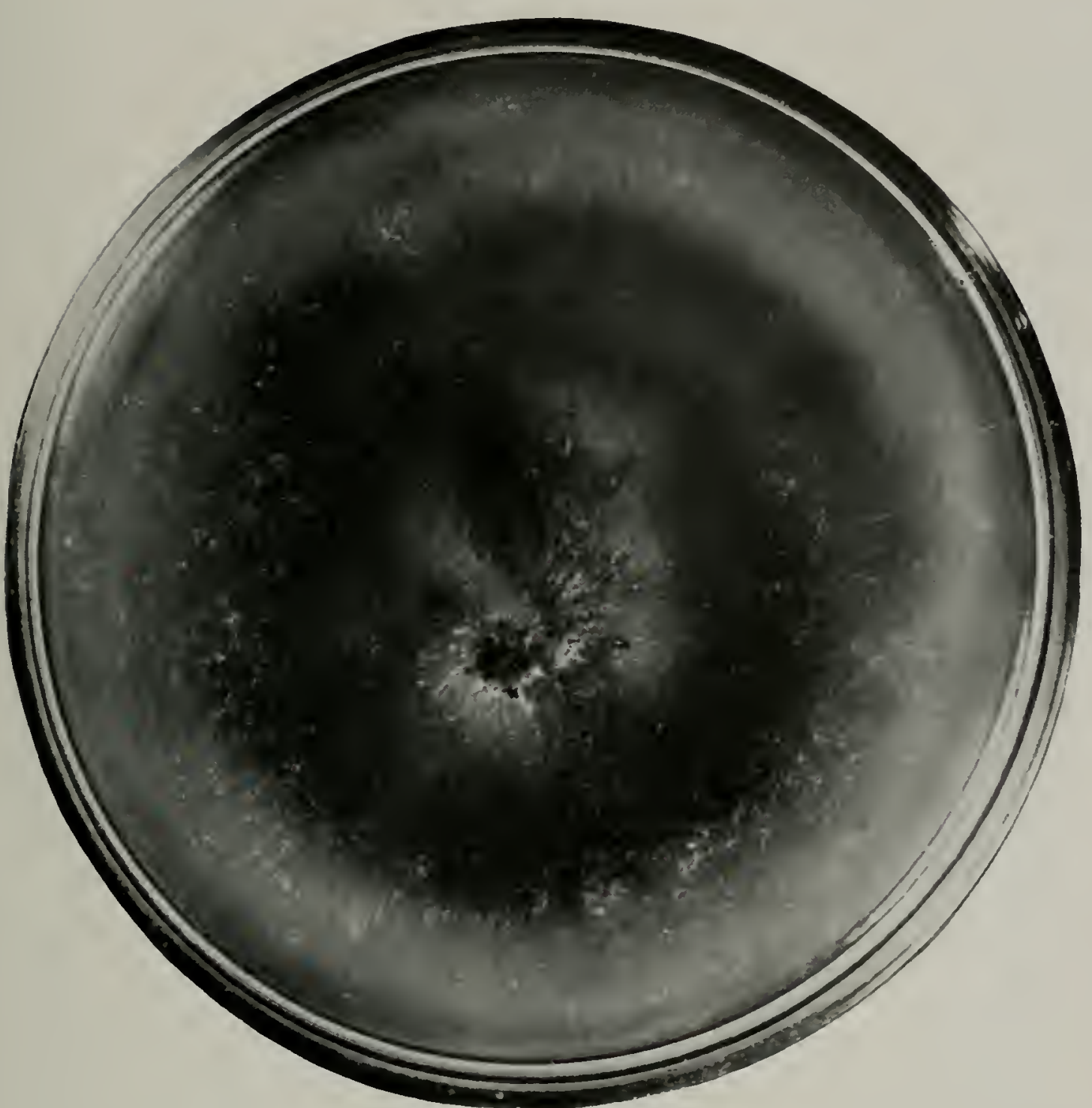

Fig. 18.-Petri-dish culture of Coniothyrium A. showing the appearance of the fungus 21 days after plating upon corn meal agal. Compare with Fig. 19.

had appeared two days before the photograph was made. Three of the wood slices remained sterile (corrosive sublimate was used in sterilizing them) and yielded no fungous growths. The discolored areas in the medium about the wood slices are due to an outward diffusion and subsequent oxidation of tannins. Other substances may be present also.

Within four or five days after a colony is started the central portion of the thallus darkens, becoming yellowish brown, and this extends gradually though rather irregularly in various directions, until the entire growth finally becomes dark brown or olivaceous. as shown in figure 18. Eventually the entire mycelial growth may become sparsely covered with short, white aerial hyphae. Pycnidia usually form abundantly after about ten days, at first chiefly in the darker, older 


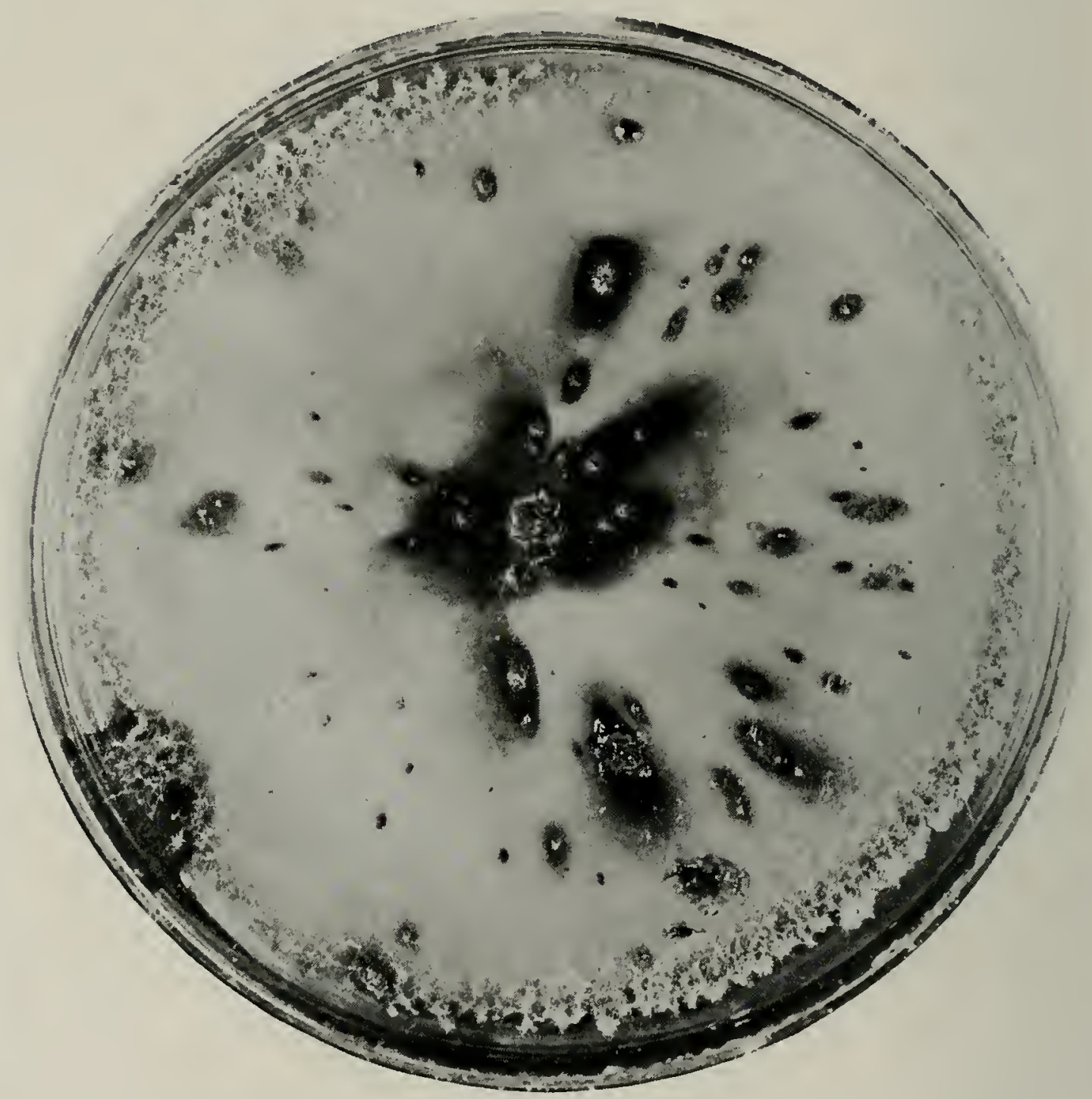

Fig. 19.-Petri-dish culture of Coniothyrium $B$, showing the character. istics of the fungus after 18 days on corn meal agar. Pycnidia are produced only in the dark areas. Compare with Fig. 18.

central portion of the growth but finally, as the thallus ages, in all parts.

Coniothyriun $B$ has pycnidia which are dark brown, membranous, spherical or nearly so, and with definite, circular ostioles which are darkened or carbonized at the margin. A variation in pycnidial size of $60-272 \mu$ has been observed. The spores, in masses, vary from dark to light brown but are only dilutely colored when separate and may sometimes appear nearly hyaline. They are one-celled, ovoid-oblong to short elliptic, and measure $2.5-6.6 \times 1.4-4.4 \mu$ but are mostly $3.6-$ $4.4 \times 1.4-2.2 \mu$.

In corn meal agar culture, the mycelium of Coniothyrium $B$, shown in figure 19 , is at first entirely white, quite fine, and very silky in appearance, and the marginal growth is regular. It remains white and 


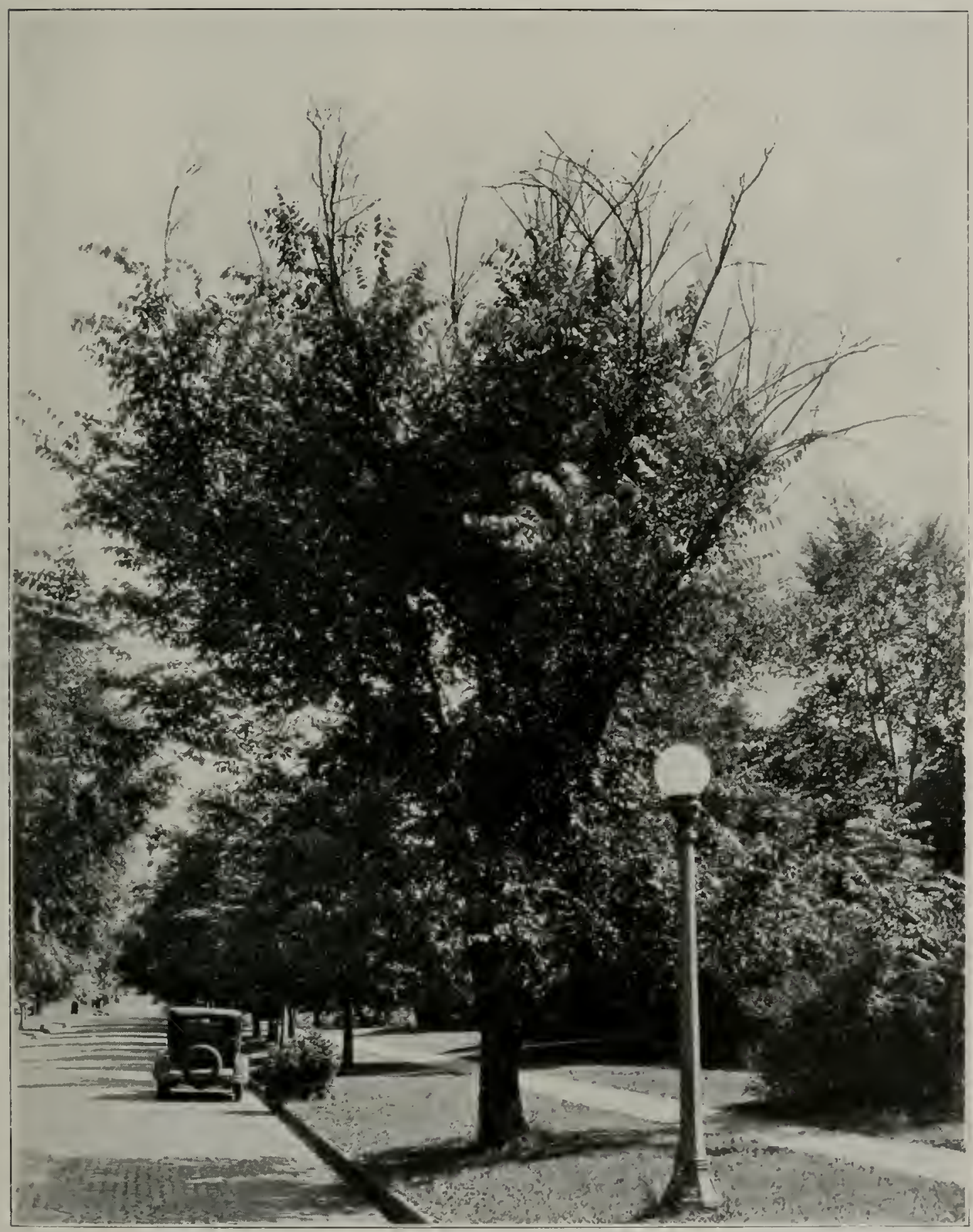

Fig. 20.- A large elm attacked by Vermicularia. Twigs and branches throughout the tree die after becoming infected. Damage is done first to the upper and outermost parts, the lower and central parts of the tree remaining healthy until invared from above. Photographed July $\$, 19: 31$.

closely appressed to the agar until the time of pycniclial formation. which usually occurs within ten to 16 days, when the central portion of the thallus and numerous scattered portions turn dark brown. Pycuiclia are formed only in these dark areas, in which they are nsually gregarious though they may also occur singly. Cultures are devoid of aerial mycelium, except for a circle of short. White. floccose srowth near the side of the plate. 


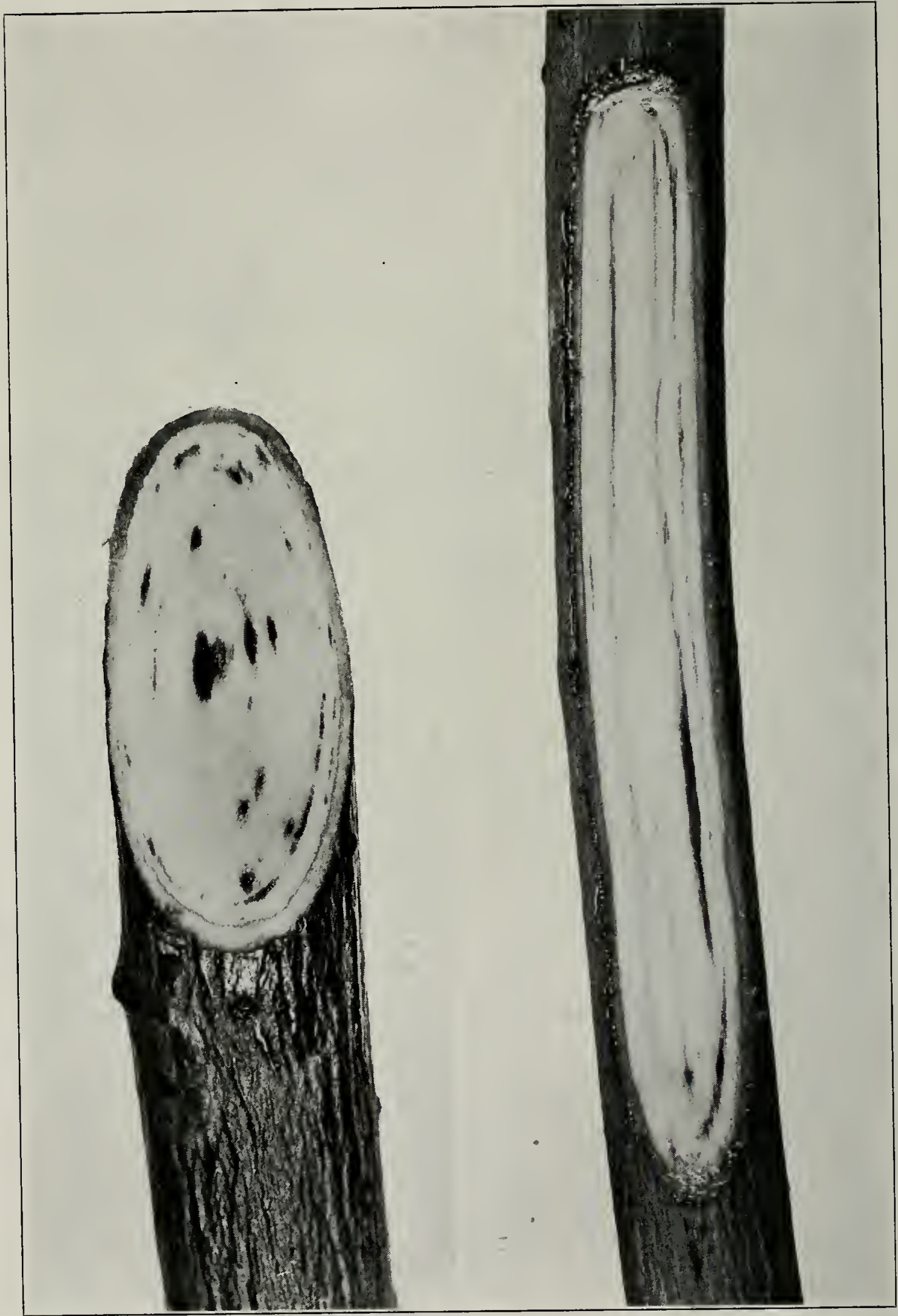

A

Fig. 21.-Wood discoloration caused by Vermicularia. A.-In an obliquely cut branch, the discoloration appears as dark brown, scattered spots. The spots are most abundant in the newest wood, forming there a discontinuous ring. $\times$ 3. B.-Wood discoloration shown, in longitudinal view, as long, continuous, rather broad streaks. $\times 2$. 
The differences which exist between these two forms of Coniothy' rium in their effect upon the host can be ascertained only after inoculation experiments have been completed. On diseased specimens no contrasting symptoms have been noted thus far between them though they are readily distinguishable in culture by the morphological differences condensed in table III.

Table III.-Compakatie Cuhural axin Morphological, Characters of Coniothyria $A$ and $B$.

\begin{tabular}{|c|c|c|c|c|c|c|c|c|}
\hline \multirow{2}{*}{ Form } & \multirow{2}{*}{$\begin{array}{l}\text { Isolation } \\
\text { growth }\end{array}$} & \multirow{2}{*}{ Mycelium } & \multirow{2}{*}{$\begin{array}{l}\text { Aerial } \\
\text { hyphae }\end{array}$} & \multicolumn{2}{|c|}{ Pycnidia } & \multicolumn{3}{|c|}{ Spores } \\
\hline & & & & Size & Ostiole & Color & Form & Size \\
\hline$A$ & $\begin{array}{c}\text { Mycelium } \\
\text { appears } \\
\text { first as } \\
\text { short aerial } \\
\text { tufts and } \\
\text { later grows } \\
\text { into the } \\
\text { medium }\end{array}$ & $\begin{array}{c}\text { Entire } \\
\text { growth } \\
\text { eventu- } \\
\text { ally turns } \\
\text { dark }\end{array}$ & $\begin{array}{c}\text { Formed } \\
\text { sparsely } \\
\text { over the } \\
\text { entire } \\
\text { growth }\end{array}$ & $95-476 \mu$ & $\begin{array}{l}\text { Not car- } \\
\text { bonized } \\
\text { and of ten } \\
\text { raised }\end{array}$ & $\begin{array}{l}\text { Oliv- } \\
\text { aceous } \\
\text { in mass } \\
\text { and } \\
\text { when } \\
\text { sepa- } \\
\text { rate }\end{array}$ & $\begin{array}{c}\text { Chiefly } \\
\text { oval }\end{array}$ & $\mid \begin{array}{l}5.1-5.8 x \\
3.6-5.1\end{array}$ \\
\hline$B$ & $\begin{array}{c}\text { Mycelium } \\
\text { grows } \\
\text { directly } \\
\text { into the } \\
\text { medium } \\
\text { without } \\
\text { forming } \\
\text { aerial tufts }\end{array}$ & $\begin{array}{c}\text { Growth } \\
\text { darkens } \\
\text { only at } \\
\text { the center } \\
\text { and in } \\
\text { scattered } \\
\text { islands }\end{array}$ & $\begin{array}{c}\text { Formed } \\
\text { only in at } \\
\text { narrow } \\
\text { band at } \\
\text { the mar- } \\
\text { gin of } \\
\text { growth }\end{array}$ & $60-272 \mu$ & $\begin{array}{c}\text { Carbon- } \\
\text { ized and } \\
\text { not } \\
\text { raised }\end{array}$ & $\begin{array}{c}\text { Pale } \\
\text { brown } \\
\text { to } \\
\text { nearly } \\
\text { hyaline } \\
\text { when } \\
\text { sepa- } \\
\text { rate }\end{array}$ & $\begin{array}{l}\text { Chiefly } \\
\text { short } \\
\text { elliptic }\end{array}$ & $\begin{array}{l}3.6-4.4 \times \\
1.4-2.2 \mu\end{array}$ \\
\hline
\end{tabular}

According to Seymour's (1929) list two species of Coniothyrimm are now known to occur upon elms in America. These are Coniothy'rium Fuckelii Sacc. on Ulmus americana L. and Coniothyrium Ulmi Tharp on Ulmus campestris $L$. The latter fungus was reported by Tharp (191\%) as the cause of a leaf spot in Texas. Through the courtesy of Dr. Tharp a portion of the type specimen of this fungus was secured. A comparative examination of it and the Coniothyria isolated from diseased elm wood showed them to be different. especially in their spore characters. The spores of Coniothyrim Llmi are smaller than those of Coniothyrimm $A$ and larger than those of Coniothyrim $B$.

It has not been possible to secure a specimen of the Coniothyrium Fuckelii reported on elm. This fungus is, however, very common on 


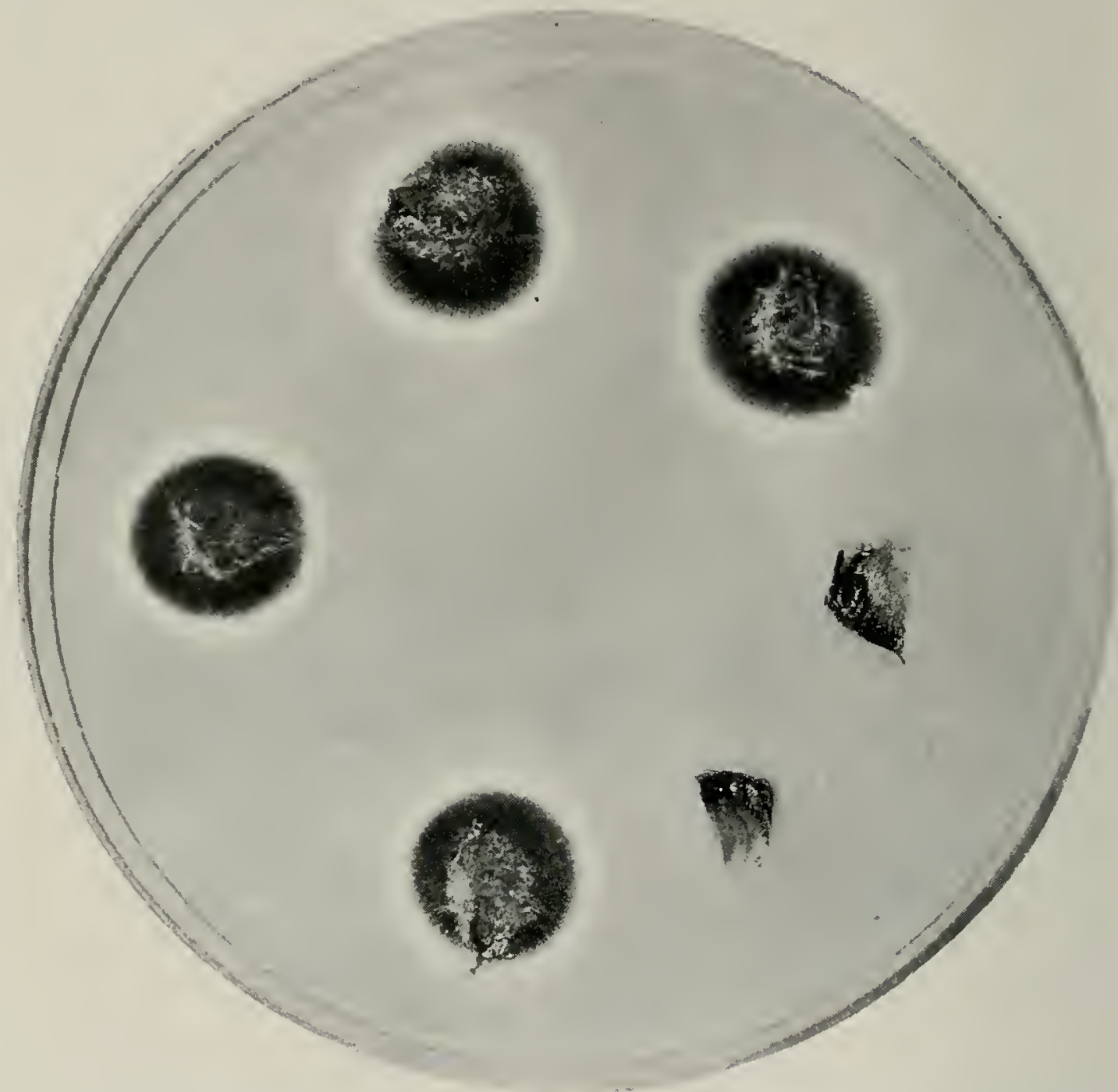

Fig. 22.- Isolation plate showing Vermicularia growing from infected wood slices planted on potato dextrose agar five days before photographing. Of the six wood slices four yielded Vermicularia growths and two remained sterile.

raspberry and material from this source has been compared with our Coniothyria $A$ and $B$. Aside from having somewhat smaller spores. the raspberry form of Coniothyrium Fuckelii and Coniothyrium $A$ are quite similar, but we are not convinced that they are identical. The characteristics of Coniothyrium $B$ are not even closely approached by either of the Coniothyria reported on elm in America.

The fact that in "elm wilt" a definite tracheonycosis occurs presents an unusual form of attack for Coniothyrimm. It is possible that our fungi are not to be classified in that genus, although we place them there tentatively at present.

\section{VERMICULARIA DISEASE}

On three occasions the fungus $V$ crmicularia was isolated from very severely diseased trees. It was obtained each time from relatively mature shade trees and has not yet been found attacking elms in nurseries. 
The furst isolation was obtained from a large parlway tree in Champaign, Illinois, in May, 1931. The tree is shown in figure 1. Nimerous braiches that have been attacked and destroyed are noticeable throughout the entire tree but are more evident in the topmost part. Some of the larger limbs are entirely dead, others nearly so, and still others are just beginning to die at the tips. The defoliated brancles so conspicuous in the top of the tree are mostly the dead tips of branches and limbs arising in the center of the tree which, thongh still alive, are badly diseased. The disease has developed so extensively that almost any of the upper limbs, large or small and selected at random, when cut through will show the distinct discoloration of the wood characteristic of the disease. A different view of the same tree. shown in figure 20 , indicates that the diseased condition is not linited to any particular part but occurs throughout the tree. $I_{1}$ this view the discased branches are even more conspicuous and destructiveness of the discase is illustrated more viridly. Observations made on this tree indicate that the disease entered through the tips of branches and progressed downward. That the discase is so general throughont the top of the tree suggests also that infection occurred originally at sercral points rather than at a single point.

Within a diseased branch, the disease manifests itself, as shown in figure $21 \mathrm{~A}$, as dark brown discolored areas or blotches scattered in circles throughout the wood. In the most recently formed wood, the sapwood, discoloration appears as a narrow, continuous band or ring. such as is indicated in the photograph. When the stem is cut lengthwise discoloration consists of continuous streaks which are often rather broad and extend through the wood for a considerable distance, as shown in figure $21 \mathrm{~B}$.

There is no difficulty in distinguishing Vermicularia infection from the Coniothyrimm tracheomycosis. I'ermicularia produces no cankers. whereas a prominent characteristic of Coniothyrimm is the formation of flattened, depressed, water soaked cankers along one side of the stem. The internal wood discolorations manifested by the two diseases are also different. In the Coniothyrimm disease the discolonation occurs chiefly along one side of the stem and is diffused. while as just noted the Vermicularia discoloration takes the form of long streaks and is also much darker than the Coniothyrimm discoloration.

Another isolation was made from a large elm in Urbana. The tree had a great many dead limbs, both large and small, which had apparently been dead for several years. Very few living branches remained on the tree and these for the most part were only very small twigs or shoots. Platings made from diseased branchlets abont onequarter inch in diameter, which showed large dark brown streaks 


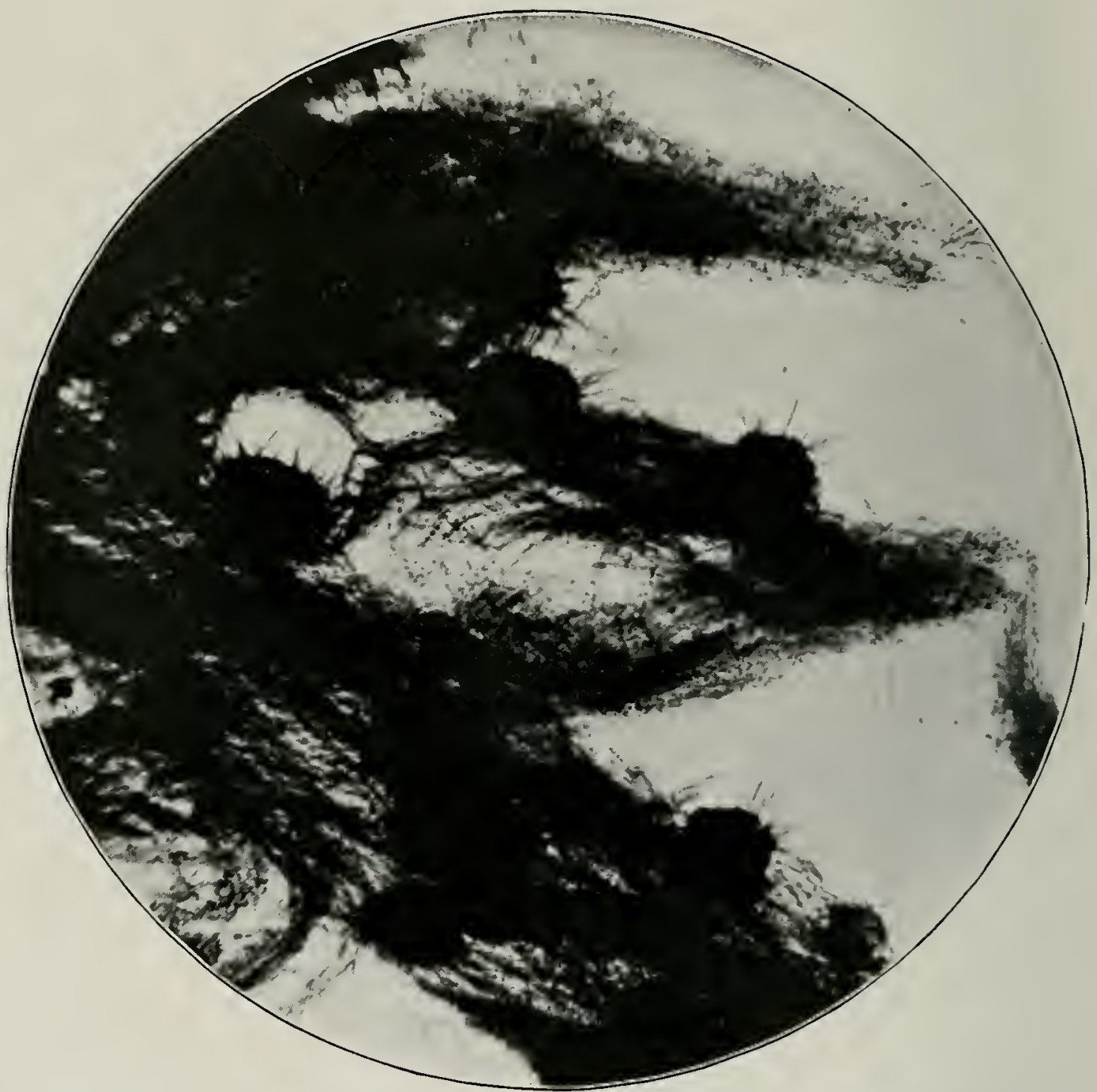

Fig. 23.-Photomicrograph, $\times 100$, of the mycelium and pycnidia of Ver. micularia produced on potato dextrose agar. Notice the numerous setae on the pycnidia.

in the wood, yielded both Vermicularia and Coniothyrimm. Both fungi were isolated from the same piece of branch and from wood slices cut from the same region with the bark removed. It seems apparent that both Vermicularia and Coniothyrimm were attacking this tree. The two were not, however, derived at any time from the same slice of wood but grew out from different slices.

The third tree from which Vermicularia was isolated was a young Moline elm at La Grange, Illinois. It was dead, save for about 6 inches along one side of the trunk just above the ground. Upon removing the bark from this area, in the current year's wood was exposed a dark brown discoloration, which was found to extend up and down the trunk in disconnected streaks. Platings of this diseased wood yielded only Vermicularia. Dead material taken from the upper parts of 
the tree yielded several different fungi, among which were Anthostomella, Nigrospora and Fusarimm.

The original culture-plate isolations made from the cliseased elm pictured in figures 1 and 20 are shown in figure $2: 2$. Wood slices were planted on potato dextrose agar and when photographed after five day's, fungous growths from four of the six slices had attained a diameter of a little over $1 \mathrm{~cm}$. The mycelial growth of $/$ crmicularia is characteristically quite compact. Three regions are readily distinguishable: the central and greater portion is dark green; the second, surrounding the first, is a narrow zone of light green; and funally, the marginal growth consists of whitish mycelium and actively growing lyphal tips. A heavy, floccose, grayish aerial mycelinm eventually covers the central portion of the thallus, but it is only slightly developed on the younger growth.

The pyenidia of I'ermicularia have not yet heen found on diseased elms, but they are formed abundantly in culture. They are dark brown, membranous, globose and without ostioles. The lower portion is frequently immersed in the mycelium. They usually occur singly, though they are sometimes formed in groups of two and three. As shown in figure 23 , their walls are covered with light brown, simple, often septate setae. These setae, however, are produced in abundance only when the fungus has been recently isolated. After it has been grown on artificial media for a while setae are usually no longer formed or at most they are but poorly developed. Pycnidia formed in culture vary $40-122 \mu$ but are chiefly $80-95 \mu$ in cliameter. The pycnidiospores are very minute, hyaline, single-celled and chiefly oblong, but vary to short elliptic or bacilliform. Their range in size is $1.8-3.6 \times$ $0 . \tau-1.4 \mu$ but they are chiefly $2.2-2.9 \times 1.4 \mu$.

\section{PHOMA CANKERS}

From the great frequency with which its fructifications are found on diseased elm specimens, Phoma appears to be very prevalent. In isolation tests of diseased trees, however, it has been obtained only 19 times. Whenever it was obtained from trees it was accompanied by heary discoloration of the sapwood. Though Phomas are of ten thought to be saprophytic bark inhabitants, evidence of the pathogenic nature of those derived by us from cliseased elms is found in the fact that they have been isolated from slices of diseased but living wood from which the bark had been removed previous to plating.

As nearly as observations will permit us to say at this time, the Phoma disease is limited in its pathological effects to the production of thickened, raised, smooth cankers of the kind shown in figure $4 \mathrm{~A}$. Young cankers are light brown and smooth, and do not have pustules. 


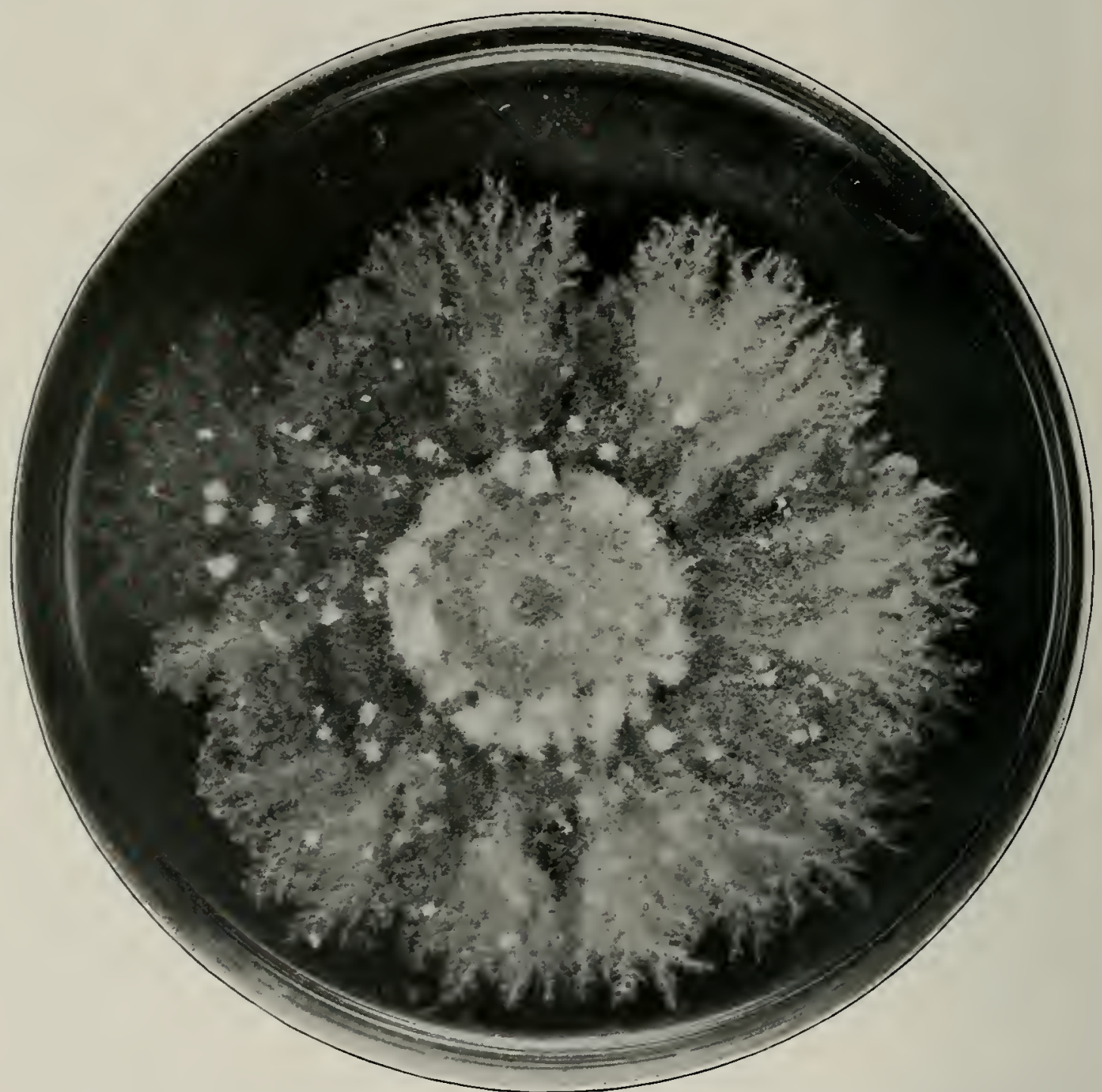

Fig. 24.--Petri-dish culture of Phoma A. On corn meal agar it forms a decided dendritic type of mycelial growth, and pycnidial formation is entirely lacking. Compare with Fig. 25.

The cankers enlarge, often symmetrically, up and down the stem and as they grow older, pycnidial pustules break through the dead bark singly or in groups and eventually occur in great abundance, as is shown in figure $4 \mathrm{~B}$. Often small cankers in proximity coalesce to form a larger canker.

The Ploma attack is also accompanied by a rather characteristic wood discoloration, which is shown in transverse and longitudinal views in figure 5. A comparison of the Phoma discoloration with that of Coniothyrimm illustrated in figures i $\mathrm{B}$ and 9 , shows very little difference. In both it is of the diffused type. The Phoma discoloration is usually present, however, along all sicles, as the lengthwise cut in figure 5 shows, while the Coniothyrimm discoloration is usually limited to one side of the stem. The pycnidial pustules which dot the Phoma cankers afford a conspicuous character by means of which Phoma and 
Coniothyrium infections can be distinguished in the field, provided older cankers of both diseases are present. In addition, the thick and raised Phoma canker, which may extend almost or entirely around even a large branch contrasts strongly with the flat, sunken Coniothyrimm canker, which usually extends along only one sicle. In very early stages, however, it is difficult, sometimes impossible, to distinguish the two diseases with certainty, except by isolating the fungi from diseased material.

The Phoma pycnidia are membranous and usually flask shaped, though often globose, aid have raised ostioles which are rather definitely carbonized around the margin. They are often so crowded as to be contiguous, though they are never continuons, and protrude through the bark singly and in twos or threes. Their range in dianeter is 1.00 - 2. is $\mu$ but they are chiefly 13.5-150 $\mu$. The ostiolar aperture may vary from 2.5 to to $\mu$ wide. The exceedingly minute, hyaline. single-celled, bacilliform pycnidiospores are commonly biguttulate. though not always or prominently so, and range in size from $1.8-1.4 \times$ $1.1-t \mu$, but are chiefly $2.9 \times 1.4-1.8 \mu$.

Two distinct strains of Phoma have been secured in isolations from diseased elnus. Though alike in pycnidial and spore sizes, they differ greatly in their behavior in culture. For convenience they are referred to in this discussion as strain $A$ and strain $B$.

Strain A seems to be more prevalent than strain B. since it las beein isolated from diseased elms the greater mumber of times. It lats failed consistently to produce pycnidia in cultures on varions agar media, but it does produce them in great abundance on sterilized eln twigs. On corn meal agar this strain forms an irregularly radiating, branching thallus with a dendritic type of growth, as may be scen in figure 24 . Occasionally, zones are formed in the mycelial growth. The mycelium early turns light brown, and this deepens to dark brown as the fungus becomes older. Short, grayish, aerial hyplate arise over the entire growth, but denser tufts are scattered over the surface and are particularly abundant in the central portions. This strain forms numerous small, dark, round structures which closely resemble pycnidia when they are seen macroscopically in a colony, but when examined with a microscope they are found to consist only of a sclerotial angregation of hyphal cells which does not undergo further differentiation.

Strain B forms a type of growth in culture altogether different from that of strain $A$, as may be seen by comparing figures ?t and ?.). When first isolated, the mycelial growth is dark green and forms numerous concentric zones. After it has grown in culture for sonne time, this zonation is only slightly evident and the myeclimm becomes 


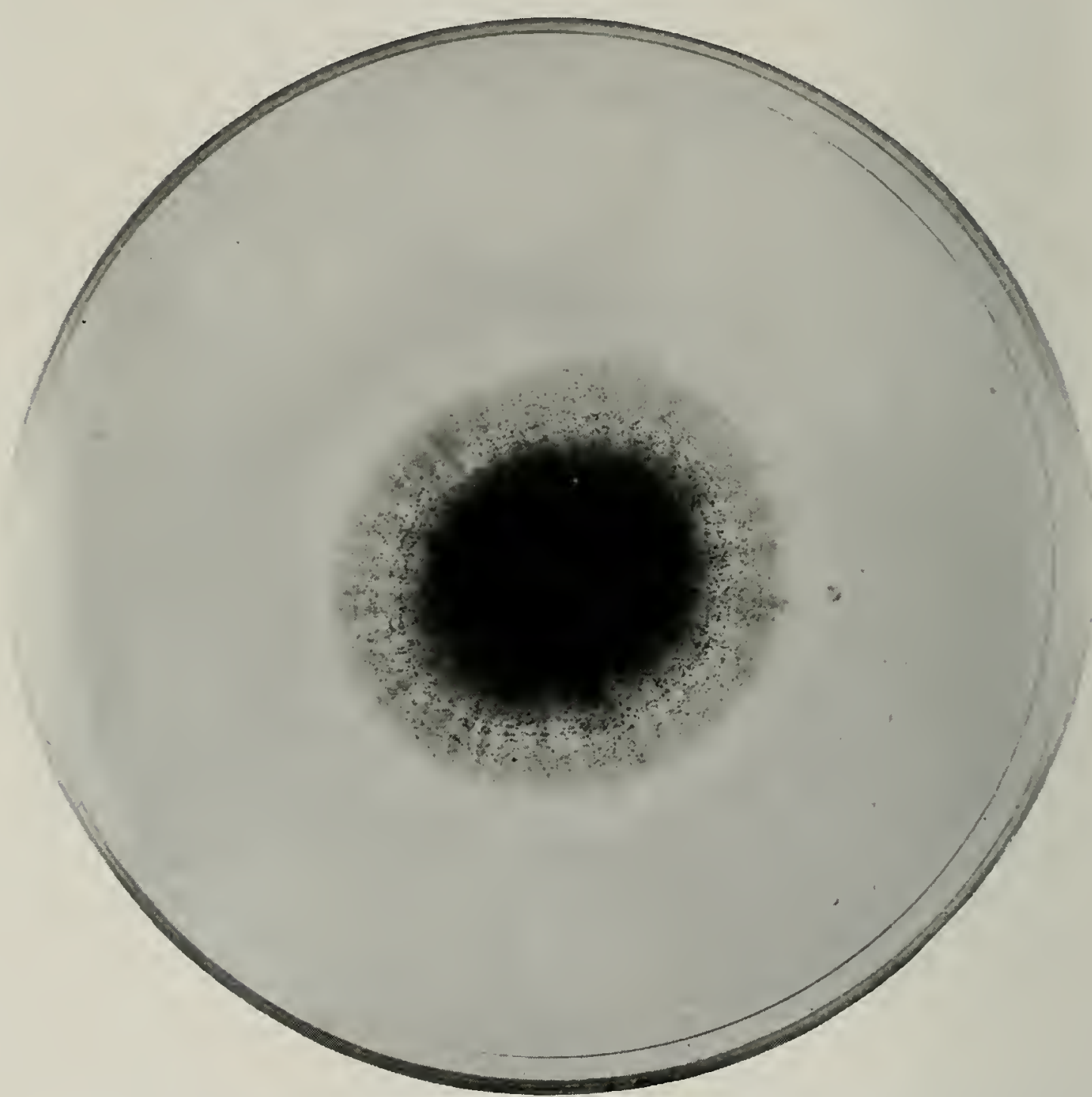

Fig. 25.-Petri-dish culture of Phoma $B$. On corn meal agar. The concentrically zonated, fine mycelium produces pycnidia in great abundance. Compare with Fig. 24.

light olivaceous or yellowish brown. Pycnidia are, however, produced very readily and abundantly.

No morphological differences have been found by which these two strains can be distinguished when the pycnidia occur on infected stems or branches of elms. Neither are there any differences between the two strains on sterilized elm twigs.

From four diseased trees a third type of Phoma has been isolated. In culture it always appeared, after a short time, to become contaminated by Alternaria. The Alternaria has appeared constantly in all isolations of this Phoma, though the greatest care has been used to grow the Phoma in pure culture, separate from the Alternaria. Twenty single-spore isolations have been made of the Phoma, but in each the Alternaria has developed. It is believed that this elm Phoma is simi- 
lar to Phoma altcrnariaccum Brooks and Searle $(19 \cdot 2 \cdot)$. which attacks the tomato and which has been shown by Chordat (1926) to have both Phoma and Altcrnaria as conidial forms. It is not known whether this polymorphic elm Phoma is pathogenic, but the fact that in isolation trials it grows ont from the bark instead of the wood suggests that it may be only a saprophyte.

\section{SPHAEROPSIS DIEBACK AND CANKER}

Sphacropsis dieback and canker was first described by Hubert and Humphrey (1920) as causing extensive clannge to shade and nursery elms in Wisconsin. It was later stated by Hubert (1931) to occur also in Pennsylvania, Maryland and Ohio. We lave found it on elnus in nurseries in Illinois also, but it is of infrequent occurrence and is of only minor importance among elm diseases in this state.

The Sphacropsis canker of elm is caused by Sphacropsis ulmicola E. and $\mathrm{E}$. The first evidence of its presence is a dying and discoloration of the tips of sulall branches throughout the top of the tree. From these the infection spreads downward into the larger limbs and finally into the lateral branches. Early death of the top branches produces a stag-headed appearance. Secondary shoots often grow out below the dead limbs, resulting in the formation of witches' brooms. Reddish brown to brownish black cankers which are often mottled by black areas are formed on the stem. Beneath the canker the canbial layer and the wood are discolored reddish brown. In older infections a darker discoloration of the wood is present. The ostiolar apertures of numerons small, black pycnidia produced beneath the bark in the cankered areas barely protrude above the surface by small necks and form pimple-like eruptions.

The scattered pycnidia are minute, $200-300 \mu$ in cliameter, white within, and form ermmpent epidermal pustules but commonly do not break the covering; the coniclia are ellipsoid or obovate, $20-30 \times 12-1.5$ $\mu$. and yellowish brown; the conidiophores are shorter than the conidia and obtuse.

\section{PHOMOPSIS CANKER}

The Phomopsis canker has been found several times in Illinois on discased elms. The pycnidia of the fungus occurred abundantly in the cankered areas but contained only the small alpha, or Phoma, type of spore. When the fungus is grown in agar cultures, it does not fruit but gives only a whitish vegretative mycelimm which, in age, turns green. Small sclerotial aggregations of hyphal cells are formed in various parts of the cultures but never develop into fructifications. Recently, however, a culture growing on sterilized eln twigs formed pycnidia which contained both the oval alpha spores and the long. 


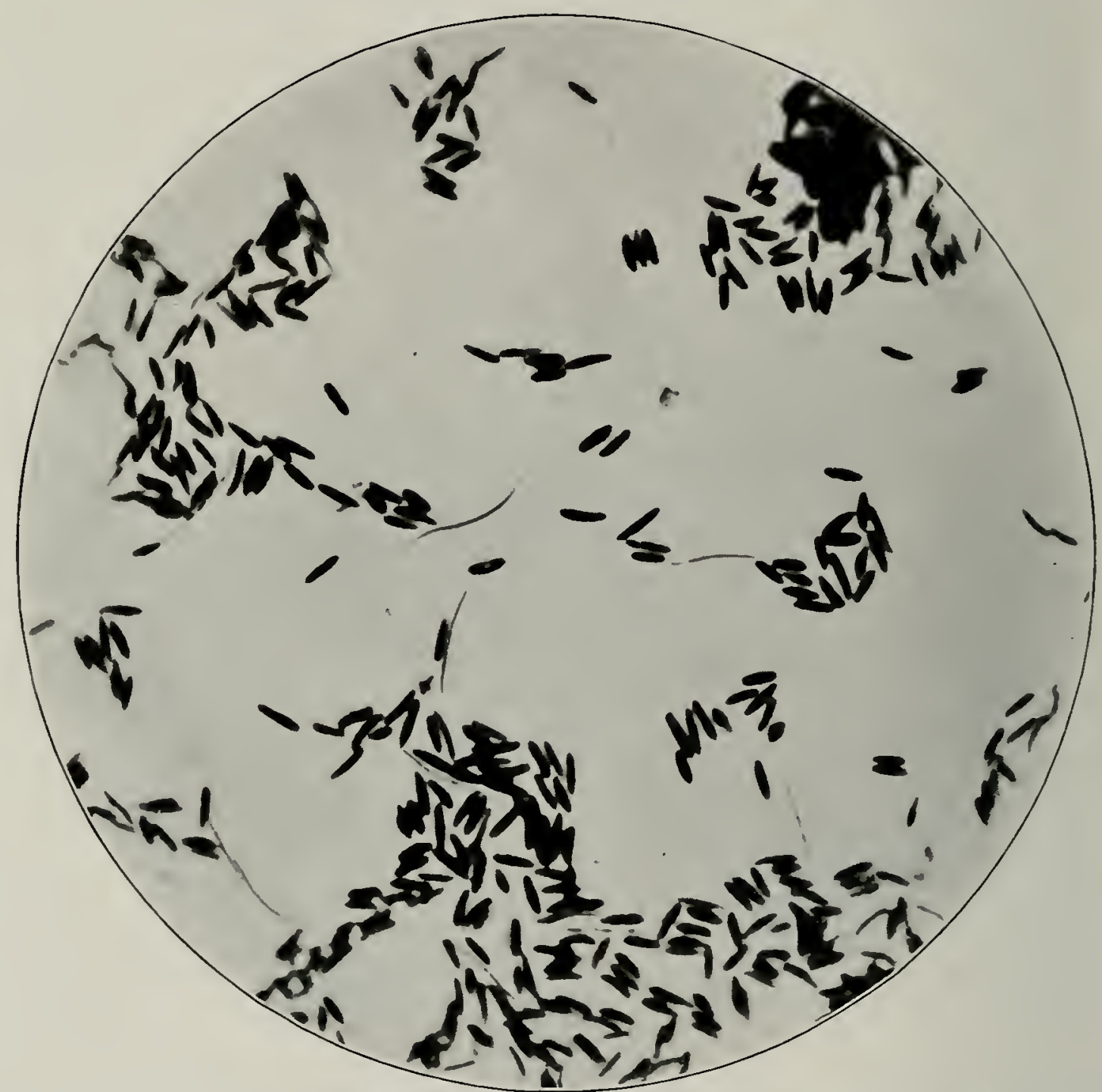

Fig. 26.-Photomicrograph, $\times 1000$, of the spores of Phomopsis. The two types of spores are produced in cultures grown on sterilized elm twigs. The slender stylospores occur less frequently and are produced in a lesser number than the oval alpha spores.

slender, curved beta or stylospores. The two types of spores are shown in figure 26. This definitely establishes the fungus as a species of Phomopsis.

A Phomopsis parasitic upon elms was found also by Buisman (Westerdijk en Buisman, 1929) in connection with her investigations of the Dutch elm disease in Holland. She found the ascigerous form of the Dutch Phomopsis to be Diaporthe. Recently Richmond (1932) reported that a cankerous disease of the-American elm in eastern Massachusetts was due to a Diaporthe which had a Phomopsis as an imperfect stage. Comparisons were made of this fungus with the Diaporthe studied by Buisman and it is stated that the two appear quite similar. Though a perfect stage of the Phomopsis isolated in Illinois has not as yet occurred in culture, the Phomopsis from Illinois elms agrees very closely in spore size with the Phomopses of Buisman 


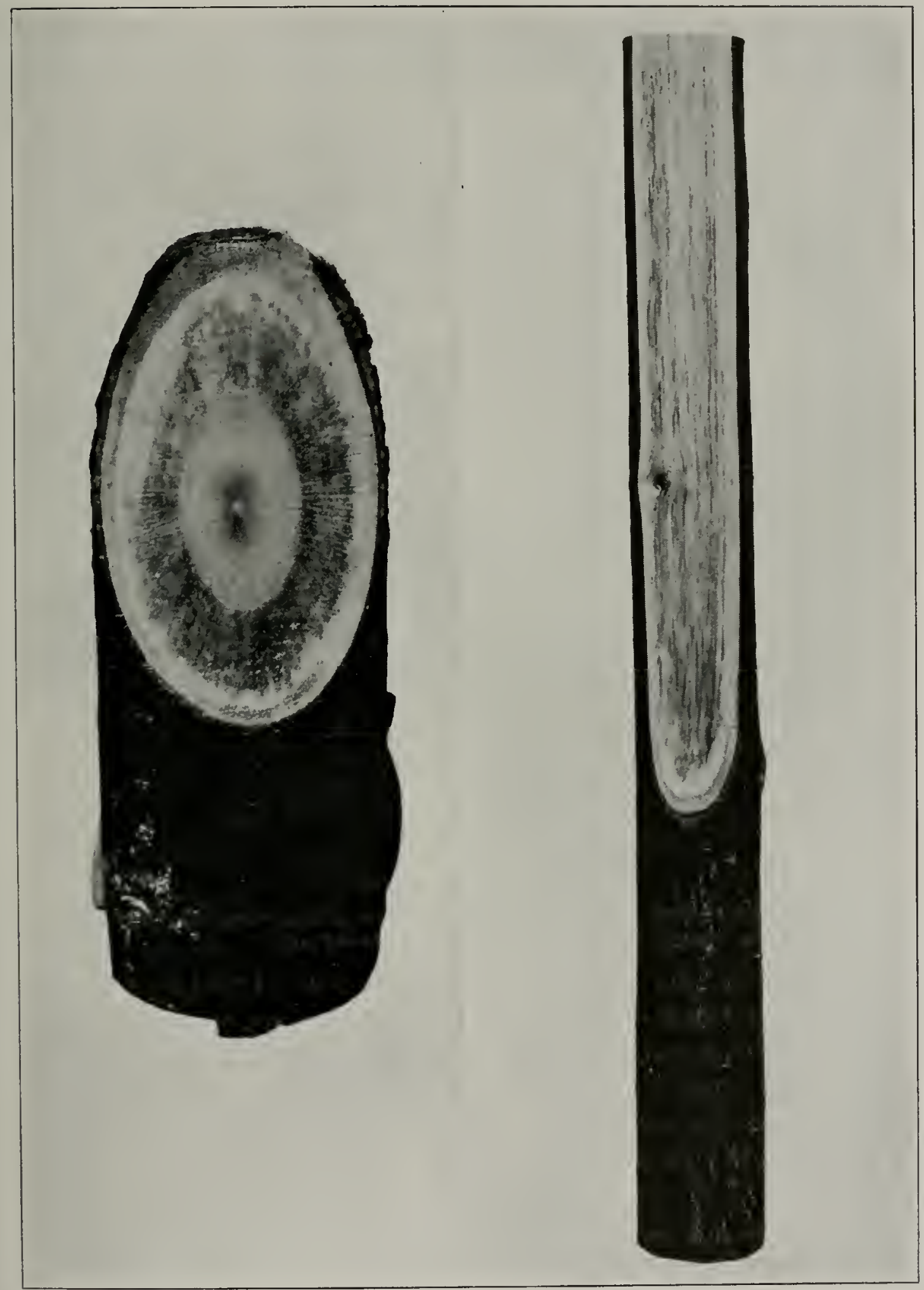

A

$\mathrm{B}$

Fig. 27.- Internal wood discoloration caused by Vertieillium. A.-In an obliquely cut branch, it appears as a general, diffused browning resulting from the discoloration of the water conducting vessels. The ray tissues, however, are not discolored. $\times 2 \frac{2}{2}$. B.-In longitudinal view, the discoloration consists of fine, short, disconnected brown lines. $\times 1$. Compare this with the discoloration shown in Figs, 5, 7 and 21. 


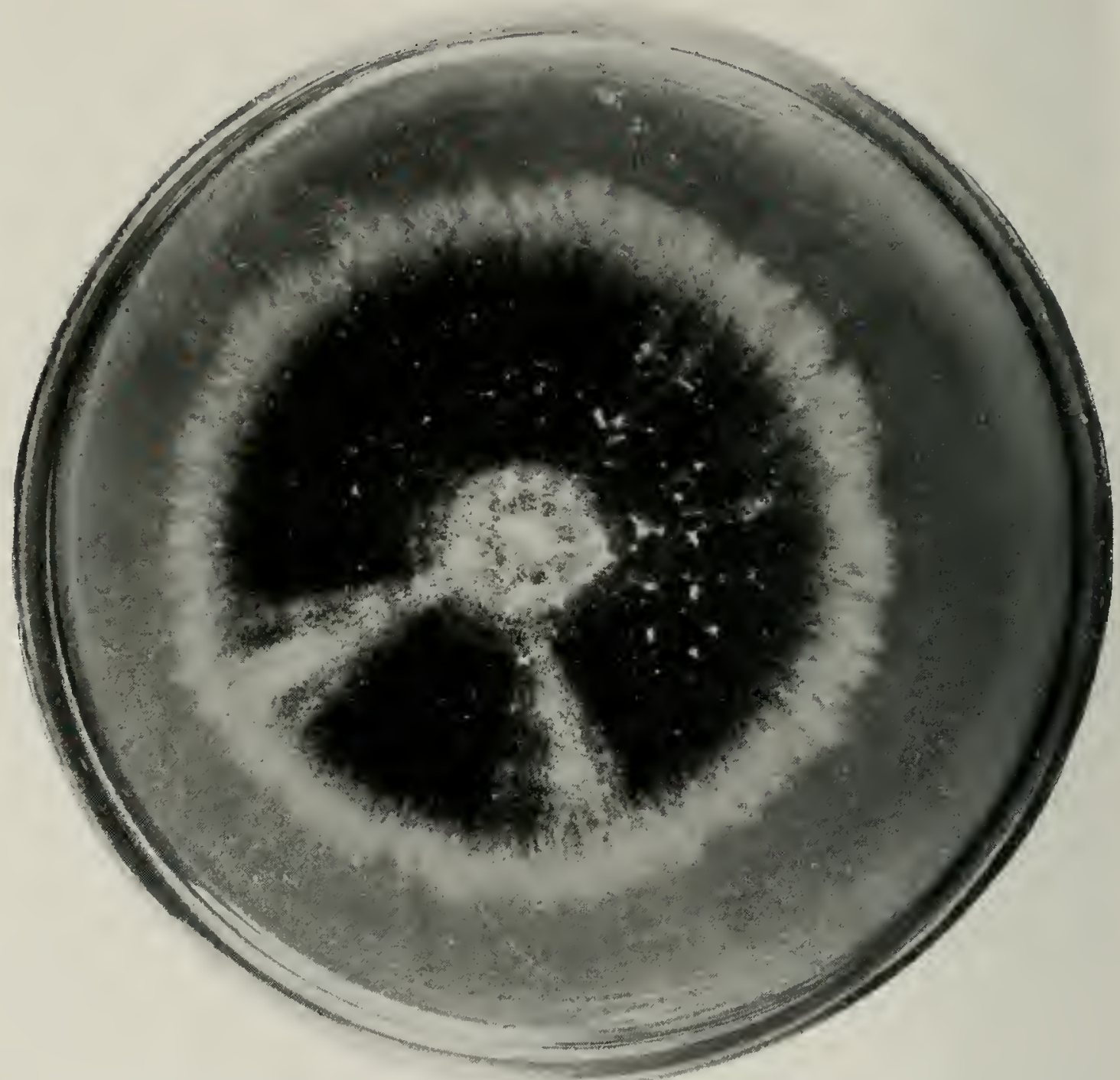

Fig. 28.-Petri-dish culture of Verticillium alboatrum, showing the appearance of the fungus after 12 days on corn meal agar.

and Richmond. Its alpha spore range is $5.8-1.7 \times 1.8-3.3 \mu$ but chiefly $7.3-8.8 \times 2.2-2.5 \mu$, and the beta spores are mostly $23.2 \times 1 \mu$. The Dutch Phomopsis, according to Buisman, has alpha spores which are generally $\% .1 \times 2.4$ and stylospores $25 \times 1 \mu$. The Phomopsis studied by Richmond has alpha spores $6.5-8.2 \times 2.7-3.5 \mu$ and stylospores $22.7-27.5 \times .98-1.3 \mu$.

\section{VERTICILLIUM WILT}

The wilt due to Verticillium alboatrum Reinke and Berth. has been found but once among the numerous cases of disease examined and cultured in this investigation. It is, however, said to be of frequent occurrence in certain localities in the state, especially near Hillsboro. The tree from which Verticillium was isolated in our study was in a northern nursery.

The Verticillimm disease affects elms in much the same manner as it does other plants or trees. It forms no cankers on the affected parts 


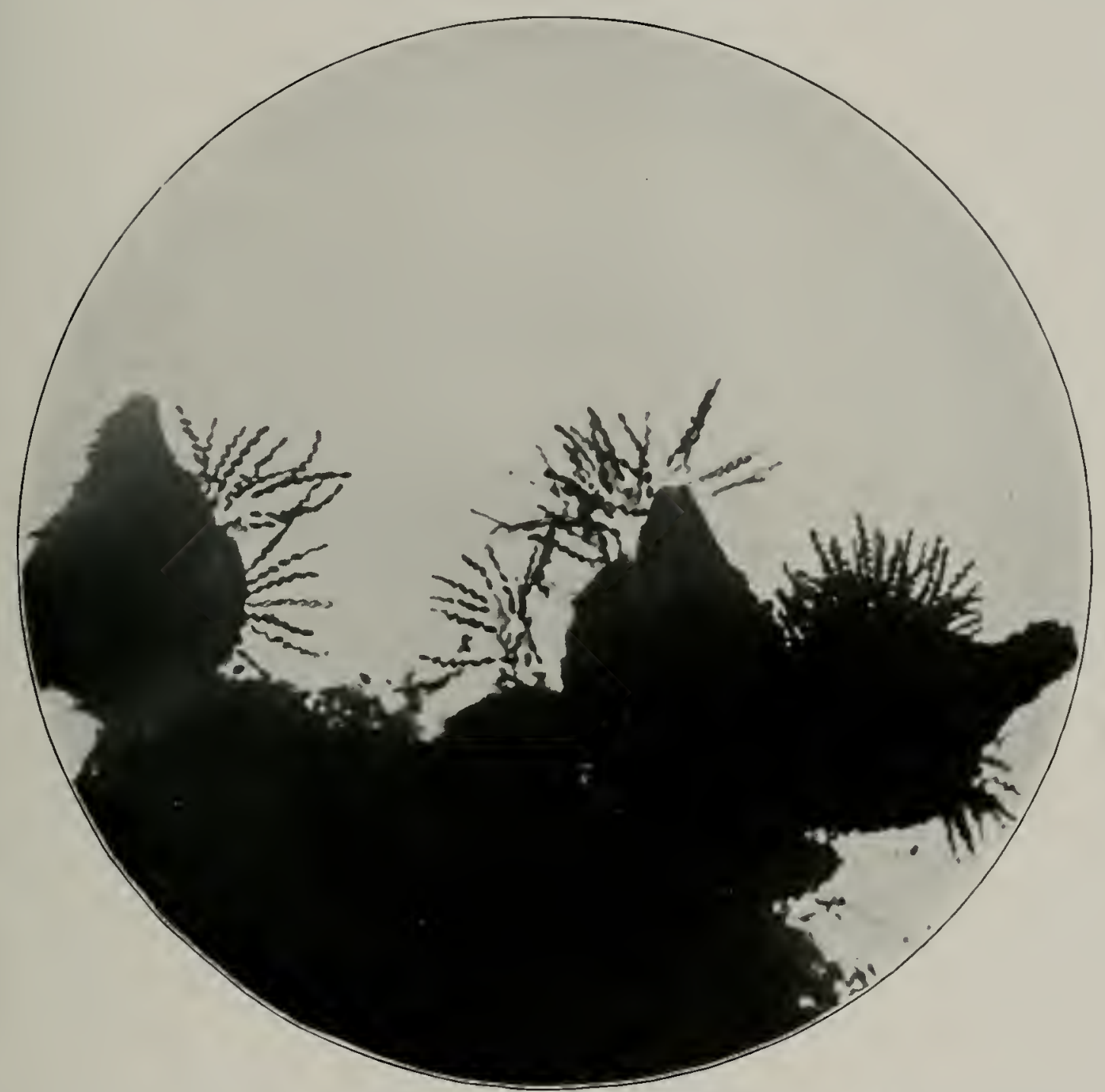

Fig. 29.-Photomicrograph, $\times 100$, of perithecia of Anthostomella produced in culture. Numerous ascospores are shown, but the asci enclosing them, being hyaline, are invisible.

and the only external symptons are a drooping and wilting of the foliage either over the entire tree or only on certain branches. An elm infected with Verticillimm has the same appearance that any plant or tree would have when wilting from lack of water. I crticillimm wilt is characterized, however, by a distinctive type of wood discoloration. In a transverse cut of a twig, as in figure $27 \mathrm{~A}$, the discoloration is restricted entirely to the woody tissue. It is not necessarily limited to certain portions but may occur throughout the wood and extend into new wood as it forms during the season. The fungus may continue to invade the woody structure until the tree dies. In the transverse cut shown in figure $27 \mathrm{~A}$ there is so much discoloration that it appears diffused and like the Coniothyrimm and Phoma discolorations. Its distinctive character is best seen, however, in a longitudinal cut such as that shown in figure ?rB. Here the discoloration is shown to consist of a multitude of very short, brownish, longitudinal streaks. These 
stand out more clearly in a fresh specimen than they do in the photograph.

The Verticillinm wilt is difficult to distinguish from the Dutch elm disease by symptoms alone. Both the wilting and internal wood cliscoloration caused by the Dutch elm infection are very similar to those of the Verticillium wilt. According to May (1931a), however, the discoloration, i.e., the streaking, is more continuous in Verticillium wilt than in the Dutch elm disease; but an absolute diagnosis of either disease is dependent upon a cultural isolation of the associated fungus.

A plate culture of the Verticillim isolated from elm in Illinois is shown in figure 28 . The abundant formation of sclerotial masses characteristic of most Verticillia when growing upon artificial media and the floccose growth of whitish, aerial hyphae which occurs in various parts of the plate, are evident. The mycelium of the fungus is endogenous, effused, and becomes dark; fertile hyphae are emergent, erect, simple, dark, paler above, verticillately branched, and few-septate: terminal branches are ascending; conidia are ovate-oblong. continuous, hyaline to very dilutely colored, $6-12 \times 3 \mu$.

\section{OTHER INFECTIONS}

Is addition to the definitely recognizable diseases just described, various samples of diseased material have been examined which have yielded a variety of fungi commonly considered to be parasitic or to cause wood or bark rots. These are described below.

\section{Fusaria}

Not less than three species of Fusarium are included among the ten isolations of this genus that have been obtained. Of these, one has been called $F$. scirpi, var. compactum by C. D. Sherbakoff and by H. IV. Wollenweber, though that determination was not wholly satisfactory and simply avoided the making of a new name. Dr. Sherbakoff states in his letter that he has had the same fungus sent to him on several occasions from Texas, where it had been isolated from cotton, and that he has grown it in culture from Texan and other soils.

A second form Dr. Sherbakoff believes to resemble F. oryspormm Schl. (Section Elegans), but it does not yield very good sporulation and does not possess other earmarks-by which he could identify it definitely. The third form has not yet been identified, and may subsequently be found to include more than one species.

The form called $F$. oxysporum predominates among our isolations. In culture it produces but few macroconidia. Microconidia and chlamydospores are produced abundantly, however. ' It is entirely white in its early growth upon corn meal agar and has a silky, rather 
slimy appearance, due to the numerous microconidia produced in roundish clusters either directly along the sides of the hyphae or npon short. simple conidiophores. Later the mycelial growth darkens to yellowish brown. The microconidia are hyaline, single-celled and vary somewhat in size and shape. They are nsually ovate to elongate-oborate and their size range is $4-16.1 \times 3.3-8.4 \mu$, but chiefly $6.6-9.5 \times 4.4-$ $6.9 \mu$.

\section{Cepha Losporiun}

In addition to the Fusaria discussed above, isolations hate been secured of fungi which are apparently true Cephalosporiu. In their early growth upon potato dextrose agar these colonies are hyaline and very slimy on the surface. Later the central portion becomes light yellowish brown and ultimately dark brown or olivaceous. Short, sparse, grayish, aerial hyphae arise in the central portion and to a linited extent over the entire growth. A slight, irregular zonation also occurs in the central portion of the growth. The conidia are hyaline, single-celled and usually biguttulate, though they often contain three or four small oil globules. They arise either directly from the growing mycelimm or upon very short, simple conidiophores. They vary greatly in shape but are usually elongated and slightly curved. From a culture of the fungus grown on potato dextrose agar a range in spore size of $4.3-10.2 \times 1.4-2.9 \mu$ was noted. Chiefly they are about $5.8 \times 2.2 \mu$.

These are not all, however, identical with the Cephalosporimm recently described by May (19:31b) as the cause of a new elm disease in Ohio, Jowa, Missonri, New York and Washington, D. C., since a culture submitted to May for comparison was stated to be different.

\section{Alternaria and Stemphylium}

Alternaria has been obtained in the isolation trials more times than any other fungus. As its conidia and mycelium occur very commonly on dead material it is believed to be saprophytic or, at most, only a weak parasite. Its mycelium does not penetrate into the woody or deeper tissues of the stem but is limited to the onter, corky tissue of the cortex. Consequently no extensive injury could result from its presence. Very young twigs which have just died and which have a very shriveled appearance have been observed to be almost completely covered by the black, dusty spore masses of Alternaria. Since the nycelimu of Alternaria penerates the bark tissues to some extent, it is very difficult to destroy by any method of surface sterilization before platings are made of samples of disease, and this readily accounts for the numerous occurrences of the fungus in platings of wood slices upon which the bark was left intact. The fungus has never grown out of slices from which the bark had been removed previous to plating. 
The importance of Stcmpilylium in its relationship to elm diseases is also undetermined. It has not been isolated as frequently as Alternaria, though it usually occurs as a growth decidedly secondary to that causing the disease. Our observations indicate that Stemphylium, like Alternaria, is also essentially bark inhabiting, since its mycelium grows in the outer tissues of the bark and not in the wood.

\section{ANThostonella}

Anthostomella is the only ascomycetous fungus which has been obtained directly in culture. It has been secured twice and in both instances apparently grew out of the bark. In one case it was isolated from the dead wood of a Moline elm along with Nigrospora and $F_{u-}$ sarium. Living, diseased wood from the same tree yielded Vernicularia. In the other instance it was isolated along with Stcmphylium and Altenaria from an American elm.

The perithecia of Anthostomella, shown in figure 29, are produced very abundantly in culture upon corn meal agar. They form upon the plated wood slices and the glass sides of the plate as well as upon the

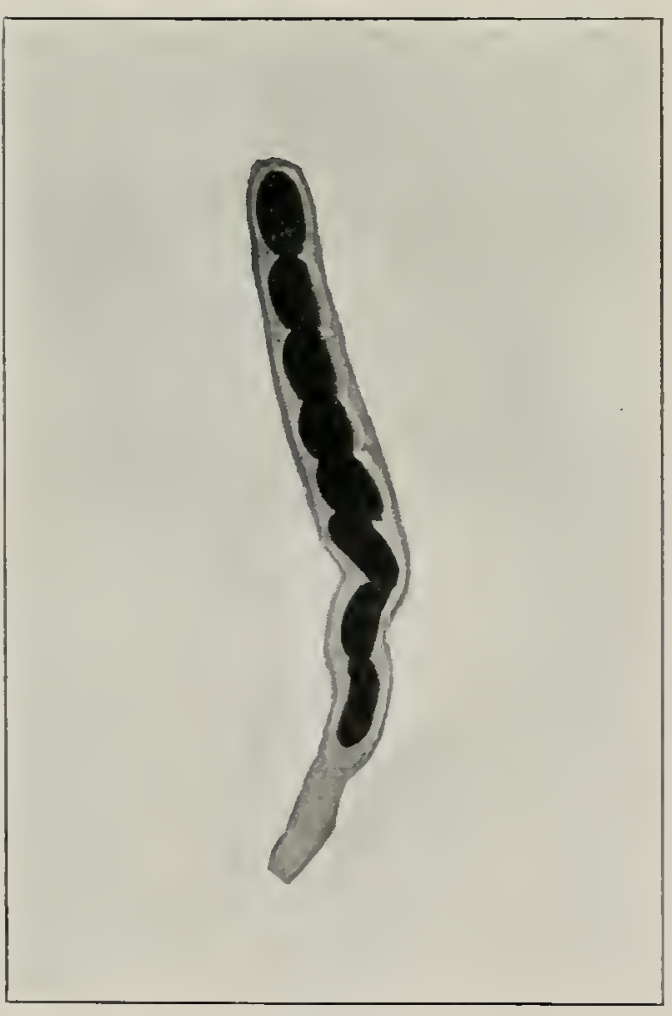

Fig. 30.-Photomicrograph, $\times 400$, of an ascus and spores of Anthostomella, showing the regular end-toend arrangement of the eight spores. The apical pore of the ascus is not clearly visible. agar itself. They are black, flask shaped, and provided with raised ostioles, and their walls are somewhat roughened and carbonous. A range of $204-394 \mu$ has been noted in their size in culture. In figure 30 a single ascus with its eight ascospores is shown. The asci are c y lind ric, hyaline, eight-spored, aparaphysate, and open by an apical pore. They measure $158-180 X$. $12-16 \mu$. The ascospores are brown, one-celled and elliptic, with a size range of $16.6-26.6 \times 8.3-$ $13.3 \mu$ but chiefly $19.9 \times 10 \mu$. No imperfect spore form has occurred in our cultures.

\section{Citospora CANKER}

Dead stems and branches of elms are commonly covered by the pustules of Cytospora, but it has as yet been obtained only once as an isolation from plated wood slices.

Discolored wood, which often occurs below dead areas occupied by this 
fungus, generally either gives no fungous growth in culture or yields other fungi. Cytospora apparently does not fruit readily in culture. Numerous platings have been made from single-spore isolations and an abundant vegetative growth was secured but thus far only a single pycnidium has been formed on agar. It does, however, produce its pycnidia in great abundance when grown upon sterilized eln twigs.

The stronnata are depressed-conical, gregarious, subepidermal, eventually ertmpent, and dark gray with the disc paler, and the conidia are allantoid, $3.3-7.3 \times .8-2.1 \mu$ but chiefly $6.6 \times 1.1 \mu$, hyaline. The fungus is apparently $C$. ambicns Sacc.

\section{Diplodia Canker}

Cankers bearing the pycnidia of a Diplodia have been found several times on diseased elms. The fungus has been grown in artificial culture from single spores segregated by methods previously described, but it has never been isolated directly from slices of diseased wood.

In attempting to determine the proper species name for the Diplodia on elms in Illinois, it was found that, though D. Ulmi had been described by Dearness (1916), the spores as measured by him were much smaller than the spores produced by the Illinois material. 1 portion of Dearness' type specimen was obtained for examination. and it was found that the spore measurements given in Dearness' description were in error, at least so far as the part of his material examined by us was concerned. A comparison is given in table IV of the measurements given in the description of Diplodia Ulmi and of the measurements obtained by us from 100 spores of the type material and of the Illinois eln fungus.

Table IV.-Siroke Measurements of Diplodia Ulmi Dealn.

\begin{tabular}{|c|c|c|c|c|c|c|c|c|}
\hline \multirow[b]{2}{*}{$\begin{array}{c}\text { Source of } \\
\text { measurements }\end{array}$} & \multicolumn{4}{|c|}{ Length, in microns } & \multicolumn{4}{|c|}{ Width, in microns } \\
\hline & Extremes & Mean & $\begin{array}{c}\text { Stand- } \\
\text { ard } \\
\text { devia- } \\
\text { tion }\end{array}$ & $\begin{array}{c}\text { Prob- } \\
\text { able } \\
\text { error }\end{array}$ & Extremes & Mean & $\begin{array}{c}\text { Stand- } \\
\text { ard } \\
\text { devia- } \\
\text { tion }\end{array}$ & $\begin{array}{l}\text { Prob. } \\
\text { able } \\
\text { error }\end{array}$ \\
\hline In description. & $15-17$ & & & & $9-10$ & & & \\
\hline Type specimen.. & $19-29$ & 23.65 & \pm 1.86 & \pm .126 & $8-11.5$ & 10.29 & \pm .607 & \pm .059 \\
\hline Illinois material.. & $19-26.5$ & 23.42 & \pm 1.62 & \pm .109 & $8.5-13.5$ & 10.65 & \pm .931 & \pm .093 \\
\hline
\end{tabular}


Even the minimum spore length measurements taken from the type samples exceeds the maximum spore length given in the description. The measurements of spore width, however, nearly approximated those given in the description. From the measurements given in the table there is no reason to doubt that the Illinois fungus is properly designated as Diplodia Ulmi Dearness, though the description of the species requires emending as follows.

Pycnidia scattered but abundant, $250-400 \mu$ in diameter, occurring singly or in small groups, subglobose, immersed in the cortex, raising the epidermis in small, scarcely visible pustules which are ruptured by the minute ostiole. Conidia brown, elliptic, constricted at the septa, $19.3-29.2 \times 8.3-11.6 \mu$. Mean spore size, $23.6 \times 10.3 \mu$.

On corn meal agar, Diplodia Ulmi produces a whitish mycelial growth provided, in its early stages of development, with sparse, grayish, aerial hyphae. Later the mycelium darkens, becoming green and finally black. Eventually, as the agar is utilized, the entire growth assumes a charred appearance. During the early growth of a culture numerous round, definitely carbonized, cellular structures are formed which have the shape of rudimentary pycnidia, but they never develop an ostiole and always remain sterile, when crushed yielding only masses of oil globules. When cultures are kept until the agar substratum becomes dry and hard, true pycuidia which do yield the characteristic brown, two-celled spores occur in aggregations at various places in the thallus. The full process of pycnidial formation has not been observed, but it is probable that the cellular structures mentioned above furnish a pseudostroma upon which the pycnidial aggregations are formed later.

\section{Nigrospora}

This fungus has been isolated thrice from diseased elms. Each time it grew from wood slices which were plated with the bark still upon them. Other fungi which we consider of more importance in causing elm diseases were obtained from the same material which yielded Nigrospora. The identification of this fungus was established for us by E. W. Mason, of the Imperial Mycological Institute, as Nigrospora sphacrica (Sacc.) Mason. Mason (192\%) believes that the proper generic designation of this kind of fungus, one species of which causes a severe cob rot of corn and is known in the United States as Basisporium gallarmm, is Nigrospora.

In its early development from platings upon corn meal agar the fungus appears as a hyaline growth with very little aerial mycelium. Later, as the thallus grows older, it assumes a brownish tint and becomes covered by a rather compact cottony growth of white to slightly grayish, aerial mycelium. In old cultures the mycelium from which 
conidiophores arise is very dark brown and has thicker walls than the ordinary vegetative mycelium, which is either light brown or hyaline. As may be seen in figure $31 \mathrm{~A}$ the spores of Nigrospora are formed in great abundance in culture. The conicliophores, figure $31 \mathrm{~B}$, may be either short and simple or rather long and several-septate. They are always swollen or enlarged at the apex, which is the point of spore attachment. The coniclia are globose or nearly so, smooth, brown when young and opaque black when mature. They usually arise singly on conidiophores though occasionally a conidiophore may branch at its apex so that two or three conidia occur there. From a culture of the fungus grown upon corn meal agar a range in spore size of $1+.0-20.8 \mu$ was noted, though the spores were chicfly $16.6 \mu$.

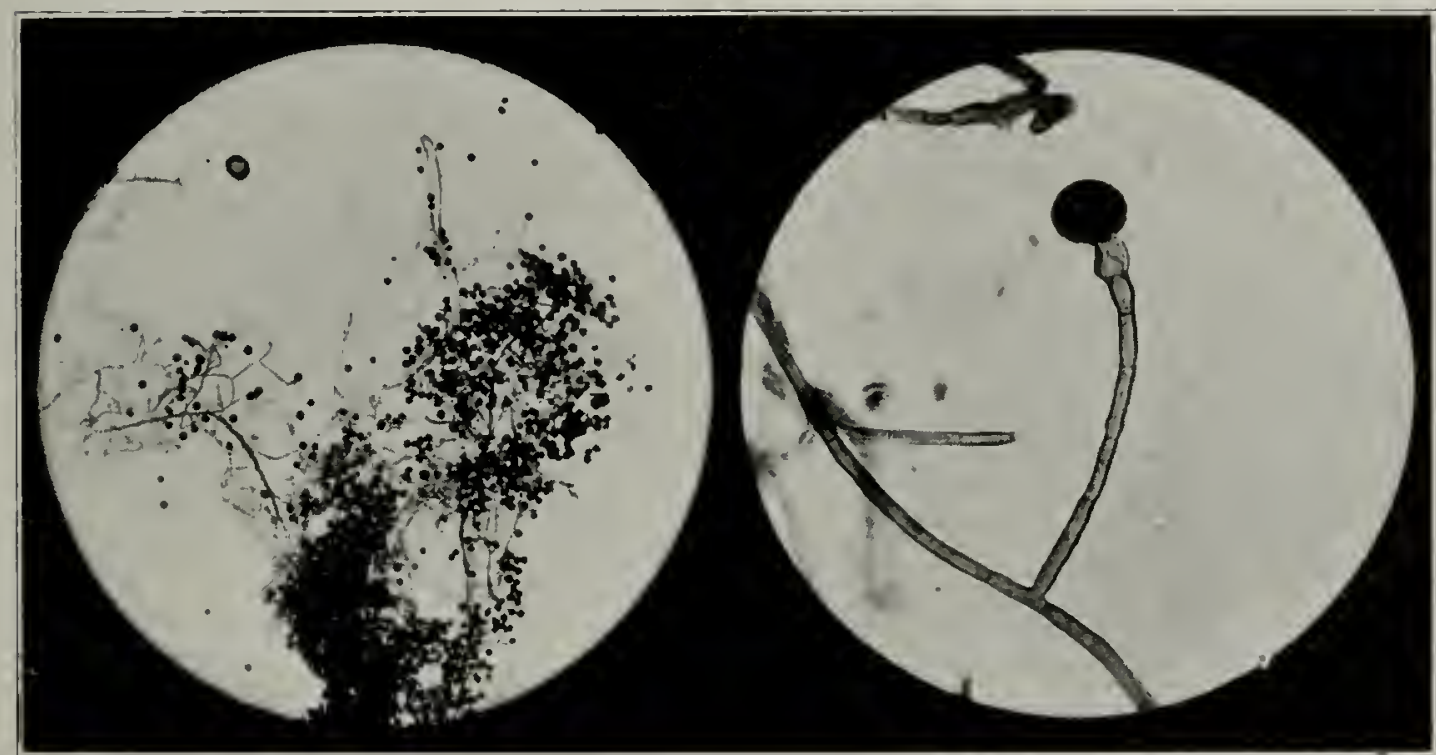

A

B

Fig. 31.-Nigrospora sphaerica, one of the unusual saprophytic fungi isolated from diseased elms. A.-Mycelium and spores $\times 60$, as produced in corn meal agar culture. B.-A septate sporophore with a spore at its apex. $\times 550$.

\section{XYLARIA}

A Tylaria isolated from wood slices taken from a diseased elm in lllinois furnished one of our most interesting finds. Various species of the genus Iylaria are associated with and believed to be the cause of serious root rots of apple trees, maple, basswood, cottonwood, black wahnut and white and red oaks. Outward symptoms shown by infected trees are dwarfing and discoloration of the crown; identification of the disease generally depends upon the presence of fruiting bodies of the fingus 11 pon infected roots and in the debris at the base of the tree.

It is, however, very musual for the fungus to penetrate into the upper branches of attacked but still living trees. and so far as we are aware it has never before been isolated directly from small twigs situated toward the ends of living branches. 


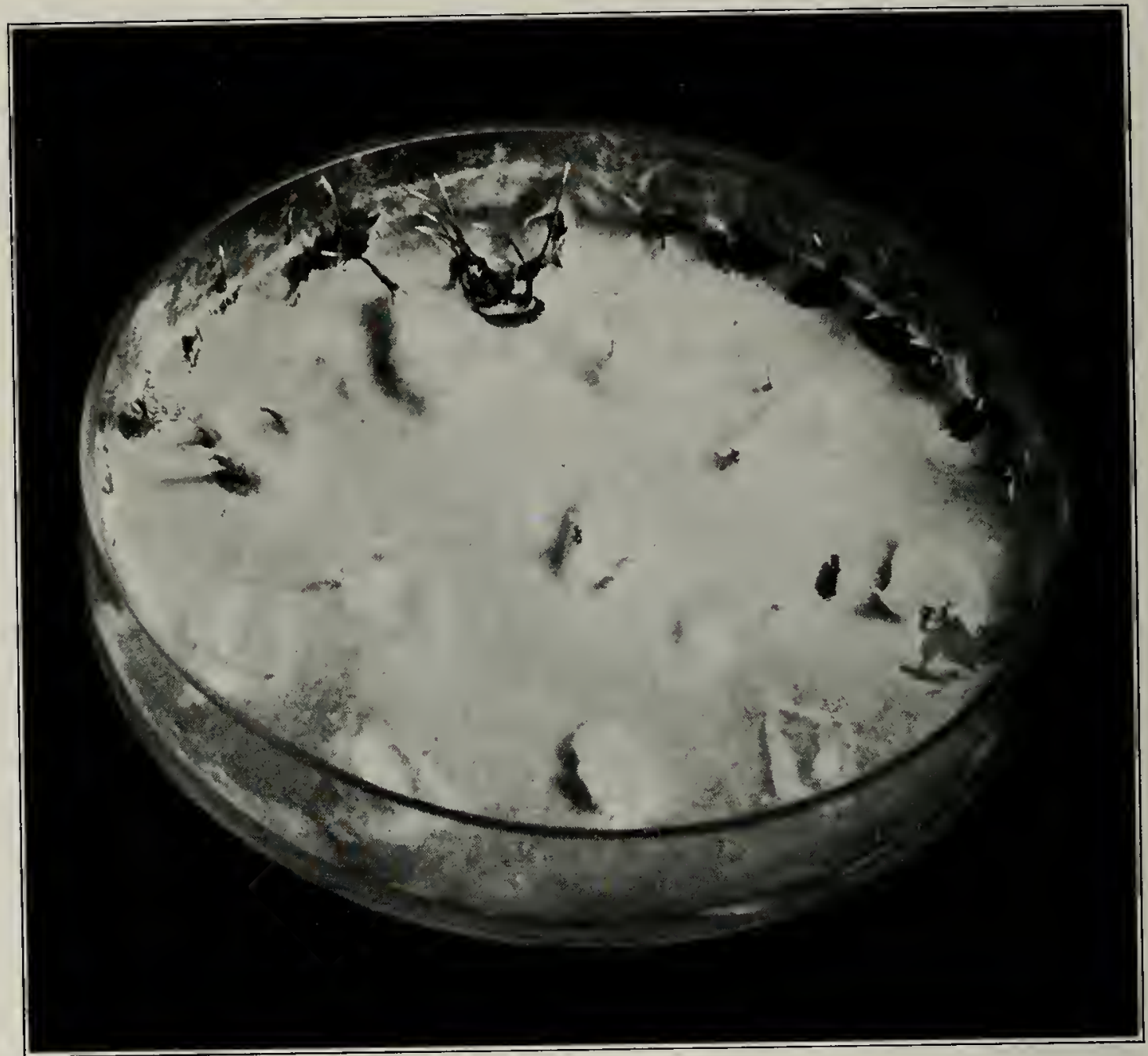

Fig. 32.-Petri-dish culture of Xylaria, showing its white, cottony my celium and a number of black stromata in various stages of early development, after 30 days on acidified potato dextrose agar.

An early stage in the development in culture of the elm Xylaria is shown in figure 32. In its early growth the nycelium is dense, cottony and pure white. Later, after having spread over the entire culture plate, the mycelium darkens, ultimately forming very black, irregular blotches either at the edge of the plate, or around or upon the wood slices from which it grew. At the same time that the black patches are formed, or even while the mycelium is still white, stalklike structures such as are shown in figure 32 begin to grow up from the mycelium.

The fungus is shown in figure 33 as it appeared six weeks after the stage pictured in figure 32 . The tips of the stalks have remained white, although as they grew the lower portions gradually turned black. Also, a considerable area in the mycelium around the base of the stalks eventually turned black.

The stromata, that is, the stalks, of this fungus exhibit the same very strong positive phototropism that is characteristic of most $X$ ylariac. 


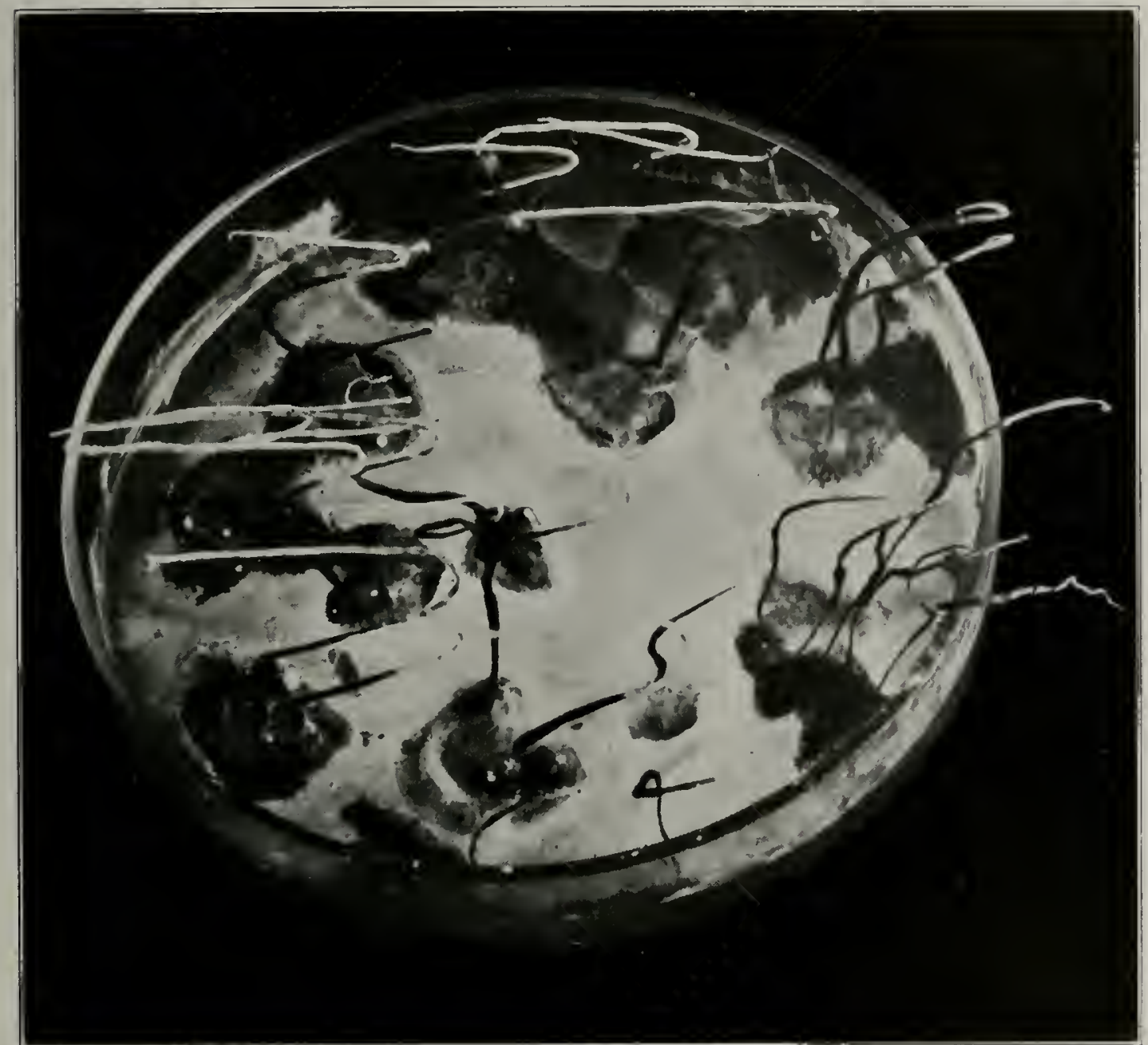

Fig. 33.-Petri-dish culture of Iyluria, showing the mycelium and stromatal branches after two and one-half months on acidified potato dextrose agar. The positive phototropic reaction of the stromata during growth is evident.

Abrupt bending of the stalks with their tendency to elongate horizontally, shown in figure 33 , is evidence of this reaction. This culture was kept at the far side of a room rather dinly lighted by windows on one side. first in one position and then in the opposite with reference to the source of light, and the striking changes in direction of growth shown in the picture resulted from shifting the position of the culture.

Snall ovoid, hyaline, single-celled coniclia are borne along the white upper portion of the stromata about ten days after they appear. In our cultures the stromata were generally unbranched, but a few becance forked near the tips. Perithecia have not developed, though swellings in the stromata have begum to form.

\section{OTHER FENGI}

Other fungi which have been isolated from discased elnus are Melminthosporimm, Rhabdospora and Epicocmm. The first has been 
isolated twice and the other two once each. The conidia and sporodochia of Epicoccum have been observed to occur frequently upon the bark of elms, and it is not surprising that it should have been obtained in culture. The significance of Helminthosporium and Rhabdospora has not been determined.

\section{B $\Lambda$ CTERIA}

A little over 8 per cent of the isolation tests made of diseased elms furnished bacterial growths. During the course of the investigations of the dying of elms in Europe, bacteria were encountered by various workers. Brussoff (1925), in particular, isolated a bacterium. which he called Micrococus Ulmi, from trees showing symptoms of wilt and dieback. A considerable controversy resulted, following publication of his report in 1925 , as the fungus Graphinm Ulmi had been described in 1922 by Schwarz as the cause of the same (or a very similar) disease. During the controversy and later, as a result of further research, Graphimm Ulmi was determined to be the cause of the Dutch elm disease and Brussoff's work received more discredit than was due it. Brussoff's evidence points definitely to the existence of bacterial elm pathogens, and this is further borne out by Buisman's (Westerdijk en Buisman, 1929) description of Psendomonas lignicola as the cause of one elm disease in Holland.

In view of the present incomplete knowledge of elm bacteria, the isolations obtained from diseased trees appear to have a potential inportance that exceeds our present results with them.

Bacterial colonies have been obtained in isolation tests for the most part when the summer temperatures were too high for fungus growth-at least, at such times the growth of most of our fungi was very slow, and some ceased growing.

Tests of the pathogenicity of several of the bacterial isolations were made upon elm seedlings grown in the laboratory. Inoculations were made in early July and the inoculated seedlings were kept under observation until late October. Negative results were obtained with all, but the conditions under which the trials were made were by no means ideal and it is not safe to conclucle that these organisms are nonpathogenic.

\section{INOCULATION TRIALS}

WiTí so large a number of fungi isolated from elms, it is readily seen that much study and experimentation with each organism will be necessary before the exact relationship existing between it and the so-called "elm wilt" can be ascertained and its importance definitely established.

As stated before, certain of the fungi that have been obtained are 
probably entirely saprophytic, others may be weak parasites capable of injurious attack only after the tree is in a weakened condition, and others must certainly be highly aggressive parasites. The facts can be determined only after thorongh inoculation tests of the individual organisms have been made.

During the past summer inoculations were attempted uncler as near an approach to field conditions as possible. Thirteen of the different fungi which had been secured from diseased chns were tested. For this purpose 1500 young Anerican elms grown from scedling stock were used. The trees, grown ont of doors, occupied approxinately a cuarter of an acre. At the time the first trials were made they were between two and three feet high and quite vigorous. They had been planted in April, in rows about the same distance apart as elms set in the mursery.

Various methods of inoculation were tried. Some of the trees were sprayed thoroughly with suspensions of spores. Other inoculations were made by placing fragments of plate cultures in the axils of unfolding leaves and shoots. Direct inoculation of the stems was also attempted by inserting cultures in incisions made in the bark and in holes bored in the sten. Adequate care was always taken to cover the inoculum against chance contanination and to maintain an alsundance of moisture for growth of the fungus. Up to this writing these experiments have given no results. Leaf fall occurred before any extenal symptons indicating positive reactions becane nunifest. It is altogether probable that a rather long period may be required before evidence of the success of the inoculations appears. In some cases another. or perhaps even two more, seasons' growth may be needed before any symptoms of disease beconne evident, while in other calses the success of inoculation trials may be dependent upon the season of the year in which the trials are made.

\section{PRELIMINARY CONTROL EXPERIMENTS}

TuE problem of finding a means for controlling these eln diseases is a decidedly complex question, since there are so many separate diseases to be combated. If control nneasures are developed which are successful against one disease they may not he equally useful against the others. However, some encouragement is to be had from the fact that, at least in nursery stock, the diseases caused ly Coniothyrimm and Phoma are of outstanding importance. They are very widely distributed and abundant, and a means for controlling them will greatly reduce the losses of elm stock in nurseries.

During the summer of 1931 two experinents upon the control of elm diseases were undertaken in murseries. Both experinents were 

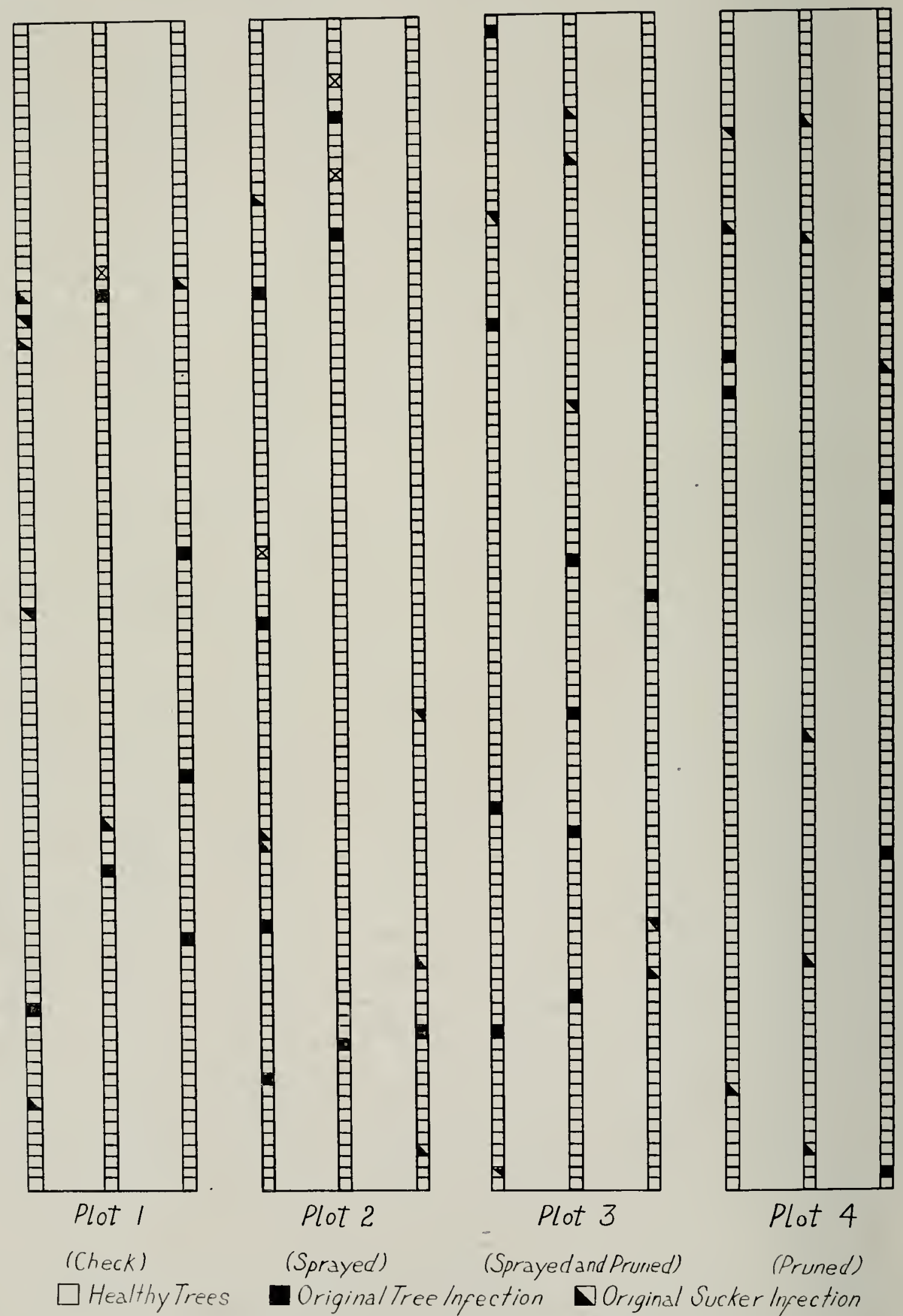

$$
\text { (Sprayed) }
$$

(Sprayed and Pruned)

(Pruned)

- OriginalTree Infection

Driginal Sucker Infection $\Delta$ Later Tree Infection

$\nabla$ Later Suckerinfection

Fig. 34.-Diagram of the nursery plots used in Experiment No. 1. Trees are represented by squares, open squares showing healthy trees, black squares originally-infected trees, and crossed squares trees infected after treatments were begun. Diseased suckers growing from stumps are shown by half black squares, as indicated in the legend. 
performed chiefly as preliminary tests which would serve as gtides for more intensive ones to follow, though it was, of course, desired to obtain as much information as possible relative to means of combating the various diseases. The two experiments were conducted with the cooperation and aid of the Swain-Nelson nursery and the Freeman nursery, both of which firms willingly and courteously contributed the use of their elm blocks to the experiments, as well as much valuable assistance in other phases of the work.

\section{EXPERIMENT NO. 1}

A diagram of the plot of trees used in the experiment conducted at the Swain-Nelson nursery is shown in figure 34. The trees were divided into four plots, each of which included three rows. As each row contained 100 trees, there were 300 in each plot and a total of 1200 trees in the experiment.

Plot 1 served as a check. It received no treatment but indicated the amount of increase in infection taking place during the course of the experiment. The trees in Plot ? were sprayed with Devoe's standard preparation of commercial Bordeaux mixture, which contains, according to the manufacturers, a metallic copper equivalent of 13 per cent or a copper oxide equivalent of 16.25 per cent. This spray was used in a $3-3-50$ concentration. Plot 3 also received a thorough spraying with the same material, and in addition all badly diseased trees, all diseased parts of trees and all dead limbs were pruncel out as carefully and completely as possible. In Plot 4 only pruning was practiced, no spray being applied.

This experiment was begtun July 29,1931 , and the final observations were made September 21, 1931. During this interval Plots : and 3 received two sprays, the first at the beginning of the experiment or August 1, and the other. August : 4 .

The results obtained from this experiment are inconclusive, due in part to the fact that only a very small number of new infections appeared in the check plot during the course of the experiment and also to the fact that sometime previous to the beginning of the experiment the nursery owners had removed all trees that appeared to them to be diseased. In the rows used for the experiment there was, of course. some difference in the number of diseased trees, but this number was uniformly small, ranging from 6 to 9 per cent, and the possibility of infection coming in from outside sources was not restricted. For a relial)le interpretation of results from an experinent such as this. it is clesirable to have a fairly large number of new infections occur in the check plot. Most of the infections in these plots previous to treatment were in the form of diseased shoots or suckers arising from the bases of diseased trees which previonsly had been cut down. 
Results of the experiment are presented in table $V$, which shows the per cent of increase of disease above that originally present in each plot.

Tamie V.-Ixcrease in Infection After Theatment in Experinext No. 1.

\begin{tabular}{c|l|c|c|c}
\hline \hline $\begin{array}{c}\text { Plot } \\
\text { Number }\end{array}$ & Treatment & $\begin{array}{c}\text { Number of original } \\
\text { infections }\end{array}$ & $\begin{array}{c}\text { Number of new } \\
\text { infections }\end{array}$ & $\begin{array}{c}\text { Per cent of } \\
\text { increase in } \\
\text { disease }\end{array}$ \\
\hline 1 & None (Check) & 6 & 1 & 16.6 \\
2 & Sprayed & 8 & 3 & 37.5 \\
3 & Sprayed and pruned & 9 & 0 & 0 \\
\hline
\end{tabular}

These results seem to indicate that spraying with Bordeaux mixture alone, at least at the times and with the strength used, is ineffective. More new infections occurred in the sprayed than in the check plot. Pruming and spraying combined seemed to be completely effective in preventing the occurrence of new cases of disease, but the same effectiveness is indicated when pruning alone was practiced.

Diseased shoots arising from stumps left after removal of diseased trees were not recorded in this experiment as new infections. Such shoots are not new cases but become diseased by growth into them of the disease from the stumps from which they arise. It has been observed, also, that if the diseased trees are cut off a consiclerable clistance below the advancing infection in the trunk, the new basal shoots often continue healthy.

The conclusions to be drawn from this experiment are first, that spraying with commercial Bordeat1x mixture in a 3-3-50 dilution is not injurious to nutsery elm stock; second, that Bordeaux applied in that strength in mid and late sunmer is not treatment sufficient to prevent occurrence of a considerable percentage of new infections; and third, that pruning alone and pruning and spraying combined are apparently effective in preventing any considerable increase in the amount of disease.

It must be understood, however, that the results of this test can be applied only where disease is relatively scarce. In badly diseased elm blocks the indications are entirely different, as the second experiment shows. 


\section{EXPERIMENT No. :}

The second experiment in controlling "elm wilt" was conducter at the Freeman nursery. A cliagram of the trees 11 sed in this experiment is shown in figure 3.). The trees were divided, ats in the first experiment. into four plots of three rows each. There were so trees in each row, making a total of 150 trees in each plot and 600 trees in the entire experiment.

The treatments employed were the same as in the first experiment. and the arrangement of the treatments by plots was as follows: Plot 1 was subjected to pruning. Plot 2 was pruned and sprayed, Plot 3 was sprayed, and Plot 4 served as a check. Pruning and spraying were done in the same way as the first experiment, the spray used being also a 3-3-.)0 concentration of Devoe's commercial Bordeanx mixture. The experiment was begin August 3, 1931, and final observations were made September $2 \cdot 2$. 1931. Plots 2 and $: 3$ were sprayed August 5 and again August 25. The results obtained are given in table VI.

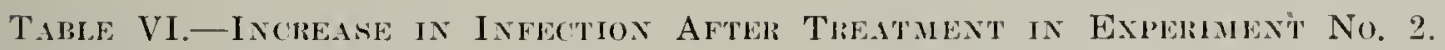

\begin{tabular}{c|l|c|c|c}
\hline $\begin{array}{c}\text { Plot } \\
\text { Number }\end{array}$ & Treatment & $\begin{array}{c}\text { Number of original } \\
\text { infections }\end{array}$ & $\begin{array}{c}\text { Number of new } \\
\text { infections }\end{array}$ & $\begin{array}{c}\text { Per cent of } \\
\text { increase in } \\
\text { disease }\end{array}$ \\
\hline 1 & Pruned & 5 & 3 & 60.0 \\
3 & Pruned and sprayed & 25 & 9 & 36.0 \\
4 & Sprayed & 27 & 7 & 25.9 \\
\hline \hline
\end{tabular}

As should be expected, the greatest increase in infection occurred in the check plot. The next greatest increase was in Plot 1, which had been treated by pruning. The occurrence of three new cases of disease in addition to the five originally present shows the increase to be 60 per cent, but this is 16 per cent less than that occurring in the check plot. Although a certain degree of control over the appearance of new cases is inclicated, as was true in the first experiment, the small number of trees originally diseased, together with the latege increase in disease, throws doubt npon the dependability of the treatment. The apparently beneficial effect of pruning might be due entirely to elimination of the source of infections material within the plot itself. 


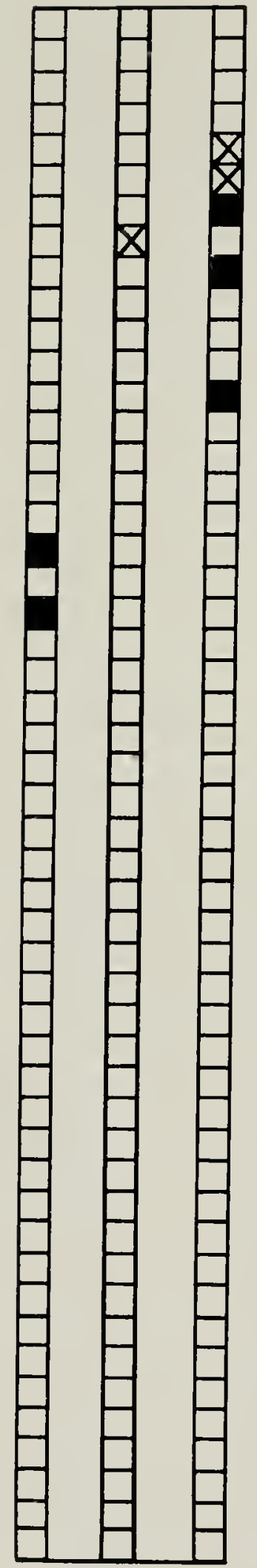

Plot 1

(Pruned)

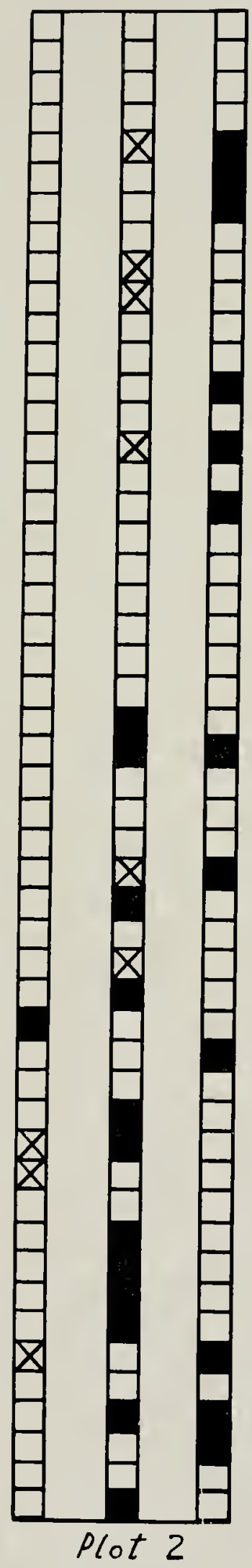

(Pruned and Sprayed)

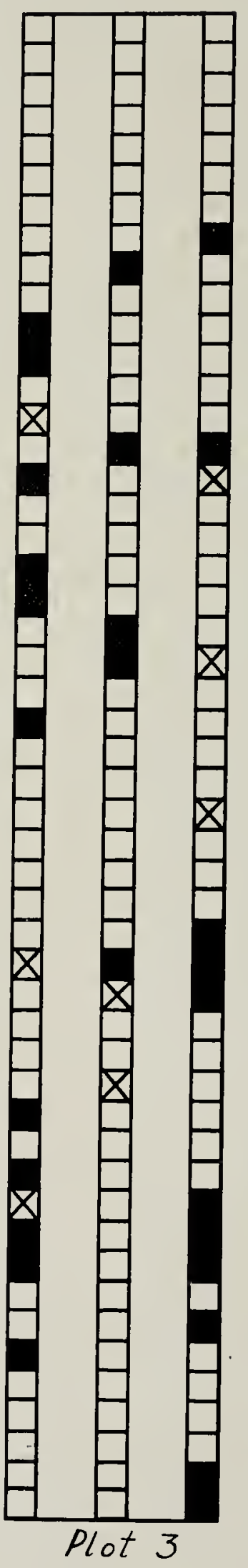

(Sprayed)

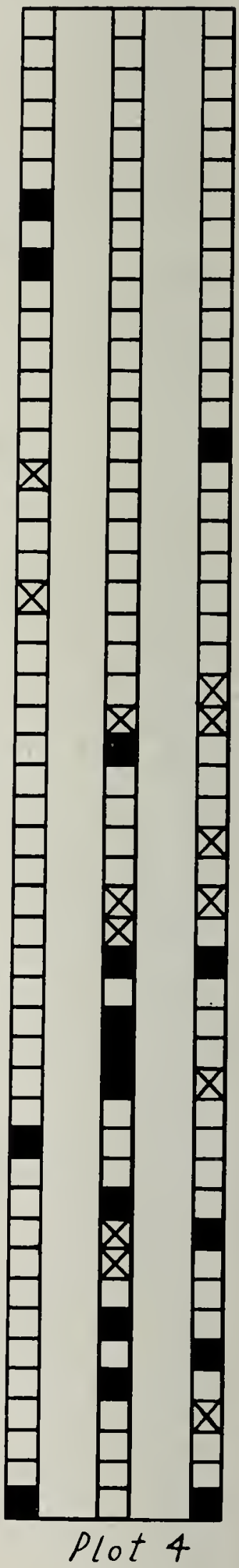

(Check)

$\square$ Healthy Trees Uriginal Infection $\square$ Later Infection

Fig. 35.--Diagram of the nursery plots used in Experiment No. 2. Trees are represented by squares, open squares showing healthy trees. black squares trees diseased before, and crossed squares trees diseased subsequent to the beginning of treatment. 
The fact that under conditions of heavy infection the lowest percentages of new cases of clisease occurred in the plots treater by spraying, or ly spraying and pruning, affords hope that the most satisfactory control maly be developer along this line. A more thorough experimentation with spraying appears especially justifiable, since increase in number of diseased trees was 50 per cent less in the plot treated by spraying alone than it was in the check, while in the pruned and sprayed plot the increase was only about to per cent of that in the check.

\section{Relation to the Problem of Control}

An important fact to be considered in connection with the results of these two experiments is the concentration of Bordeanx mixture used. The 3-3-50 concentration was employed, not because it was thought to be strong enough to afford maximum, or even satisfactory, protection but because no one knew definitely what concentration elm foliage conld endure without injury. The trees enployed in the experiments were of considerable commercial value to their owners. In the experiments, however, no elm suffered any injury from the spray. and we are therefore assured that a more strongly fungicidal concentration could be used without endangering the trees.

These experiments have been concerned with preventing occurrence of new cases of disease rather than with curing trees after they have become diseased. The facts concerning effect, probable time and place of infection, and spread of infection presented. especially in connection with the important Coniothyrimm disease of nursery elm stock. scem to show that attempts to cure sick trees are not likely to meet with satisfactory success, especially since trimming out, or amputating. diseased parts is the only curative measure that can be applied. It is. of course, obvious that if diseased parts of trees conld be cut out so as certainly to remove all internal infection and at the same time leave the tree in salable condition from the nurserymen's point of view, the problem of control would be solved, except for the great cost of doing the work. But there is no indication at the present time that trinming performed by ordinary workmen can be depended upon to accomplish that result. There is, also, the obvious possibility of removing diseased trees from nursery blocks. This, of course, will destroy infection present at the time the removal is performed. but the healthy trees left in the blocks still remain exposerl to infection from outsicle sources. and year by year a varying proportion of these trees will becone diseased and have to be removed. The cumulative effect of the process will be a gradual but certain demolition of the elm block and a consequent loss to the nurseryman, which will depend upon the age at which he is able to sell his trees.

Trimning, and its possible effectiveness, needs further detailed 
study before it can be recommended. The nurseryman will recognize that its use, together with the immediate removal and destruction of badly diseased trees, is a protective measure which, if taken, will eliminate many sources of infection in the elm block itself. But, in addition, protection must be secured against the introduction of infection from outside sources, and it is this at which a spraying program is aimed.

Once the disease establishes itself within a tree, no amount of spraying or other kind of treatment now known will afford a cure. A claim has been made by a European pharmacist (Anonymous, 1931) that a remedy has been discovered which will cure elm trees even after they have become badly cliseased. The injection of this remedy into the roots, its subsequent absorption by the root system and conduction into affected parts of the tree supposedly effects the cure. It is very doubtful whether practical results can be had from the use of this treatment. May and Liming (1931) state that in no instance have carefully controlled experiments shown any of these injected substances to be of value.

Beneficial effects may be secured by pruning, provided all infection is removed. In the experimental work this was indicated by the fact that a further progress of disease was not observed, up to the time when our final check was made, in any trees treated by pruning. Proof of this must depend, however, upon what happens during another season's growth, as it has been found in other trees treated by pruning that unless complete removal of the infection is accomplished the disease will continue through the tree and eventually kill it. Nere removal of all external manifestations of disease is not sufficient. In the case of the Conioth yrium disease, actual infection in the interior of the wood is known to extend an indeterminate distance below the lower limits of the externally visible cankers, and cacn beyond aisible wood discoloration. Pruning is to be recommended, therefore. only when the number of diseased trees is so small that it can be clone effectively at low cost.

Cleanliness in the nursery cannot be disregarded as a practical step in lessening the number of sources of infection and the amount of infectious material.

The crowded condition which conmonly prevails in nursery elm blocks probably infuences the prevalence and severity of disease. The moist environment created by closely planted trees favors fungous growth and probably spore production, but since it is usually the top parts of the trees which first become affected, it is evident that exposure to sunlight and free circulation of air are necessary for infection. 
Some varieties of the American elm are evidently more resistant to disease than others. No experinental work has been done in this connection but our observations in nurseries where the Moline and lase chus are cultivated show that these varieties are always quite free from disease. That these varicties may be attacked by fungons parasites is evident. however, from the fact that we have isolated a I'crmicularia from a MLoline chn.

\section{SUMMARY}

Results of the present investigations concerning the nature of the elm malady in Illinois show, primarily, that the so-called "elm wilt" is not a single disease but is in reality several different diseases. These discases manifest themselves in a number of forms, such as twig blights, cankers, diebacks and true wilts. They are statewide in distribution and occur in nursery, parkway and lawn trees. During the past few years thousands of eluns have been lost in nurseries and many valuable trees standing in cities have been lijled.

Most important of these diseases in Illinois is one that appears to be caused by Coniothyium. It manifests itself outwardly as a twig b)ight and canker and internally as a mycosis of the water conducting tissues. Other important diseases are caused by Phoma, Sphacropsis, I'ermicularia and Terticillium.

The Dutch elm disease has never heen found in Illinois, though the other diseases have been popularly mistaken for it.

Nearly ?00 diseased trees have received laboratory examinations during the conrse of the investigation and over 500 isolations of fungi have been secured, among which are 20 genera and about 30 species. The pathogenicity of these various fungi is as yet not completely rletermined, though infection experiments are progressing at the present tine.

The problem of controlling these diseases will prove complex, since several diseases, rather thain one, have to be considered. In prelininary experiments conducted in nurseries, Bordeanx mixture has given enconraging results, and prinning when carefully practiced has proved valuable also.

\section{LITERATURE CITED}

Axmersox, P.se J., and H. W. Anderson

1912 The chestnut blight fungus and a related saprophyte.

Penusylvania Chestnut Tree Blight Commission, Bulletin No.

4. 26 pp., 6 figs. 


\section{Literature Cited-Con'T'D}

Axorymous

1931 La luttre contre la maladie des ormes.

La Tribune Horticole, Vol. XVI, No. 755, pp. 322-323.

Brooks. F. T., and G. O. Searle

1922 An investigation of some tomato diseases, pp. 192-194.

The British Mycological Society Transactions, Vol. VII, pp. 173-179.

Brussofe, A.

1925 Die holländische Ulmenkrankheit-eine Bakteriosis.

Centralblatt für Bacteriologie, Parasitenkunde und Infektionskrankheiten, Zweite Abteilung, Vol. 63, pp. 256-257. 1 pl.

Buisias, Christine

1932 Ceratostomella UImi, de geslachtelijke vorm van Graphium Ulmi Schwarz.

Tidschrift over Plantenziekten 38 , pp. 1-8. 3 pls.

Chordat, F.

1926 Recherches experimentales sur la mutation chez les champignons, pp. 66-136.

Bulletin de la Société Botanique de Genève, Second series, Vol. XVIII, pp. 41-144. Illus.

Davis, W. H'.

1930 Single spore isolation.

Proceedings of the Iowa Academy of Science for 1930, Vol. XXXVII, pp. 151-159.

DEARNESS, JoHN

1916 New or noteworthy species of fungi.

Mycologia, Vol. VIII, pp. 98-107.

Forbes, Stephex Alfred

1885 Insects injurious to the elm.

Fourteenth Report of the State Entomologist on the Noxious and Beneficial Insects of the State of Illinois, (for the Year 1884) pp. 112-115.

1912 What is the matter with the elms in Illinois?

University of Illinois Agricultural Experinent Station Bulletin No. 154 , pp. 1-22. 4 figs., 6 pls.

GARMAN, H.

1899 The elms and their diseases.

Kentucky Agricultural Experinent Station of the State College of Kentucky, Bulletin No. 84, pp. 51-76. 13 figs.

Hubert, ERNest E.

1931 An outline of forest patlology, pp. 238-41.

Joln Wiley and Sons, Inc. New York, London.

Hunert, Envist E., and C. J. Humphrey

1920 A canker of the white elm in Wisconsin.

Biennial Report of the Wisconsin State Department of Agriculture for the years 1919-1920, pp. 158-162. 1 pl. 
HUMPHREY, C. J.

1913 Winter injury to the white elm.

Phytopathology, Vol. 3, pp. 62-63.

M.sson, E. W.

1927 On species of the genus Nigrospora Zimmerman recorded on mono. cotyledons.

Transactions of the British Mycological Society, Vol. XIl, Parts II and III, pp. 152-165. 1 pl.

MaY, CURTIS

1930 The Dutch elm disease.

Sixth National Shade Tree Conference, Proceedings of Annual Meeting, Cleveland, Ohio, pp. 91-94.

1931a The Dutch elm disease.

United States Department of Agriculture Circular No. 170. 10 pp., 6 figs.

1931b A new elm disease.

Science, Vol. 74, 1). 437.

MAY, CuR'Tis, and O. N. Liming

1931 A serious elm disease in Ohio.

Ohio Agricultural Experiment Station. The Bimonthly Bulletin, No. 150 , pp. 106-112. 3 figs.

MEER, J1KKE H. H. VAN DER

1926 Verticillium-wilt of maple and elm-seedlings in Holland.

Phytopathology, Vol. XVI, pp. 611-614. 1 fig., 1 pl.

Miles, L. E.

1921 Leaf spots of the elm.

The Botanical Gazette, Vol. LXXI, No. 3, pp. 161-196. 1 fig, 3 pls.

RICHMOXD, BLYTHE G.

1932 A Diaporthe canker of American elm.

Science, Vol. 75, pp. 110-111.

ROSENBAIX, J.

1912 Infection experiments with Theilavia basicola on ginseng, p. 194. Phytopathology, Vol. II, No. 5, pp. 191-196.

SCHWARZ, M. B.

1922 Das Zweigsterben der Ulmen, Trauerweiden und Pfirsichbáume. Mededeeling uit het Phytopathologisl Laboratorium "Willie Commelin Scholten" Baarn, 5, pp. 1-32.

SFymouk, Arthur Bliss

1929 Host index of the fungi of North America, pp. 273-278.

Harvard University Press, Cambridge.

THARP, B. C.

1917 Texas parasitic fungi.

Mycologia, Vol. IX, No. 2, pp. 105-124. 


\section{Literature Cited-CONCL’D}

Viughax, R. E.

1914 A method for the differential staining of fungous and host cells. Annals of the Missouri Botanical Garden, Vol. I, pp. 241-242.

Westeritrk, Johaxis, en Christine Buisman

1929 De iepenziekte. Rapport over het onderzoek verricht op verzoek van de nederlandsche Heidemaatschappij.

Nederlandsche Heidemaatschappij te Aarnhem. 78 pp., Illus. 